IZA DP No. 7359

Dynamic Panel Data Models with Irregular Spacing: With Applications to Early Childhood Development

Daniel L. Millimet

Ian K. McDonough

April 2013 


\title{
Dynamic Panel Data Models with Irregular Spacing: With Applications to Early Childhood Development
}

\author{
Daniel L. Millimet \\ Southern Methodist University \\ and IZA \\ Ian K. McDonough \\ Southern Methodist University
}

Discussion Paper No. 7359

April 2013

IZA

P.O. Box 7240

53072 Bonn

Germany

Phone: +49-228-3894-0

Fax: +49-228-3894-180

E-mail: iza@iza.org

\begin{abstract}
Any opinions expressed here are those of the author(s) and not those of IZA. Research published in this series may include views on policy, but the institute itself takes no institutional policy positions. The IZA research network is committed to the IZA Guiding Principles of Research Integrity.

The Institute for the Study of Labor (IZA) in Bonn is a local and virtual international research center and a place of communication between science, politics and business. IZA is an independent nonprofit organization supported by Deutsche Post Foundation. The center is associated with the University of Bonn and offers a stimulating research environment through its international network, workshops and conferences, data service, project support, research visits and doctoral program. IZA engages in (i) original and internationally competitive research in all fields of labor economics, (ii) development of policy concepts, and (iii) dissemination of research results and concepts to the interested public.
\end{abstract}

IZA Discussion Papers often represent preliminary work and are circulated to encourage discussion. Citation of such a paper should account for its provisional character. A revised version may be available directly from the author. 
IZA Discussion Paper No. 7359

April 2013

\section{ABSTRACT}

\section{Dynamic Panel Data Models with Irregular Spacing: With Applications to Early Childhood Development}

With the increased availability of longitudinal data, dynamic panel data models have become commonplace. Moreover, the properties of various estimators of such models are well known. However, we show that these estimators breakdown when the data are irregularly spaced along the time dimension. Unfortunately, this is an increasingly frequent occurrence as many longitudinal surveys are collected at non-uniform intervals and no solution is currently available when time-varying covariates are included in the model. In this paper, we propose several new estimators for dynamic panel data models when data are irregularly spaced and compare their finite sample performance to the naïve application of existing estimators. We illustrate the practical importance of this issue by turning to two applications on early childhood development.

JEL Classification: $\quad$ C23, C51, 121

Keywords: panel data, irregular spacing, interactive fixed effects, student achievement, obesity

Corresponding author:

Daniel Millimet

Department of Economics

Southern Methodist University

Box 0496

Dallas, TX 75275-0496

USA

E-mail: millimet@smu.edu

\footnotetext{
* The authors benefited from discussions with Manuel Arellano, Badi Baltagi, David Drukker, and Rusty Tchernis, as well as seminar participants at Syracuse University, SMU, Texas Econometrics Camp XVIII.
} 


\section{Introduction}

Dynamic panel data (DPD) models were first analyzed in Balestra and Nerlove (1966) and have since become commonplace in economics. Since then, much progress has been made in terms of understanding the properties of a variety estimators of this model, as well as extending this model along numerous dimensions. However, a relatively overlooked issue, and one that is becoming more prominent with the increased availability of longitudinal surveys, pertains to panel data designs with irregular spacing. For example, an often used data set, the Early Childhood Longitudinal Survey-Kindergarten Cohort (ECLS-K), is a survey of roughly 20,000 children who entered kindergarten in the United States in Fall 1998. Information is collected on this sample over seven waves: Fall and Spring Kindergarten, Fall and Spring First Grade, Spring Third Grade, Spring Fifth Grade, and Spring Eighth

Grade. Thus, the first four waves are spaced roughly six months apart, waves four, five, and six are spaced two years apart, and waves six and seven are spaced three years apart. Other examples from developed countries are provided in Table $1 .{ }^{1}$ As we demonstrate below, irregularly spaced data generates a host of difficulties for the estimation of DPD models that researchers cannot ignore.

Before continuing, however, two important statements must be made. First, a formal definition of irregular spacing is required in order to fix ideas. For purposes of this paper, we use the term irregular spacing to characterize longitudinal surveys with successive waves that do not conform to successive periods as defined by the underlying data-generating process (DGP). In time series, the distance between successive waves is referred to as the observation interval, whereas the unit period denotes the reference unit of time for the underlying process (Fuleky 2011). In discrete time models in time series, it is commonplace to set the unit period equal to the observation interval (Hamilton 1994). However, this assumption is difficult to rationalize in cases such as the ECLS-K where the observation interval varies substantially.

Second, longitudinal data collected at uniform intervals but with gaps are irregularly spaced according to our definition if the underlying DGP does not have such gaps; i.e., the unit period is smaller than the observation interval. For example, if the true DGP is based on periods representing a year but the data are only collected biennially, then the data are irregularly spaced. Less obvious, if the data are collected annually, the data are also irregularly spaced if the unit period according to the DGP is, say, a week. For instance, using annual longitudinal data to estimate a DPD model for labor supply may not be irregularly spaced if labor supply is measured using annual hours of work. However, if labor supply is measured using hours worked in the past week, then the 'true' length of a period may be one week, in which case the data are irregularly spaced under our definition.

Thus, irregular spacing in our context is used to denote longitudinal data where the observation interval does not equal the unit period over the entire sample. ${ }^{2}$ As a result, a missing data problem is introduced, where the pattern of missing data is dictated by the survey design and is not observation-specific. In other words, if data are missing for a particular time period, they are missing for the entire sample and for all variables. This differs from most of

\footnotetext{
${ }^{1}$ McKenzie (2001) provides a similar list of longitudinal surveys from developing countries.

${ }^{2}$ If the DGP is specified in continuous time, then all data (with possible exception of real-time financial data) are irregularly spaced. Robinson (2009) provides a brief survey of this issue in the context of time series models. While worthy of future research in a panel context, throughout this paper we assume that the DGP is a discrete time process.
} 
the literature on missing data where the focus is on observation-specific missing data in certain waves (e.g., Griliches et al. 1978; Little and Rubin 2002; Baltagi and Song 2006). While related, we do not consider this issue here.

In this paper, we have several goals. First, we formally discuss the pitfalls to commonly employed DPD estimators if the data are irregularly spaced. Second, we present several new estimators designed to address the spacing issue. Third, we assess the finite sample performance of our new estimators in a Monte Carlo study. Finally, we illustrate the practical importance of addressing the spacing issue when estimating dynamic models of early childhood development using data from the ECLS-K.

As noted above, the existing literature on DPD models with irregularly spaced data is very limited. Rosner and Munoz (1988) address the issue in the context of a DPD model with no time invariant, unobserved heterogeneity (i.e., a dynamic Pooled Ordinary Least Squares (POLS) model). The solution proposed is a Pooled Nonlinear Least Squares (NLS) estimator. Jones and Boadi-Boateng (1991) derive an exact maximum likelihood estimator using the Kalman filter to estimate a static, random coefficients panel data model with serially correlated errors and unequal spacing. To address the serial correlation, the authors assume the errors have a continuous-time first-order autoregressive, $A R(1)$, structure. Alternatively, Baltagi and Wu (1999) present a feasible Generalized Least Squares (GLS) estimator for a static panel data model with $A R(1)$ errors and irregularly spaced data. Finally, in the paper most similar to ours, McKenzie (2001) analyzes the issue of irregular spacing in the context of dynamic pseudo-panel models. The author shows that consistent estimation is feasible as the number of observations per cohort goes to infinity. However, while covariates other than the lagged dependent variable are allowed in the model, the estimation strategy requires that these covariates be observed in the missing periods as well. This limits the researcher to only time-invariant covariates or time-varying covariates that are obtained from outside data sources not subject to the irregular spacing.

The issue of irregular spacing has received more attention in the time series literature. In one strand, Savin and White (1978), Jones (1980, 1985, 1986), Dunsmuir and Robinson (1981), Harvey and Pierse (1984), Palm and Nijman (1984), Dufour and Dagenais (1985), Robinson (1985), Kohn and Ansley (1986), and Shively (1993) confront the problem of irregularly spaced data in the context of an $A R M A(p, q), A R I M A(p, d, q)$, and $A R M A X(p, q, r)$ models. The solutions generally center on using a state-space representation along with the Kalman filter to derive the exact likelihood function. In another strand, Ryan and Giles (1998), building on Shin and Sarkar (1994a,b), are interested in testing for the presence of unit roots with missing data. The authors assess the performance of various solutions relying on imputation of the missing data. Finally, the problem of missing data due to utilizing data collected at different frequencies (so-called mixed frequency data) has received much attention; Foroni and Marcellino (2013) provide an excellent survey. Chiu et al. (2012), for example, are interested in estimating a multivariate Vector Autoregression (VAR) with mixed frequency data; for example, a bivariate VAR where one variable is available at monthly intervals and one at quarterly intervals. The authors address the issue in a Bayesian framework using data augmentation to simulate the missing data for the variable observed at the lower frequency.

In light of this background, our paper is the first to our knowledge to explicitly address the issue of irregular spacing in a standard (i.e., non-pseudo) DPD model with unobserved effects and individual, time-varying covariates. We obtain several striking findings. First, all commonly used DPD estimators are inconsistent in the presence of 
irregularly spaced data. This arises for three reasons: (i) typical transformations no longer eliminate the time invariant, observation-specific unobserved effect as this effect has a time-varying factor structure akin to that considered in the interactive fixed effects literature, (ii) the coefficient on the lagged dependent variable depends on the gap structure, and (iii) covariates (and idiosyncratic errors) from the missing time periods are relegated to the error term. Moreover, this inconsistency matters in practice; the finite sample performance of the commonly used DPD estimators can be extremely poor.

Second, if the covariates are strictly exogenous and serially uncorrelated, several consistent estimators are available. In finite samples, we obtain superior performance by our new estimators: a quasi-differenced GMM estimator and an extended, nonlinear version of an estimator recently proposed in Everaert (2012). Third, in the presence of serially correlated covariates, no single estimator dominates. However, we find consistently good performance by our quasi-differenced GMM estimator as well as our extended, nonlinear version of Everaert's (2012) estimator combined with the assumption that the covariates follow an $A R(1)$ process. Finally, our empirical application indicates that ignoring irregular spacing in the ECLS-K when estimating dynamic models for early childhood development - as measured by student achievement and health measures - alters conclusions regarding the degree of state dependence in human capital formation and the efficacy of various human capital inputs. These conclusions, in combination with the fact that even uniformly spaced longitudinal data may be irregularly spaced, should prompt applied researchers to think much more carefully than is currently the norm about what constitutes the 'true' length of a period in the underlying DGP before estimating dynamic models.

The remainder of the paper is organized as follows. Section 2 presents the DPD model along with the various estimators considered. Section 3 describes the Monte Carlo Study. Section 4 contains the applications to early childhood development. Finally, Section 5 concludes.

\section{Model}

\subsection{Setup}

The DGP in the standard DPD framework is given by

$$
y_{i t}=\gamma y_{i t-1}+x_{i t} \beta+\alpha_{i}+\varepsilon_{i t}, \quad i=1, \ldots, N ; t=1, \ldots, T
$$

where $y_{i t}$ is the outcome for observation $i$ in period $t, \gamma$ is the autoregressive parameter $(|\gamma|<1), x$ is a $1 \times K$ vector of covariates with associated parameter vector $\beta, \alpha_{i}$ is the observation-specific unobserved effect, and $\varepsilon_{i t}$ is the idiosyncratic, mean zero error term. Implicit in this specification is that $y_{i 0}$ is the initial condition. Throughout the paper, we focus on the case where $\gamma \neq 0$.

Given a random sample, $\left\{y_{i t}, x_{i t}\right\}_{i=1, . ., N ; t=1, \ldots, T}$, along with data on the initial condition, (1) may be estimated using a number of techniques depending on the nature of the dependence between $x$ and the error components, $\alpha$ and $\varepsilon$. Even if $x$ is independent of both error components (conditional on $y_{i t-1}$ ), pooled OLS (POLS), fixed effects (FE), and first-differenced (FD) estimation of (1) are biased and inconsistent for fixed $T$ (Nickell 1981). However, instrumental variable (IV) estimation of (1) is consistent as $x_{i t-1}$ represents a valid exclusion restriction. In fact, 
further lags $-x_{i t-2}, x_{i t-3}, \ldots$ - may also be incorporated in a Generalized Method of Moments (GMM) framework.

If $x$ is dependent on $\alpha$, then the preceding estimation strategy is no longer valid. Absent external instruments for $y_{i t-1}$ and $x$, another strategy is needed. The typical approach based on Anderson and Hsiao (1981) is to eliminate $\alpha$ via FD and estimate the model using IV. Specifically, given the model

$$
\Delta y_{i t}=\gamma \Delta y_{i t-1}+\Delta x_{i t} \beta+\Delta \varepsilon_{i t}, \quad i=1, \ldots, N ; t=2, \ldots, T
$$

where $\Delta$ represents the difference operator, $x_{i t-2}$ represents a valid exclusion restriction. Again, additional moment conditions may be incorporated in a GMM framework (Arellano and Bond 1991; Arellano and Bover 1995; Blundell and Bond 1998). ${ }^{3}$ Other proposed solutions utilize long-differences (LD) combined with IV (Hahn et al. 2007), deviations from backward means combined with a Hausman and Taylor (1981) IV approach (Everaert 2012), or a bias-corrected least squares dummy variable (LSDV) approach (Kiviet 1995; Hahn and Kuersteiner 2002; Bun and Carree 2005).

Unfortunately, when the observed data are irregularly spaced, FE or FD transformations no longer succeed in eliminating the unobserved effect. ${ }^{4}$ To proceed, begin by noting the following result obtained trivially from repeated substitution in (1)

$$
\begin{aligned}
y_{i t} & =\gamma^{s} y_{i t-s}+\sum_{j=0}^{s-1} x_{i t-j} \gamma^{j} \beta+\sum_{j=0}^{s-1} \gamma^{j} \alpha_{i}+\sum_{j=0}^{s-1} \gamma^{j} \varepsilon_{i t-j}, \quad i=1, \ldots, N ; t=1, \ldots, T \\
& =\gamma^{s} y_{i t-s}+\sum_{j=0}^{s-1} x_{i t-j} \gamma^{j} \beta+\left(\frac{1-\gamma^{g_{m}}}{1-\gamma}\right) \alpha_{i}+\sum_{j=0}^{s-1} \gamma^{j} \varepsilon_{i t-j},
\end{aligned}
$$

for all $s \geq 1$. Let $m=0,1,2, \ldots, M$ index the $M+1$ periods of data observed in the sample, where $M<T$. Note, the same periods are assumed to be observed for all observations, $i$. For example, Figure 1 illustrates the case where the DGP defined by (1) applies to periods $t=1, \ldots, 8$ (with period 0 representing the initial period). However, the sample only includes data from periods $t=0,1,4,5,8$. Thus, in this example, $M=4$ while $T=8$.

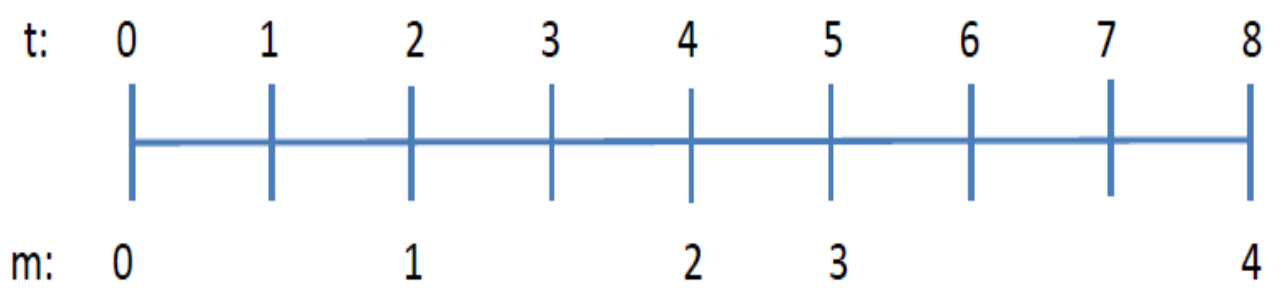

Figure 1. Illustration of Irregularly Spaced Panel Data

Given the DGP in (1), the result in (3), and irregularly-spaced observed data, the model defined over the observed

\footnotetext{
${ }^{3}$ Hereafter, we refer to the Anderson and Hsaio (1981) estimator as AH, the Arellano and Bond (1991) GMM estimator as AB, and the Blundell and Bond (1998) system GMM estimator as BB.

${ }^{4}$ In general, LD will also not succeed in removing the unobserved effect unless the data are regularly spaced at the beginning and end periods of the sample.
} 
periods is given by

$$
\begin{aligned}
y_{i m}=\gamma^{g_{m}} y_{i m-1} & +\sum_{j=0}^{g_{m}-1} x_{i, t(m)-j} \gamma^{j} \beta+\left(\frac{1-\gamma^{g_{m}}}{1-\gamma}\right) \alpha_{i} \\
& +\sum_{j=0}^{g_{m}-1} \gamma^{j} \varepsilon_{i, t(m)-j}, \quad i=1, \ldots, N ; m=1, \ldots, M \\
= & \gamma^{g_{m}} y_{i m-1}+x_{i m} \beta+\left[\sum_{j=1}^{g_{m}-1} x_{i, t(m)-j} \gamma^{j} \beta+\left(\frac{1-\gamma^{g_{m}}}{1-\gamma}\right) \alpha_{i}+\sum_{j=0}^{g_{m}-1} \gamma^{j} \varepsilon_{i, t(m)-j}\right]
\end{aligned}
$$

where $g_{m}, m=1, \ldots, M$, is the gap size or the number of periods between observed periods $m$ and $m-1, t(m)$ is the actual period reflected by observed period $m$, and the term in brackets contains all unobserved determinants of $y_{\text {im }} .^{5}$

Several observations based on (5) are noteworthy. First, if $g_{m}=1$ for all $m$, then the data are regularly spaced and (5) simplifies to (1). Second, the coefficient on the lagged dependent variable is not constant, but rather depends on the number of true periods spanned by the observed time periods. Third, the error term in brackets contains the covariates, $x$, and the idiosyncratic errors, $\varepsilon$, from the missing periods in between periods $m-1$ and $m$, in addition to the contemporaneous error. Fourth, the unobserved effect, $\alpha$, is now scaled by a period-specific factor loading that depends on the autoregressive parameter and the gap size between periods $m$ and $m-1$. As a result, this model is closely related to recent work on interactive fixed effects models (Ahn et al. 2001; Nauges and Thomas 2003; Pesaran 2006; Bai 2009; Lee et al. 2012). ${ }^{6}$ On the one hand, the model in (5) is simpler than those considered in the interactive fixed effects literature in that the period-specific factor loading on $\alpha_{i}$ is fixed with a known functional form. On the other hand, this prior literature does not confront the issue of unobserved $x$ 's from missing periods in the error term. Finally, if $g_{m}=g>1$ for all $m$, where $g$ is any finite constant, then the data are equally-spaced but with gaps. In this case, FE, FD, and LD will eliminate $\alpha$. However, complications still arise in that the coefficient on $y_{i m-1}$ is now $\gamma^{g}$ and $x$ 's from the missing periods are in the transformed error term.

\subsection{Estimation}

To evaluate the behavior of various estimators of (5), re-write the model more compactly as

$$
y_{i m}=\gamma^{g_{m}} y_{i m-1}+x_{i m} \beta+\theta_{m} \alpha_{i}+\widetilde{\varepsilon}_{i m}, \quad i=1, \ldots, N ; m=1, \ldots, M,
$$

where

$$
\theta_{m} \equiv\left(\frac{1-\gamma^{g_{m}}}{1-\gamma}\right) ; \quad \widetilde{\varepsilon}_{i m} \equiv \sum_{j=1}^{g_{m}-1} x_{i, t(m)-j} \gamma^{j} \beta+\sum_{j=0}^{g_{m}-1} \gamma^{j} \varepsilon_{i, t(m)-j} .
$$

As noted above, this resembles the model considered in the recent literature on interactive fixed effects models except that $\theta_{m}$ is fixed with a known structure and $\widetilde{\varepsilon}$ has a more complex structure. In the remainder of this section, we begin by first assessing the performance of existing estimators applied to (6). We then move on to discuss our new estimators.

\footnotetext{
${ }^{5}$ For example, in Figure $1 t(0)=0, t(1)=2, t(2)=4, t(3)=5$, and $t(4)=8$. Moreover, $g_{m}=t(m)-t(m-1)$.

${ }^{6}$ The model is also related to prior work on time-varying inefficiency in panel data stochastic frontier models (e.g., Cornwell et al. 1990).
} 
Pooled OLS The POLS estimator, ignoring the unequal spacing issues, entails applying OLS to the estimating equation

$$
y_{i m}=\gamma_{0} y_{i m-1}+x_{i m} \beta+\widetilde{\widetilde{\varepsilon}}_{i m}, \quad i=1, \ldots, N ; m=1, \ldots, M,
$$

where

$$
\widetilde{\widetilde{\varepsilon}}_{i m}=\left(\gamma^{g_{m}}-\gamma_{0}\right) y_{i m-1}+\sum_{j=1}^{g_{m}-1} x_{i, t(m)-j} \gamma^{j} \beta+\theta_{m} \alpha_{i}+\sum_{j=0}^{g_{m}-1} \gamma^{j} \varepsilon_{i, t(m)-j} .
$$

This case is worth noting for three reasons. First, even if $\alpha_{i}=\alpha$ for all $i$ and $\varepsilon_{i t}$ is serially uncorrelated, $y_{i m-1}$ will not be independent of the error term in $(7)$ due to $\left(\gamma^{g_{m}}-\gamma_{0}\right) y_{i m-1}$. This dependence may also arise if $x$ is not strictly exogenous (in the sense that $\mathrm{E}\left[x_{i t} \varepsilon_{i s}\right]=0 \forall s, t$ ); specifically, if $x$ is correlated with lagged shocks, then $x$ from the unobserved periods occurring between periods $m-1$ and $m$ will be correlated with $y_{i m-1}$ through $\varepsilon_{i m-1}$. Second, even if $\gamma_{0}$ is consistently estimated, it lacks any structural interpretation as it represents a weighted average of various polynomials of $\gamma$. Third, the estimates of $\beta$ will be biased and inconsistent, even if $x$ is uncorrelated with $\alpha$ and strictly exogenous, if $x$ is serially correlated (due to the inclusion of $x$ from the unobserved periods occurring between periods $m-1$ and $m$ in $\left.\widetilde{\widetilde{\varepsilon}}_{i m}\right)$.

Nonlinear Least Squares (NLS) POLS ignores the fact that the coefficient on the lagged dependent variable varies across periods depending on the gap size. Because one knows the structure of this coefficient, we can instead estimate the model

$$
y_{i m}=\gamma^{g_{m}} y_{i m-1}+x_{i m} \beta+\widetilde{\widetilde{\varepsilon}}_{i m}, \quad i=1, \ldots, N ; m=1, \ldots, M
$$

where now

$$
\widetilde{\widetilde{\varepsilon}}_{i m}=\sum_{j=1}^{g_{m}-1} x_{i, t(m)-j} \gamma^{j} \beta+\theta_{m} \alpha_{i}+\sum_{j=0}^{g_{m}-1} \gamma^{j} \varepsilon_{i, t(m)-j},
$$

using NLS. NLS is consistent for $\gamma$ and $\beta$ if $\alpha_{i}=\alpha$ for all $i, x$ is strictly exogenous and not serially correlated, and $\varepsilon_{i t}$ is serially uncorrelated. This is the case considered in Rosner and Munoz (1988). If an unobserved effect is present in the model (or $\varepsilon_{i t}$ is serially correlated), then a NLS-IV procedure may be possible. Specifically, $x_{i m-1}$ is a valid IV if $x$ is uncorrelated with $\alpha$, predetermined (in the sense that $\mathrm{E}\left[x_{i t} \varepsilon_{i s}\right]=0 \forall s \geq t$ ), and serially uncorrelated. Thus, the inclusion of $x$ from the missing periods in the composite error severely limits the ability of lagged $x$ to serve as a valid exclusion restriction. However, consistent estimates of $\beta$ require strict exogeneity (in the sense that $\left.\mathrm{E}\left[x_{i t} \varepsilon_{i s}\right]=0 \forall s, t\right)$. If $x$ is predetermined as opposed to strictly exogenous, $x_{i m}$ will be correlated with $\widetilde{\widetilde{\varepsilon}}_{i m}$ due to the inclusion of the idiosyncratic error from the periods between $m-1$ and $m$. As such, estimates of $\beta$ will be inconsistent even if $\gamma$ is consistently estimated. We refer to this as the NLS-IV estimator. ${ }^{7}$

An alternative NLS approach entails following the Mundlak (1978) correlated random effects (CRE) approach. Assuming

$$
\mathrm{E}\left[\alpha_{i} \mid x_{i}\right]=\bar{x}_{i} \delta
$$

we can write $\alpha_{i}=\bar{x}_{i} \delta+v_{i}$. Then, (8) becomes

$$
y_{i m}=\gamma^{g_{m}} y_{i m-1}+x_{i m} \beta+\bar{x}_{i}\left(\frac{1-\gamma^{g_{m}}}{1-\gamma}\right) \delta+\left[v_{i}+\widetilde{\varepsilon}_{i m}\right] .
$$

\footnotetext{
${ }^{7}$ We apologize to the reader now for the number of acronyms used in the paper for the various estimators!
} 
IV is still required for consistent estimation of (10), however, since $y_{i m-1}$ is correlated with the random effect, $v_{i}$. In this case, $x_{i m-1}$ is a valid IV if $x$ is strictly exogenous and serially uncorrelated; $\beta$ can also be consistently estimated under these conditions. Note, strict exogeneity is required for a consistent estimate of $\gamma$ as otherwise $\operatorname{Cov}\left(\bar{x}_{i}, \widetilde{\varepsilon}_{i m}\right) \neq 0$ and $\operatorname{Cov}\left(x_{i m-1}, \bar{x}_{i}\right) \neq 0$. We refer to this as the NLS-CRE-IV estimator.

First-Differencing If the unobserved effect, $\alpha$, appears in the DGP in (1), an alternative to the Mundlak (1978) approach is to transform the model to eliminate $\alpha$ from the estimating equation. However, with irregularly spaced data, the usual transformations no longer succeed in this regard. Consider FD, as utilized in the Anderson and Hsiao (1981), Arellano and Bond (1991), and Blundell and Bond (1998) approaches. First-differencing the model in (6) yields

$$
\begin{gathered}
y_{i m}-y_{i m-1}=\gamma^{g_{m}} y_{i m-1}-\gamma^{g_{m-1}} y_{i m-2}+\left(x_{i m}-x_{i m-1}\right) \beta+\alpha_{i}\left(\theta_{m}-\theta_{m-1}\right) \\
+\widetilde{\varepsilon}_{i m}-\widetilde{\varepsilon}_{i m-1}, \quad i=1, \ldots, N ; m=2, \ldots, M \\
\Delta y_{i m}=\gamma^{g_{m}} y_{i m-1}-\gamma^{g_{m-1}} y_{i m-2}+\Delta x_{i m} \beta+\alpha_{i} \Delta \theta_{m}+\Delta \widetilde{\varepsilon}_{i m}
\end{gathered}
$$

where $\Delta$ represents the difference between consecutive, observed periods (indexed by $m$ ) and $\Delta \theta_{m}=\left(\gamma^{g_{m-1}}-\right.$ $\left.\gamma^{g_{m}}\right) /(1-\gamma)$.

Several comments are in order. First, ignoring the irregular spacing issue entails estimating

$$
\Delta y_{i m}=\gamma_{0} \Delta y_{i m-1}+\Delta x_{i m} \beta+\left[\alpha_{i} \Delta \theta_{m}+\gamma^{g_{m}} y_{i m-1}-\gamma^{g_{m-1}} y_{i m-2}-\gamma_{0} \Delta y_{i m-1}+\Delta \widetilde{\varepsilon}_{i m}\right]
$$

by POLS. Not only does $\gamma_{0}$ lack any structural interpretation, but $\Delta y_{i m-1}$ is not independent of the composite error. Moreover, because the error term includes $y_{i m-1}$ and $y_{i m-2}$, any proposed IV for $\Delta y_{i m-1}$ will also be correlated with the error term. Second, because FD does not eliminate the unobserved effect from (11), NLS estimation of (11) will also be inconsistent unless $\alpha_{i}=\alpha$ for all $i$. However, an NLS-IV procedure utilizing $x_{i m-1}$ as an IV for $y_{i m-1}$ provides consistent estimates if $x$ is independent of $\alpha$, strictly exogenous, and serially uncorrelated. ${ }^{8}$ We refer to this as the FD-NLS-IV estimator. Third, a Mundlak (1978) correlated random effects approach is feasible under different restrictions. Specifically,

$$
\Delta y_{i m}=\gamma^{g_{m}} y_{i m-1}-\gamma^{g_{m-1}} y_{i m-2}+\Delta x_{i m} \beta+\bar{x}_{i}\left(\frac{\gamma^{g_{m-1}}-\gamma^{g_{m}}}{1-\gamma}\right) \delta+\left[v_{i}+\Delta \widetilde{\varepsilon}_{i m}\right]
$$

is estimable via NLS-IV using $x_{i m-1}$ as an IV for $y_{i m-1}$ provided $x$ is strictly exogenous and serially uncorrelated. We refer to this estimator as FD-NLS-CRE-IV. However, because FD does not eliminate the unobserved effect, there would seem to be little gain, relative to the prior NLS estimators, to justify the loss in efficiency.

Long-Differencing Hahn et al. (2007) propose the use of long-differencing to eliminate the unobserved effect, $\alpha$. As with FD, this transformation no longer succeeds in this regard with irregularly spaced data. Long-differencing the model in (6) yields

$$
y_{i M}-y_{i 1}=\gamma^{g_{M}} y_{i M-1}-\gamma^{g_{1}} y_{i 0}+\left(x_{i M}-x_{i 1}\right) \beta+\alpha_{i}\left(\theta_{M}-\theta_{1}\right)+\widetilde{\varepsilon}_{i M}-\widetilde{\varepsilon}_{i 1}, \quad i=1, \ldots, N
$$

\footnotetext{
${ }^{8}$ Note, $y_{i m-2}$ is exogenous if $x$ and $\varepsilon$ are serially uncorrelated.
} 
where $\theta_{M}-\theta_{1}=\left(\gamma^{g_{1}}-\gamma^{g_{M}}\right) /(1-\gamma)$. Thus, the unobserved effect is not eliminated unless $g_{1}=g_{M}$. Absent this case, there does not appear to be any advantage of the LD approach over the FD approach in this context. Thus, we do not consider LD estimators beyond this point.

Fixed Effects The FE transformation attempts to eliminate $\alpha$ by mean-differencing. Mean-differencing the model in (6) yields

$$
\begin{array}{rl}
y_{i m}-\bar{y}_{i}= & \gamma^{g_{m}} y_{i m-1}-\frac{1}{M} \sum_{j=1}^{M} \gamma^{g_{j}} y_{i j-1}+\left(x_{i m}-\bar{x}_{i}\right) \beta+\alpha_{i}\left(\theta_{m}-\bar{\theta}_{m}\right) \\
+\widetilde{\varepsilon}_{i m}-\overline{\widetilde{\varepsilon}}_{i}, \quad i=1, \ldots, N ; m=1, \ldots, M & i=\ddot{x}_{i}, \ddot{\theta}_{m}+\ddot{\widetilde{\varepsilon}}_{i m},
\end{array}
$$

where $\because$ denotes deviations from the observation-specific mean computed over the observed sample, $c_{i}$ denotes the observation-specific, weighted average of $y$ computed over the observed periods $m=0, \ldots, M-1$, and

$$
\ddot{\theta}_{m}=-\frac{1}{1-\gamma}\left(M \gamma^{g_{m}}-\sum_{j=1}^{M} \gamma^{g_{j}}\right) .
$$

Again, several comments are in order. First, as in the FD case, the FE transformation fails to eliminate the unobserved effect. Conventional FE estimation ignoring the irregular spacing would lead one to estimate the misspecified model given by

$$
\ddot{y}_{i m}=\gamma_{0} \ddot{y}_{i m-1}+\ddot{x}_{i m} \beta+\left[\left(\gamma^{g_{m}}-\gamma_{0}\right) y_{i m-1}+\frac{1}{M} \sum_{j=1}^{M}\left(\gamma_{0}-\gamma^{j}\right) y_{i j-1}+\alpha_{i} \ddot{\theta}_{m}+\ddot{\widetilde{\varepsilon}}_{i m}\right] .
$$

As with FD, FE estimation of this model is inconsistent, no valid IV procedure is available, and $\gamma_{0}$ does not have a structural interpretation. Second, NLS estimation of (14) confronts two difficulties: the presence of $\alpha$ in the composite error and the term $c$. If $c$ is not controlled for explicitly, the model becomes

$$
\ddot{y}_{i m}=\gamma^{g_{m}}\left(\frac{M-1}{M}\right) y_{i m-1}+\ddot{x}_{i m} \beta+\left[\alpha_{i} \ddot{\theta}_{m}-\frac{1}{M} \sum_{j=1, j \neq m}^{M} \gamma^{g_{j}} y_{i j-1}+\ddot{\widetilde{\varepsilon}}_{i m}\right] \text {. }
$$

Here, $y_{i m-1}$ is endogenous due to the presence of the unobserved effect as well as the correlation with $y$ in other periods through the dynamic process. Moreover, valid IVs are likely not possible since any variable correlated with $y_{i m-1}$ is likely to be correlated with $y$ in other periods due to the autoregressive nature of $y$.

On the other hand, incorporating the elements of $c$ as additional covariates creates a non-traditional model akin to Chamberlain's fixed effects model (Chamberlain 1984). Specifically, the model becomes

$$
\ddot{y}_{i m}=\sum_{j=1}^{M} \gamma_{m j} y_{i j-1}+\ddot{x}_{i m} \beta+\left[\alpha_{i} \ddot{\theta}_{m}+\ddot{\widetilde{\varepsilon}}_{i m}\right]
$$

where

$$
\gamma_{m j}= \begin{cases}\gamma^{g_{m}}\left(\frac{M-1}{M}\right) & \text { if } m=j \\ -\gamma^{g_{m}}\left(\frac{1}{M}\right) & \text { if } m \neq j\end{cases}
$$


Thus, estimation of (18) must account not only for the endogeneity of $\left\{y_{i j-1}\right\}_{j=1}^{M}$, but also the period-specific coefficients on these covariates. However, if $x$ is independent of $\alpha$, strictly exogenous, and serially uncorrelated, $\left\{x_{i j-1}\right\}_{j=1}^{M}$ are valid IVs for $\left\{y_{i j-1}\right\}_{j=1}^{M}$.

Finally, note that one could eliminate $c_{i}$ entirely by first-differencing (14). Interestingly, doing so yields

$$
\begin{aligned}
\Delta \ddot{y}_{i m} & =\gamma^{g_{m}} y_{i m-1}-\gamma^{g_{m-1}} y_{i m-2}+\Delta \ddot{x}_{i m} \beta+\alpha_{i} \Delta \ddot{\theta}_{m}+\ddot{\widetilde{\varepsilon}}_{i m} \\
\Rightarrow \Delta y_{i m} & =\gamma^{g_{m}} y_{i m-1}-\gamma^{g_{m-1}} y_{i m-2}+\Delta x_{i m} \beta+\alpha_{i} \Delta \theta_{m}+\widetilde{\varepsilon}_{i m},
\end{aligned}
$$

which is identical to the FD model in (11). Thus, we do not consider FE-type estimators beyond this point.

Quasi-Differencing (QD) While FD, LD, and FE do not eliminate the unobserved effect, a QD approach does. To see this, we set up the following quasi-differenced equation

$$
\begin{aligned}
y_{i m}-\varphi_{m} y_{i m-1}=\gamma^{g_{m}} y_{i m-1}-\varphi_{m} \gamma^{g_{m-1}} y_{i m-2}+\left(x_{i m}-\varphi_{m} x_{i m-1}\right) \beta & \\
& +\alpha_{i}\left(\theta_{m}-\varphi_{m} \theta_{m-1}\right)+\widetilde{\varepsilon}_{i m}-\varphi_{m} \widetilde{\varepsilon}_{i m-1}, \quad i=1, \ldots, N ; m=2, \ldots, M .
\end{aligned}
$$

Defining

$$
\varphi_{m} \equiv \frac{\theta_{m}}{\theta_{m-1}}=\frac{1-\gamma^{g_{m}}}{1-\gamma^{g_{m-1}}}
$$

implies that (21) simplifies to

$$
y_{i m}-\varphi_{m} y_{i m-1}=\gamma^{g_{m}} y_{i m-1}-\varphi_{m} \gamma^{g_{m-1}} y_{i m-2}+\left(x_{i m}-\varphi_{m} x_{i m-1}\right) \beta+\widetilde{\widetilde{\varepsilon}}_{i m},
$$

where

$$
\begin{aligned}
\widetilde{\widetilde{\varepsilon}}_{i m} & =\widetilde{\varepsilon}_{i m}-\varphi_{m} \widetilde{\varepsilon}_{i m-1} \\
& =\left[\sum_{j=1}^{g_{m}-1} x_{i, t(m)-j} \gamma^{j}-\varphi_{m} \sum_{j=1}^{g_{m-1}-1} x_{i, t(m-1)-j} \gamma^{j}\right] \beta+\sum_{j=0}^{g_{m}-1} \gamma^{j} \varepsilon_{i, t(m)-j}-\varphi_{m} \sum_{j=0}^{g_{m-1}-1} \gamma^{j} \varepsilon_{i, t(m-1)-j}
\end{aligned}
$$

Referring to the example in Figure 1, the values of $\varphi_{m}$ are shown in Table 2.

If $\varphi_{m}$ were known, (23) is estimable by NLS-IV. Specifically, $x_{i m-1}$ is a valid IV for $y_{i m-1}$ if $x$ is strictly exogenous and $x$ is serially uncorrelated. ${ }^{9}$ However, as $\gamma$ is unknown, our first set of newly proposed estimators include three feasible approaches to quasi-differencing.

First, one may apply a Union of Confidence Intervals (UCI) approach. ${ }^{10}$ This approach entails estimating (23) over a set of possible values for $\gamma$ (and hence $\varphi_{m}$ ), testing whether the estimated value of $\widehat{\gamma}\left(\gamma_{0}\right)=\gamma_{0}$, where $\widehat{\gamma}\left(\gamma_{0}\right)$ represents the estimated value of $\gamma$ obtained when the QD is performed assuming $\gamma=\gamma_{0}$, and forming a confidence interval for $\gamma$ as the union of the confidence intervals over $\widehat{\gamma}\left(\gamma_{p}\right)$, where $\gamma_{p}$ denotes all the values where $\widehat{\gamma}\left(\gamma_{p}\right)=\gamma_{p}$ cannot be rejected. If the union of $(1-\alpha) \%$ confidence intervals are used, then the UCI approach will have a coverage rate of at least $(1-\alpha)$, where $1-\alpha$ denotes the significance level if the model is otherwise correctly specified. For $x_{m-1}$ to be a valid IV for $y_{i m-1}$ in (23), this requires $x$ to be strictly exogenous and serially uncorrelated. Correct coverage for $\beta$ requires $x$ to be strictly exogenous. We refer to this as the QD-UCI approach.

\footnotetext{
${ }^{9}$ Note, $y_{i m-2}$ is exogenous if $x$ and $\varepsilon$ are serially uncorrelated.

${ }^{10}$ For another application of a UCI approach, see Conley et al. (2012).
} 
An alternative approach follows the logic in Lee et al. (2012), who build on quantile regression estimators developed in Chernozhukov and Hansen $(2006,2008)$. To proceed, re-write (23) as

$$
\begin{aligned}
y_{i m}-\left(\frac{1-\gamma^{g_{m}+g_{m-1}}}{1-\gamma^{g_{m-1}}}\right) y_{i m-1}+ & \left(\frac{\gamma^{g_{m-1}}-\gamma^{g_{m}+g_{m-1}}}{1-\gamma^{g_{m-1}}}\right) y_{i m-2} \\
& =\left[x_{i m}-\left(\frac{1-\gamma^{g_{m}}}{1-\gamma^{g_{m-1}}}\right) x_{i m-1}\right] \beta+\widetilde{\widetilde{\varepsilon}}_{i m} .
\end{aligned}
$$

Given a vector of IVs for $y_{i m-1}$, say $z_{i m}$, and a specified value of $\gamma$, we can obtain estimates of $\pi(\gamma)$ and $\beta(\gamma)$ using POLS applied to

$$
\begin{aligned}
y_{i m}-\left(\frac{1-\gamma^{g_{m}+g_{m-1}}}{1-\gamma^{g_{m-1}}}\right) y_{i m-1}+ & \left(\frac{\gamma^{g_{m-1}}-\gamma^{g_{m}+g_{m-1}}}{1-\gamma^{g_{m-1}}}\right) y_{i m-2} \\
& =z_{i m} \pi+\left[x_{i m}-\left(\frac{1-\gamma^{g_{m}}}{1-\gamma^{g_{m-1}}}\right) x_{i m-1}\right] \beta+\widetilde{\widetilde{\varepsilon}}_{i m} .
\end{aligned}
$$

Since the IVs do not belong in (26) when $\gamma$ is set equal to its true value and the original DGP in (1) is correctly specified, $\gamma$ may be estimated by minimizing the length of $\widehat{\pi}(\gamma)$ as

$$
\widehat{\gamma}=\arg \min _{\gamma} \widehat{\pi}(\gamma)^{\prime} W \widehat{\pi}(\gamma)
$$

where $W$ is some positive definite weighting matrix. Taking $z_{i m}=x_{i m-1}, \widehat{\gamma}$ and $\widehat{\beta}(\widehat{\gamma})$ are consistent if $x$ is strictly exogenous and serially uncorrelated. Alternatively, $z_{i m}$ may be replaced by the fitted values from the first-stages for $y_{i m-1}$. Following Lee et al. (2012), we refer to this as the QD-LS-MD approach where MD refers to the distance minimization that takes place in the second step, given in (27).

Our final approach follows from the GMM estimator proposed in Nauges and Thomas (2003). The set of moment conditions considered is given by

$$
\mathrm{E}\left[w_{i m} \widetilde{\widetilde{\varepsilon}}_{i m}\right]=0,
$$

where $w_{i m}=\left\{x_{i m}, x_{i m-1}, y_{i m-2}\right\}$. GMM is consistent if $x$ is strictly exogenous and serially uncorrelated. Here, the fact that $\varphi_{m}$ is a function of $\gamma$ is incorporated into the moment conditions and (implicitly) estimated. We refer to this estimator as QD-GMM.

Orthogonal to Backward Mean Transformation Recently, Everaert (2012) proposed an alternative technique for estimating DPD models. The approach does not entail transforming the model to eliminate the unobserved effect; rather, the model in levels is estimated via IV. With regularly spaced data, the model is given by (1), repeated here for convenience:

$$
y_{i t}=\gamma y_{i t-1}+x_{i t} \beta+\alpha_{i}+\varepsilon_{i t}, \quad i=1, \ldots, N ; t=1, \ldots, T .
$$

The proposed instrument for $y_{i t-1}$ is the OLS residual of $y_{i t-1}$ regressed on its backward mean, $\bar{y}_{i t-1}^{b}$, defined as

$$
\bar{y}_{i t-1}^{b} \equiv \frac{1}{t} \sum_{s=0}^{t-1} y_{i s} .
$$

If $x_{i t}$ is independent of $\alpha_{i}$ and $\varepsilon_{i t}$, then this estimator is consistent as $T \rightarrow \infty$, but not as $N \rightarrow \infty$ for fixed $T$. However, the inconsistency for fixed $T$ is shown to be relatively small in practice. 
If $x$ is correlated with the unobserved effect, then Everaert (2012) suggests using Hausman and Taylor (1981) type instruments for $x$; namely, deviations from individual sample means, $\ddot{x}$. A Mundlak approach (1978) approach in combination with use of the residual from the backward mean regression as an instrument for $y_{i t-1}$ is also consistent as $T \rightarrow \infty$.

With irregularly spaced data, the model is given in (6), again repeated for convenience:

$$
y_{i m}=\gamma^{g_{m}} y_{i m-1}+x_{i m} \beta+\theta_{m} \alpha_{i}+\widetilde{\varepsilon}_{i m}, \quad i=1, \ldots, N ; m=1, \ldots, M
$$

where

$$
\theta_{m} \equiv\left(\frac{1-\gamma^{g_{m}}}{1-\gamma}\right) ; \quad \widetilde{\varepsilon}_{i m} \equiv \sum_{j=1}^{g_{m}-1} x_{i, t(m)-j} \gamma^{j} \beta+\sum_{j=0}^{g_{m}-1} \gamma^{j} \varepsilon_{i, t(m)-j} .
$$

Our second set of newly proposed estimators are based on nonlinear versions of Everaert's (2012) approach. The first such estimator, denoted E-NLS-IV, is consistent as $T \rightarrow \infty$ if $x$ is strictly exogenous and serially uncorrelated. This estimator utilizes the IVs suggested in Everaert (2012) in an NLS framework to address the time-varying coefficient on the lagged dependent variable.

A Mundlak (1978) version is also feasible. The NLS-IV estimator applied to the following estimating equation

$$
y_{i m}=\gamma^{g_{m}} y_{i m-1}+x_{i m} \beta+\bar{x}_{i}\left(\frac{1-\gamma^{g_{m}}}{1-\gamma}\right) \delta+\left[v_{i}+\widetilde{\varepsilon}_{i m}\right],
$$

using orthogonal deviations from its backward mean as an instrument for $y_{i m-1}$ is referred to as E-NLS-CRE-IV. This estimator also requires that $T \rightarrow \infty$ and $x$ be strictly exogenous and serially uncorrelated. We develop further variants of the nonlinear Everaert (2012) approach in the next section.

\subsection{Extension}

The requirements for consistent estimation of the structural parameters, $\gamma$ and $\beta$, in (1) are summarized in Table 3. As should be clear, perhaps the most salient issue created by unequally spaced panel data is the relegation of the covariates from the missing periods into the error term. This implies that serial correlation in $x$ causes all the estimators considered thus far to be inconsistent due to the endogeneity of $x$ and the inability to obtain suitable IVs for the lagged dependent variable. ${ }^{11}$ Since serial correlation in $x$ is likely to be present, this is problematic.

As an alternative, we first consider an extension to the prior estimators where we impute $x$ from the missing periods and incorporate the imputed values into the estimating equation. ${ }^{12}$ This is analogous to the strategy pursued in Ryan and Giles (1998) who analyze the problem of testing for unit roots with irregularly spaced time series. In their context, they consider imputing data for the missing periods using two strategies: linear interpolation and carrying the last value forward. ${ }^{13}$

\footnotetext{
${ }^{11}$ Note, while the focus here has been on obtaining valid IVs using lagged $x$, even futher lags of $y$ will not yield a valid IV procedure when $x$ is serially correlated. This arises since further lags of $y$ will be also be correlated with the missing values of $x$ since $y$ depends on $x$.

${ }^{12}$ We do not consider imputing missing data on $y$ since this is the variable we are trying to model.

${ }^{13}$ Ryan and Giles (1998) also consider the implications of ignoring the issue by collapsing the data. This corresponds to our naïve estimators discussed above where the irregular spacing is ignored.
} 
In our case, the relevant term we are trying to approximate is

$$
\sum_{j=1}^{g_{m}-1} x_{i, t(m)-j} \gamma^{j} \beta
$$

which is part of the composite error in (6). While one could impute distinct values for $x_{i, t(m)-j}, j=1, \ldots, g_{m}-1$, this creates a difficulty in that $y_{i m}$ is now a function of $g_{m}-1$ lags of $x$, with $g_{m}$ varying with $m$ in the case of unequal spacing. Thus, the number of covariates differs across observations. To circumvent this issue, we impute a single value of $x$ for all $x$ missing between periods $m$ and $m-1$. Let $x_{i m}^{o}$ denote this value. We can write

$$
\sum_{j=1}^{g_{m}-1} x_{i, t(m)-j} \gamma^{j} \beta \approx x_{i m}^{o}\left(\frac{\gamma-\gamma^{g_{m}}}{1-\gamma}\right) \beta
$$

The equation of interest in (6) becomes

$$
y_{i m}=\gamma^{g_{m}} y_{i m-1}+x_{i m} \beta+D_{i m} x_{i m}^{o}\left(\frac{\gamma-\gamma^{g_{m}}}{1-\gamma}\right) \beta+\theta_{m} \alpha_{i}+\sum_{j=0}^{g_{m}-1} \gamma^{j} \varepsilon_{i, t(m)-j},
$$

where $D_{i m}=\mathrm{I}\left(g_{m}>1\right)$ and $\mathrm{I}(\cdot)$ is the indicator function.

Estimation of (31) has its own difficulties. If $x_{i m}^{o}$ is taken as the last observed value, $x_{i m-1}$, or as a linear function of $x_{i m}$ and $x_{i m-1}$, then this precludes $x_{i m-1}$ from being a valid instrument in the IV procedures discussed above. Given $M$ sufficiently large, this may not be overly problematic as further lags of $x$ may be used as instruments. However, the problem of weak instruments may arise. To avoid this concern, we only focus on two estimators, E-NLS-IV and E-NLS-CRE-IV, when replacing $x^{o}$ with either the last observed value or the average of the current and last observed values. Denote these estimators as E-NLS-IV-L and E-NLS-CRE-IV-L and E-NLS-IV-A and E-NLS-CRE-IV-A, respectively.

Alternatively, we can take $x_{i m}^{o}$ as the current observed value, $x_{i m}$. In this case, (31) becomes

$$
y_{i m}=\gamma^{g_{m}} y_{i m-1}+\left(1-D_{i m}\right) x_{i m} \beta+D_{i m} x_{i m} \beta\left(\frac{1-\gamma^{g_{m}}}{1-\gamma}\right)+\theta_{m} \alpha_{i}+\sum_{j=0}^{g_{m}-1} \gamma^{j} \varepsilon_{i, t(m)-j} .
$$

Utilizing the Everaert (2012) approach, we denote these estimators of (32) as E-NLS-IV-C and E-NLS-CRE-IV-C.

As a second alternative, we consider explicitly modeling the autoregressive process of $x{ }^{14}$ Suppose that each covariate follows an $A R(1)$ process

$$
x_{i t}=x_{i t-1} \times \operatorname{diag}\left[\rho_{1}, \ldots, \rho_{K}\right]+u_{i t},
$$

where $x_{i t}, x_{i t-1}$, and $u_{i t}$ are $1 \times K$ vectors and $\operatorname{diag}\left[A_{1}, \ldots, A_{K}\right]$ is a $K \times K$ diagonal matrix with elements $A_{1}, \ldots, A_{K}$ along the diagonal. Repeated substitution of (33) into (30) yields

$$
\begin{aligned}
y_{i m}= & \gamma^{g_{m}} y_{i m-1}+x_{i m} \beta+\theta_{m} \alpha_{i} \\
& +D_{i m} x_{i m-1} \times \operatorname{diag}\left[\sum_{j=1}^{g_{m}-1} \rho_{1}^{g_{m}-j} \gamma^{j}, \ldots, \sum_{j=1}^{g_{m}-1} \rho_{K}^{g_{m}-j} \gamma^{j}\right] \times \beta+\stackrel{\vee}{\varepsilon}_{i m}, \quad i=1, \ldots, N ; m=1, \ldots, M,
\end{aligned}
$$

\footnotetext{
${ }^{14}$ Although not in a Bayesian context, this approach is similar to Chiu et al. (2012) who use data augmentation to simulate missing data in a VAR model with mixed frequency data.
} 
where

$$
\stackrel{\vee}{\varepsilon}_{i m} \equiv \sum_{j=1}^{g_{m}-1} u_{i, t(m)-j}\left(\sum_{l=1}^{j} \rho^{l-1} \gamma^{j+1-l} \beta\right)+\sum_{j=0}^{g_{m}-1} \gamma^{j} \varepsilon_{i, t(m)-j} .
$$

Assuming $x$ is strictly exogenous with respect to both $u$ and $\varepsilon$, and (1) and (33) are correctly specified, then ENLS-IV or E-NLS-CRE-IV applied to (34) is consistent as $T \rightarrow \infty$ and also yields estimates of $\rho_{k}, k=1, \ldots, K$. We denote these estimators as E-NLS-IV-AR1 and E-NLS-CRE-IV-AR1. We ignore other possible estimators of (34) as these would require use of instruments further back in time than $m-1$ introducing potential problems associated with weak identification.

\section{Monte Carlo Study}

\subsection{Design of the Data Generating Process}

To compare the finite sample performance of the various estimators discussed above, we utilize the basic Monte Carlo design in Everaert (2012). The general structure for the DGP, with a single covariate, is as follows:

$$
\begin{aligned}
y_{i t}= & \gamma y_{i t-1}+\beta x_{i t}+\alpha_{i}+\varepsilon_{i t}, \quad i=1, \ldots, N ; t=1, \ldots, T \\
y_{i 0}= & \pi_{0}+\pi_{1}\left[\frac{\alpha_{i}+\beta \theta \alpha_{i}(1-\rho)^{-1}}{1-\gamma}\right]+\zeta_{i 0}, \\
& \zeta_{i 0} \stackrel{\mathrm{iid}}{\sim} N\left(0, \sigma_{\zeta_{0}}^{2}\right) \\
\alpha_{i} \stackrel{\mathrm{iid}}{\sim} & N\left(0, \sigma_{\alpha}^{2}\right) \\
x_{i t}= & \theta \alpha_{i}+\rho x_{i t-1}+\xi_{i t} \\
x_{i 0}= & \frac{\theta \alpha_{i}}{1-\rho}+\xi_{i 0}\left(\frac{1}{1-\rho^{2}}\right)^{1 / 2} \\
& \xi_{i t} \stackrel{\text { iid }}{\sim} N\left(0, \sigma_{\xi}^{2}\right) \\
\varepsilon_{i t} \stackrel{\mathrm{iid}}{\sim} & N\left(0, \sigma_{\varepsilon}^{2}\right)
\end{aligned}
$$

where

$$
\begin{aligned}
\sigma_{\zeta_{0}}^{2} & =\pi_{2}\left[\frac{\sigma_{\varepsilon}^{2}}{1-\gamma^{2}}+\frac{\beta^{2} \sigma_{\xi}^{2}(1+\gamma \rho)}{(1-\gamma \rho)\left(1-\gamma^{2}\right)\left(1-\rho^{2}\right)}\right] \\
\sigma_{\alpha}^{2} & =\sigma_{\varepsilon}^{2}(1-\gamma)^{2} \\
\sigma_{\xi}^{2} & =\left(\sigma_{s}^{2}-\frac{\gamma^{2}}{1-\gamma^{2}} \sigma_{\varepsilon}^{2}\right)\left[\frac{(1-\gamma \rho)\left(1-\gamma^{2}\right)\left(1-\rho^{2}\right)}{\beta^{2}(1+\gamma \rho)}\right] .
\end{aligned}
$$

In all the cases, we set $\pi_{0}=0, \pi_{1}=\pi_{2}=1, \sigma_{\varepsilon}^{2}=1$, and $\sigma_{s}^{2}=2$, where $\sigma_{s}^{2}$ represents the variance of the signal explaining $y_{i t}$ contained in the within variation of $x_{i t}$ and $y_{i t-1}$ relative to the noise contained in $\alpha_{i}$ and $\varepsilon_{i t}$ (Everaert 2012). Moreover, we always set $N=500$ and perform 250 replications for each experiment.

We conduct five experiments in total. The first four are

$(\mathrm{DGP} 1) \operatorname{Cov}\left(x_{i t}, \alpha_{i}\right)=0, \operatorname{Cov}\left(x_{i t}, x_{i t-1}\right)=0: \theta=0, \rho=0$

$(\mathrm{DGP} 2) \operatorname{Cov}\left(x_{i t}, \alpha_{i}\right) \neq 0, \operatorname{Cov}\left(x_{i t}, x_{i t-1}\right) \approx 0: \theta=1, \rho=-0.05$ 
(DGP3) $\operatorname{Cov}\left(x_{i t}, \alpha_{i}\right)=0, \operatorname{Cov}\left(x_{i t}, x_{i t-1}\right) \neq 0: \theta=0, \rho=0.30$

$(\mathrm{DGP} 4) \operatorname{Cov}\left(x_{i t}, \alpha_{i}\right) \neq 0, \operatorname{Cov}\left(x_{i t}, x_{i t-1}\right) \neq 0: \theta=1, \rho=0.30$.

Thus, the four cases alter the serial correlation of the covariate and the correlation between the covariate and the unobserved effect. In each experiment, we vary the level of persistence in the outcome and the relative importance of the covariate, setting

$$
(\gamma, \beta)=\left\{\begin{array}{c}
(0.2,0.8), \\
(0.5,0.5), \\
(0.8,0.2), \\
(0.2,0.2), \\
(0.8,0.8)
\end{array}\right\} .
$$

Finally, we induce a pattern of irregular spacing to mimic the structure of the ECLS-K, where a 'true' period is approximately six months. Moreover, we wish to ensure that the initial conditions play no role in our results. Thus, when simulating the data, we set $t=-99,-98, . .-1,0,1, \ldots, 17$, and then retain periods $\{0,1,2,3,7,11,17\}$ for estimation. Thus, $M=6$ in our notation with $m=0$ representing the initial period in the data sample.

Our final experiment (denoted DGP5) is similar to the fourth experiment - serial correlation in $x$ and correlation between $x$ and $\alpha$ - except we extend the time dimension. ${ }^{15}$ Now, we set $t=-99,-98, . .-1,0,1, \ldots, 102$ and retain 37 periods. In essence, we replicate the irregular spacing pattern of the ECLS-K five more times, setting $M=36$ with $m=0$ representing the initial period in the data sample.

\subsection{Results}

The results are presented in Tables 4-9. We report the mean absolute error (MAE) and root mean squared error (RMSE) for both $\gamma$ and $\beta$. However, in the interest of brevity, we focus our discussion on RMSE only. Table 4 displays the results when $\gamma=0.2$ and $\beta=0.8$. Table 5 displays the results when $\gamma=0.5$ and $\beta=0.5$. Table 6 displays the results when $\gamma=0.8$ and $\beta=0.2$. Table 7 displays the results when $\gamma=0.2$ and $\beta=0.2$. Table 8 displays the results when $\gamma=0.8$ and $\beta=0.8$. Lastly, Table 9 present the coverage rates and mean interval widths for the QD-UCI estimator for each case. ${ }^{16}$

To begin, consider DGP1 and DGP2 where $x$ is strictly exogenous and serially uncorrelated. From Table 3 , we know several of the estimators are consistent as $N \rightarrow \infty$ : NLS-CRE-IV, FD-NLS-CRE-IV, QD-LS-MD, and QD-GMM. In addition, E-NLS-(CRE-)IV and E-NLS-(CRE-)IV-AR1 are consistent as $T \rightarrow \infty$ as well. The results, however, indicate important finite sample differences. ${ }^{17}$ We observe several results. First, E-NLS-CRE-IV and ENLS-CRE-IV-AR1 generally outperform their non-CRE counterparts. This is especially true for the AR1 estimator.

\footnotetext{
${ }^{15}$ Alvarez and Arellano (2003) discuss the asymptotic behavior of several DPD estimators under regular spacing and different combinations of $N$ and $T$ tending to infinity.

${ }^{16}$ Tables A1-A6 in the Appendix report the same results but in relative terms (i.e., normalizing the best performance in each column to unity).

${ }^{17} \mathrm{As}$ is always the case with results based on Monte Carlo simulations, the results are subject to the caveat that they may be specific to the DGPs considered.
} 
Second, there is little difference in the overall performance of E-NLS-CRE-IV and E-NLS-CRE-IV-AR1 despite the fact that $x$ is not serially correlated in the population. Thus, there may be some gain to controlling for any finite sample serial correlation in $x .{ }^{18}$ Third, QD-GMM outperforms QD-LS-MD and FD-NLS-CRE-IV in every case. With respect to FD-NLS-CRE-IV this is not surprising since the first-differencing does not remove the unobserved effect and thus sacrifices efficiency. NLS-CRE-IV performs comparably to QD-GMM in terms of estimating $\beta$, but generally performs worse overall in terms of estimating $\gamma$. Fourth, the performances of QD-GMM, E-NLS-CRE-IV, and E-NLS-CRE-IV-AR1 are very similar. Perhaps the biggest difference arises with the superior performance of QD-GMM in terms of estimating $\gamma$ when $\gamma$ is relatively low; the converse is true when the degree of persistence is relatively high (i.e., $\gamma=0.8$ ). There is much less difference in performance of these estimators in terms of estimating $\beta$. Fifth, the performance of the QD-UCI estimator (Table 9), is extremely poor, especially with respect to estimating $\gamma$.

The final results relate to the performance of the usual DPD estimators: AH, AB, and BB. In terms of estimating $\beta$, these estimators perform reasonably well in all cases considered. Moreover, generally $\mathrm{BB}(\mathrm{AH})$ performs best (worst) amongst the three estimators. In terms of estimating of $\gamma$, the usual estimators perform much worse than the QD estimators, NLS-CRE-IV, E-NLS-CRE-IV, and E-NLS-CRE-IV-AR1. However, a few noteworthy patterns exist. First, whereas the RMSE of the AH estimator is monotonically increasing in the degree of persistence, the RMSE of AB (and to a lesser extent BB) follows an inverted U-shaped pattern. In fact, AB significantly outperforms $\mathrm{BB}$ regardless of the level of persistence. This is striking since BB is recommended over AB when $\gamma>0.8$ with regularly spaced panel data (Blundell and Bond 1998). ${ }^{19}$

Now turn to DGP3 and DGP4 where $x$ is strictly exogenous but serially correlated. In DGP3 (DGP4), the average sample correlation between $x_{i t}$ and $x_{i t-1}$ is $0.30(0.45)$. With DGP3, the only consistent estimator (as $\left.N, T \rightarrow \infty\right)$ is E-NLS-(CRE-)IV-AR1. With DGP4, $x$ no longer follows a strictly $A R(1)$ process and thus none of the estimators considered are consistent. Again, we summarize several salient findings. First, E-NLS-CRE-IV-AR1 performs as well as, if not significantly better, than E-NLS-IV-AR1 in nearly all cases. Moreover, E-NLS-CRE-IV-AR1 is consistently among the top performers in terms of estimating $\beta$ across the majority of all experiments. However, in terms of estimating $\gamma$, its performance is relatively weak when the degree of persistence is relatively low (i.e., $\gamma<0.8$ ). Second, generally speaking, the performance across the various estimators is more similar in terms of estimating $\beta$ than $\gamma$. Furthermore, performance in terms of estimating $\beta$ deteriorates appreciably among many of the estimators as the degree of persistence of increases. Third, QD-GMM, E-NLS-CRE-IV, and E-NLS-CRE-IV-AR1 perform consistently well in terms of both estimating both $\gamma$ and $\beta$ across the different experiments. Thus, while asymptotically biased, the finite sample performance of these estimators is very good in these cases considered here. QD-LS-MD and NLSCRE-IV deserve mention for performing well in the majority of cases. Fourth, when the degree of persistence is high (i.e., $\gamma=0.8$ ), many of the estimators incorporating imputation perform well in terms of estimating $\gamma$. However, their performance in terms of estimating $\beta$ is not particularly good with the exception of E-NLS-CRE-IV-AR1. Fifth, the performance of the QD-UCI estimator (Table 9) continues to be poor.

\footnotetext{
${ }^{18}$ This finding is analagous to that in the program evaluation literature where over-specifying the propensity score model yields improvements in finite sample performance (see, e.g., Millimet and Tchernis 2009).

${ }^{19}$ It is important to mention, however, that in unreported simulations with $\gamma=0.95$ and $\beta=0.5$, BB significantly outperformed AB.
} 
Turning to the performance of the usual DPD estimators when $x$ is serially correlated, we again obtain a few interesting results. In terms of estimating $\beta, \mathrm{AB}$ and $\mathrm{BB}$ continue to perform reasonably well in all cases considered, with $\mathrm{BB}$ performing marginally better. AH performs well when the degree of persistence is relatively low (i.e., $\gamma<0.8$ ), but much worse when persistence is high (i.e., $\gamma=0.8$ ). In terms of estimating $\gamma$, the usual estimators perform worse to much worse than QD-GMM in every case. Interestingly, though, the RMSE of the AH estimator continues to be monotonically increasing in the degree of persistence, while the RMSE of AB (and to a lesser extent BB) follows an inverted U-shaped pattern. Finally, AB continues to outperform BB in terms of estimating $\gamma$ regardless of the level of persistence.

Because the Everaert-type estimators require large $N$ and $T$ for consistency, DGP 5 explores the effect of increasing the time dimension. In the interest of brevity, we simply note that while the performance of many estimators improves, the qualitative conclusions formed above are not altered. Two findings are worth mentioning. First, there is a noticeable deterioration in the performance of $\mathrm{AB}$ in terms of estimating $\gamma$, particularly when the degree of persistence is relatively high (i.e., $\gamma=0.8$ ). Now, the performance of $\mathrm{AB}$ and $\mathrm{BB}$ are comparable (and much worse than the other estimators considered here). Second, the longer sample has a sizeable beneficial effect on the performance of the E-NLS-CRE-IV, E-NLS-CRE-IV-AR1, and, to a lesser extent, QD-GMM estimates of $\gamma$. However, performance in terms of estimating $\beta$ is only modestly improved.

In Tables 4-8, one finding that emerges is that the relative performance of the estimators depends, in part, on whether one focuses on $\gamma$ or $\beta$. One way to summarize the overall performance of estimators is to assess the MAE and RMSE of estimates of the long-run effect of $x$, given by $\beta /(1-\gamma)$. Table 10 presents the results for this estimand. In the interest of brevity, we display the results for DGP2 and DGP4 only. Focusing on performance in terms of RMSE, we obtain several interesting results. First, QD-GMM and E-NLS-CRE-IV-AR1 outperform the other estimators. E-NLS-CRE-IV also performs well, but E-NLS-CRE-IV-AR1 produces a smaller RMSE in nearly every case. Second, QD-GMM outperforms E-NLS-CRE-IV-AR1 in three of five cases when $x$ is serially correlated (DGP4). The only exception is when $\beta=0.2$ and $\beta=0.8$. However, when $\beta=0.2$ both estimators perform very well. Finally, while these two estimators perform best overall, performance of both (as well as all other estimators) is significantly worse when $\gamma=\beta=0.8$. We interpret this case as one where the outcome is highly persistent and the covariates represent a significant portion of the variation in the outcome.

Since QD-GMM, E-NLS-CRE-IV-AR1, and E-NLS-CRE-IV generally outperform the other estimators considered here, we undertake one final comparison of these estimators. For each experiment analyzed, we compute Pitman's (1937) Nearness Measure, denoted $P N$. Formally, this measure is given by

$$
P N=\operatorname{Pr}\left[\left|\widehat{\theta}_{1}-\theta\right|<\left|\widehat{\theta}_{2}-\theta\right|\right],
$$

where $\widehat{\theta}_{j}, j=1,2$, represent two distinct estimators of the parameter $\theta, \theta \in\{\gamma, \beta, \beta /\{1-\gamma)\}$. Thus, $P N>0.5$ indicates superior performance of the first estimator. The advantage of $P N$ is that it summarizes the entire sampling distribution of an estimator, whereas bias and RMSE rely only on the first two moments. In practice, $P N$ is estimated by its empirical counterpart: the fraction of simulated data sets for each experimental design where one estimator is closer to the true parameter value than another estimator. 
The results for $P N$ are given in Table 11. In DGP1 and DGP2, when $x$ is not serially correlated, QD-GMM tends to outperform both of the Evereart-type estimators as long as the degree of persistence is not too high (i.e., $\gamma<0.8)$. Neither of the Everaert-type estimators clearly dominates the other. In DGP3 and DGP4, when $x$ is serially correlated, the $P N$ criteria continues to indicate superior performance by QD-GMM except in terms of estimating $\gamma$ when the degree of persistence is relatively high. Moreover, the E-NLS-CRE-IV-AR1 estimator performs marginally better than overall relative to the E-NLS-CRE-IV estimator. Finally, note that the relative performance of the ENLS-CRE-IV-AR1 estimator is sensitive to the time dimension of the sample. In particular, the relative performance of the E-NLS-CRE-IV-AR1 estimator in terms of estimating $\gamma$ improves with an increase in the time dimension of the sample.

In sum, it is clear that no single estimator dominates the others. That said, QD-GMM and E-NLS-CRE-IV-AR1 appear to be the most consistent performers across the various experiments, with QD-GMM appearing superior when $x$ is serially correlated according to Pitman's (1937) Nearness Measure. Furthermore, while these estimators perform well in practice in the data designs considered, the relatively poor performance of all the estimators considered especially in terms of estimating the long-run effects - when $x$ is serially correlated, $x$ explains a relatively large portion of the variance in the outcome, and persistence is relatively high ought to give applied researchers pause when estimating DPD models on irregularly spaced data. This situation, unfortunately, is probably encountered often in practice.

\section{Application}

\subsection{Motivation}

In the application, we utilize the ECLS-K to estimate dynamic models of early human capital development. Specifically, we estimate so-called value added models of student achievement to assess persistence in the accumulation of knowledge during primary school, as well as the relationship between various inputs and test scores. We also estimate dynamic models of child body mass index (BMI) to analyze the role of various factors in the childhood obesity epidemic.

Estimation of DPD models in both of these contexts is now fairly commonplace. Cunha and Heckman (2010) and Conti and Heckman (2012) present a general discussion of the measures of child well-being, dynamics of early childhood development, and the importance of early interventions. Hanushek (1979), Todd and Wolpin (2003) and Meghir and Rivkin (2011) provide in-depth discussions related to the value added model of student achievement. Hanushek (2003) and Meghir and Rivkin (2011) offer summaries of the findings from the value added literature in terms of the effects of a few commonly assessed inputs (e.g., teachers and class size). Strauss and Thomas (2008) give a detailed treatment of dynamic models of health. Cawley (2010) provides a general overview of the economics of childhood obesity. 


\subsection{Data}

Collected by the US Department of Education, the ECLS-K surveys a nationally representative cohort of children throughout the US in fall and spring kindergarten, fall and spring first grade, spring third grade, spring fifth grade, and spring eighth grade. The sample includes data on over 20,000 students who entered kindergarten in one roughly 1,000 schools during the 1998-99 school year. Information is collected on a host of topics, including family background, teacher and school characteristics, student test scores, and student height and weight. The fall first grade wave was only administered to a portion of the sample and thus we ignore this wave.

When assessing student test scores, we utilize a balanced sample of children through fifth grade for whom we have non-missing math and reading scores. We ignore the eighth grade wave as many of the teacher and school level variables change due to the transition into middle school. Our final sample includes 5,977 students with math test scores in fall and spring kindergarten and spring first, third, and fifth grades. For reading, our final sample includes 5,564 students. The following covariates are included in the model: teacher experience (binary indicators for one year or less and between 1.5 and ten years), teacher education (binary indicator for master's degree or higher), teacher certification status (binary indicator for elementary certification), class size, teacher race (binary indicator for white), teacher-student racial match (binary indicator for both being white), class behavior (binary indicator for teacher describing class as well-behaved or exceptional), number of gifted and talented (GT) students in the class, number of boys in the class, household socioeconomic status (SES), number of children's books in the household, binary indicator for a computer at home, household size, and family type (binary indicators for two parents and one parent). Interactions between teacher experience, certification status, class size, and class behavior are also included. Missing values for the covariates are imputed and imputation dummies are added to the control set.

When assessing student health outcomes, we utilize a balanced sample of children through eighth grade for whom we have non-missing data on age and gender and valid measures of height and weight. ${ }^{20}$ From the information on height and weight of the children, we create a $z$-score for body mass index (BMI). The $z$-score is obtained using CDC 2000 growth charts; these are age- and gender-specific, are adjusted for normal growth. ${ }^{21}$ Covariates included in the model are: an index of SES status, binary indicator for current Temporary Aid for Needy Families (TANF) participation, binary indicator for current Supplemental Nutrition Assistance Program (SNAP) participation, binary indicator for health insurance, number of children's books in the household, household size, family type (binary indicators for two parents and one parent), hours spent watching television during the school week, hours spent watching television during the weekend, binary indicator for household rules regarding television watching, days per week household eats breakfast together, days per week household eats dinner together. Missing values for the covariates are imputed and imputation dummies are added to the control set.

\footnotetext{
${ }^{20}$ Refer to Millimet and Tchernis (2012) for a detailed description of the data creation process.

${ }^{21} z$-scores and their percentiles are obtained using the -zanthro- command in Stata.
} 


\subsection{Results}

Tables 12-14 present the results for math and reading test scores, respectively. Table 15 displays the results for BMI. In light of Monte Carlo results, we report only a subset of the coefficient estimates and a subset of the estimators. ${ }^{22}$ Specifically, we report the $\mathrm{AH}, \mathrm{AB}$, and $\mathrm{BB}$ estimates as these represent the typical, naïve estimators one might use if the spacing issue is ignored. We also report QD-GMM, E-NLS-CRE-IV, and E-NLS-IV-CRE-AR1. ${ }^{23}$

Student Achievement Examining the value added models for achievement, a few salient findings emerge. First, the traditional DPD estimators yield estimates of $\gamma$ that are predominantly much smaller than those taking account of the irregular spacing, particularly the Everaert-type estimators. ${ }^{24}$ Whereas BB yields an estimated coefficient on lagged test score of 0.314 (0.520) for math (reading), QD-GMM produces an estimate of 0.497 (0.709). The Evereart-type estimators produce estimates around 0.8. The higher persistence in achievement is consistent with prior studies of primary school children. Thus, ignoring the spacing issue appears to understate the effects of early shocks on long-run learning. Second, the Evereart-type estimators are extremely imprecise relative to QD-GMM; the standard errors are roughly 1.5 times larger (except for the standard error for $\widehat{\gamma}$ ). As a result, the coefficients on the covariates are scarcely statistically significant at conventional levels. Thus, the Everaert-type estimators, relying on the Mundlak (1978) approach, appear to be much less efficient in practice, relative to quasi-differencing, when the number of covariates is fairly large.

Third, several of the variables reflecting teacher experience, certification, class size, and class behavior are statistically significant at conventional levels for math using QD-GMM; many fewer are statistically significant for reading. Interestingly, the parameter estimates are very similar across the typical DPD estimators and QD-GMM. To aid in interpretation, Table 14 reports marginal effects of teacher certification by experience level and class size by behavior and experience level. For math, only three marginal effects are statistically significant at conventional levels using QD-GMM: certification has a positive association for experienced teachers (10+ years) and class size has a small, negative association in well-behaved classes with inexperienced (one year) and medium experienced (1.5 to 10 years) teachers. The negative association between class size and achievement for inexperienced teachers contrasts with Mueller (2013) who examines the interaction between class size and teacher experience using data from Project

\footnotetext{
${ }^{22}$ Full results are available upon request. The heteroskedasticity-robust standard errors should be interpreted a bit cautiously as they fail to account for uncertainty from the first-stage predictions in the case of the Everaert-type estimators.

${ }^{23}$ For the E-NLS-IV-CRE-AR1 estimator, we estimate a restricted model with only four distinct correlation coefficients for the covariates when analyzeing student achievement. Specifically, the teacher variables (experience, education, certification, and race) are assumed to follow the same autoregressive process; the class variables (class size, class behavior, number of GT students, and number of boy students) are assumed to follow the same autoregressive process; the family background variables (SES, number of children's books, household size, computer at home, and family type) are assumed to follow the same autoregressive process; and, the imputation dummies for missing covariates are assumed to follow the same autoregressive process. When analyzing BMI, we estimate a restricted model with only three distinct correlation coefficients. Specifically, the family background variables (SES, number of children's books, household size, family type, and health insurance) are assumed to follow the same autoregressive process; the household behavior variables (TANF, SNAP, television hours per day during the school week, television hours per day on the weekend, household televsion rules, school lunch, family breakfast, and family dinner) are assumed to follow the same autoregressive process; and, the imputation dummies for missing covariates are assumed to follow the same autoregressive process.

${ }^{24} \mathrm{AH}$ yields a similarly high estimate for $\gamma$ for math. However, the standard error is quite large.
} 
STAR and finds negative class size effects only for experienced teachers. However, class behavior is not included in the analysis; Lazear (2001) suggests the effects of class size are intertwined with class behavior. The positive association with certification for experienced teachers only contrasts with Kane et al. (2008) who find only small effects of teacher certification for inexperienced teachers. However, for reading, we obtain statistically significant marginal effects of teacher certification at all experience levels, with the largest association for inexperienced teachers. Class size and behavior are not associated with reading achievement at conventional levels of significance.

Body Mass Index Turning to the models for child BMI, we obtain several interesting results. First, the traditional DPD estimators, along with QD-GMM, produce estimates of $\gamma$ that are much smaller than those produced by the Everaert-type estimators. Second, the Evereart-type estimators are again extremely imprecise relative to QD-GMM; the standard errors are roughly 1.5-3 times larger (except for the standard error for $\widehat{\gamma}$ ). Here, the coefficients on the covariates are never statistically significant at conventional levels using the E-NLS-IV-CRE-AR1 estimator.

Third, the health-income gradient suggested by the traditional DPD estimators differs from those estimated by the QD-GMM and E-NLS-CRE-IV estimators. Specifically, AB and AH suggests no statistically meaningful association between SES on BMI, whereas BB produces a statistically significant negative association at conventional levels. QD-GMM and E-NLS-CRE-IV, however, both indicate a positive and statistically meaningful association of SES although the magnitude is not large. Fourth, the various estimators provide divergent evidence regarding associations between BMI and health insurance and school-provided lunches. In terms of health insurance, while prior evidence on the effect of insurance along the extensive margin on weight is mixed (see, e.g., Bhattacharya and Sood 2011), the traditional DPD estimators and QD-GMM indicate a positive and statistically significant association. However, the magnitude is about twice as large when using the BB and QD-GMM estimators. The relationship is not statistically meaningful using the Everaert-type estimators. In terms of the school lunch program, while prior evidence based on static models suggests a positive effect of school-provided lunches on childhood obesity (e.g., Millimet et al. 2010), the point estimates become small and statistically indistinguishable from zero at conventional levels once we move away from the traditional DPD estimators.

Finally, all estimators indicate a negative (positive) association hours per day of television watching during the school week (weekend) and BMI; the estimates are statistically significant at conventional levels for all estimators except E-NLS-CRE-IV-AR1. In addition, QD-GMM also indicates a negative, statistically significant association between the presence of household rules regarding television and the number of days per week the household eats breakfast together and BMI.

\section{Conclusion}

Problems associated with missing data have a lengthy history in econometrics. In the case of dynamic models, missing data may arise not just from the usual, observation-specific sources such as nonresponse or clerical error, but also from a data structure that does not align the observation interval with the unit interval from the underlying data generating process. Dealing with problems of the latter sort in univariate time series models dates back to at least the 1960s, with Bergstrom (1966) investigating the issue of using discrete time data to estimate continuous 
time processes. However, this issue has been relatively ignored in the literature on dynamic panel data models. Unfortunately, many longitudinal data sets are designed such that data are collected at irregular intervals, making it impossible to justify the assumption of equality between the observation and unit intervals.

As demonstrated here, irregular spacing invalidates the typical approaches to estimation of dynamic panel data models for three reasons. First, the coefficient on the lagged dependent variable is no longer constant. Second, first-differencing no longer eliminates the unobserved effect. Third, covariates (and idiosyncratic errors) from the missing time periods are relegated to the error term, invalidating typical instrumental variable strategies and making the covariates endogenous if they are serially correlated. Simulations reveal that the performance of the commonly used Anderson and Hsiao (1981), Arellano and Bond (1991), and Blundell and Bond (1998) estimators can be quite poor when irregular spacing is ignored.

As an alternative, we propose two new sets of estimators. The first set contains three estimators utilizing quasidifferencing to remove the unobserved effect in combination with a nonlinear least squares or generalized method of moments estimator to handle the nonlinearity. The second set contains several extended, nonlinear versions of the estimator proposed in Everaert (2012). In particular, we also consider our version of the Everaert (2012) estimator augmented by either imputing the missing covariates or assuming they follow a first-order autoregressive process.

Simulations reveal that our new estimators perform significantly better than the Anderson and Hsiao (1981), Arellano and Bond (1991), and Blundell and Bond (1998) estimators in the presence of irregular spacing. Specifically, we find superior performance by two estimators: GMM combined with quasi-differencing and an extended version of the Everaert (2012) estimator combined with the assumption that the covariates follow an $A R(1)$ process. However, our applications reveal that the Everaert-type estimators proposed here are less efficient in practice when there are many covariates. Finally, our applications reveal meaningful, quantitative differences in the estimation of dynamic models for child human capital development when accounting for irregular spacing, particularly as it relates to the degree of persistence. Given the plethora of longitudinal surveys with irregular spacing, from both developed and developing countries, researchers must be wary of spacing. 


\section{References}

[1] Ahn, S.C., Y.H. Lee, and P. Schmidt (2001), "GMM Estimation of Linear Panel Data Models with Time-Varying Individual Effects," Journal of Econometrics, 101, 219-255.

[2] Anderson, T.W. and C. Hsiao (1981), "Estimation of Dynamic Models with Error Components," Journal of the American Statistical Association, 77, 598-606.

[3] Alvarez, J. and M. Arellano (2003), "The Time Series and Cross-Section Asymptotics of Dynamic Panel Data Estimators," Econometrica, 71, 1121-1159.

[4] Arellano, M. and S. Bond (1991), "Some Tests of Specification for Panel Data: Monte Carlo Evidence and an Application to Employment Equations," Review of Economic Studies, 58, 277-297.

[5] Arellano, M. and O. Bover (1995), "Another Look at the Instrumental Variable Estimation of Errorcomponents Models," Journal of Econometrics, 68, 29-51.

[6] Bai, J. (2009), "Panel Data Models with Interactive Fixed Effects," Econometrica, 77, 1229-1279.

[7] Balestra, P. and M. Nerlove (1966), "Pooling Cross Section and Time Series Data in the Estimation of a Dynamic Model: The Demand for Natural Gas," Econometrica, 34, 585-612.

[8] Baltagi, B.H. and S.H. Song (2006), "Unbalanced Panel Data: A Survey," Statistical Papers, 47, 493-523.

[9] Baltagi, B.H. and P.X. Wu (1999), "Unequally Spaced Panel Data Regressions with AR(1) Disturbances," Econometric Theory, 15, 814-823.

[10] Bergstrom, A.R. (1966), "Nonrecursive Models as Discrete Approximations to Systems of Stochastic Differential Equations," Econometrica, 34, 173-182.

[11] Bhattacharya, J. and N. Sood (2011), "Who Pays for Obesity?" Journal of Economic Perspectives, 25, 139-158.

[12] Blundell, R. and S. Bond (1998), "Initial Conditions and Moment Restrictions in Dynamic Panel Data Models," Journal of Econometrics, 87, 115-143.

[13] Bun, M. and M. Carree (2005), "Bias-Corrected Estimation in Dynamic Panel Data Models," Journal of Business and Economic Statistics, 23, 200-210.

[14] Cawley, J. (2010), "The Economics of Child Obesity," Health Affairs, 29, 364-371.

[15] Chamberlain, G. (1984), "Panel Data," in Z. Griliches and M.D. Intriligator (eds.) Handbook of Econometrics Vol. 2, Amsterdam: North-Holland, 1247-1318.

[16] Chernozhukov, V. and C. Hansen (2006), "Instrumental Quantile Regression Inference for Structural and Treatment Eøect Models," Journal of Econometrics, 132, 491-525. 
[17] Chernozhukov, V. and C. Hansen (2008), "Instrumental Variable Quantile Regression: A Robust Inference Approach," Journal of Econometrics, 142, 379-398.

[18] Chiu, C.W., B. Eraker, A.T. Foerster, T.B. Kim, and H.D. Seoane (2012), "Estimating VAR's Sampled at Mixed or Irregular Spaced Frequencies: A Bayesian Approach," Federal Reserve Bank of Kansas City RWP 11-11.

[19] Conley, T.G., C.B. Hansen, and P.E. Rossi (2012), "Plausibly Exogenous," Review of Economics and Statistics, 94, 260-272.

[20] Conti, G. and J.J. Heckman (2012), "The Economics of Child Well-Being," NBER Working Paper No. 18466.

[21] Cornwell, C., P. Schmidt, and R. Sickles (1990), "Production Frontiers with Cross-Sectional and Time-Series Variation in Efficiency Levels," Journal of Econometrics, 46, 185-200.

[22] Cunha, F. and J.J. Heckman (2010), "Investing in Our Young People," in A. Reynolds, A. Rolnick, M. Englund, and J.A. Temple (eds.) Cost-Effective Programs in Children's First Decade: A Human Capital Integration, New York: Cambridge University Press.

[23] Dufour, J.-M. and M.G. Dagenais (1985), "Durbin-Watson Tests for Serial Correlation in Regressions with Missing Observations," Journal of Econometrics, 27, 371-381.

[24] Dunsmuir, W. and P.M. Robinson (1981), "Estimation of Time Series Models in the Presence of Missing Data," Journal of the American Statistical Association, 76, 560-568.

[25] Everaert, G. (2012), "Orthogonal to Backward Mean Transformation for Dynamic Panel Data Models," Econometrics Journal, forthcoming.

[26] Foroni, C. and M. Marcellino (2013), "A Survey of Econometric Methods for Mized-Frequency Data," Norges Bank Research Working Paper 2013-06.

[27] Fuleky, P. (2011), "On the Choice of the Unit Period in Time Series Models," unpublished manuscript, U of Hawaii.

[28] Griliches, Z., B.H. Hall, and J.A. Hausman (1978), "Missing Data and Self-Selection in Large Panels," Annales de l'INSEE, 30-31, 137-176.

[29] Hahn, J., J. Hausman, and G. Kuersteiner (2007), "Long Difference Instrumental Variables Estimation for Dynamic Panel Models with Fixed Effects," Journal of Econometrics, 140, 574-617.

[30] Hahn, J. and G. Kuersteiner (2002), "Asymptotically Unbiased Inference for a Dynamic Panel Model with Fixed Effects When Both N and T are Large," Econometrica, 70, 1639-1657.

[31] Hamilton, J. (1994), Time Series Analysis, Princeton University Press.

[32] Hanushek, E.A. (1979), "Conceptual and Empirical Issues in the Estimation of Educational Production Functions," Journal of Human Resources, 14, 351-388 
[33] Hanushek, E.A. (2003), "The Failure of Input-Based Schooling Policies," Economic Journal, 113, F64-F98

[34] Harvey, A.C. and R.G. Pierse (1984), "Estimating Missing Observations in Economic Time Series," Journal of the American Statistical Association, 79, 125-131

[35] Hausman, J. and W. Taylor (1981), "Panel Data and Unobservable Individual Effects," Econometrica, 49, $1377-1398$.

[36] Jones, R.H. (1980), "Maximum Likelihood Fitting of ARMA Models to Time Series with Missing Observations," Technometrics, 22, 389-395.

[37] Jones, R.H. (1985), "Time Series Analysis with Unequally Spaced Data," in E.J. Hannan, P.R. Krishnaiah, and M.M. Rao (eds) Handbook of Statistics, Vol. 5: Time Series in the Time Domain, New York: North-Holland, $157-177$.

[38] Jones, R.H. (1986), "Time Series Regression with Unequally Spaced Data," Journal of Applied Probability, 23, 89-98.

[39] Jones, R.H. and F. Boadi-Boateng (1991), "Unequally Spaced Longitudinal Data with AR(1) Serial Correlation," Biometrics, 47, 161-175.

[40] Kane, T.J., J.E. Rockoff, and D.O. Staiger (2008), "What Does Certification Tell Us About Teacher Effectiveness? Evidence from New York City," Economics of Education Review, 27, 615-631.

[41] Kiviet, J.F. (1995), "On Bias, Inconsistency and Efficiency of Various Estimators in Dynamic Panel Data Models," Journal of Econometrics, 68, 53-78.

[42] Kohn, R. and C.F. Ansley (1986), "Estimation, Prediction, and Interpolation for ARIMA Models with Missing Data," Journal of the American Statistical Association, 81, 751-761.

[43] Lazear, E.P. (2001), "Educational Production," Quarterly Journal of Economics, 116, 777-803.

[44] Lee, N., H.R. Moon, and M. Weidner (2012), "Analysis of Interactive Fixed Effects Dynamic Linear Panel Regression with Measurement Error," Economics Letters, 117, 239-242

[45] Little, R.J.A. and D.B. Rubin (2002), Statistical Analysis with Missing Data, 2nd Edition, John Wiley \& Sons, Inc., Hoboken New Jersey.

[46] McKenzie, D.J. (2001), "Estimation of AR(1) Models with Unequally-Spaced Pseudo-Panels," Econometrics Journal, 4, 89-108.

[47] Meghir, C. and S. Rivkin (2011), "Econometric Methods for Research in Education," in E.A. Hanushek, S. Machin, and L. Woessmann (eds.) Handbook of the Economics of Education, Vol. 3, Elsevier, 1-87.

[48] Millimet, D.L. and R. Tchernis (2009), "On the Specification of Propensity Scores: with Applications to the Analysis of Trade Policies," Journal of Business 83 Economic Statistics, 27, 397-415 
[49] Millimet, D.L., R. Tchernis, and M. Husain (2010), "School Nutrition Programs and the Incidence of Childhood Obesity," Journal of Human Resources, 45, 640-654.

[50] Millimet, D.L. and R. Tchernis (2012), "Estimation of Treatment Effects Without an Exclusion Restriction: with an Application to the Analysis of the School Breakfast Program," Journal of Applied Econometrics, forthcoming.

[51] Mueller, S. (2013), "Teacher Experience and the Class Size Effect - Experimental Evidence," Journal of Public Economics, 98, 44-52.

[52] Mundlak, Y. (1978), "On the Pooling of Time Series and Cross Section Data," Econometrica, 46, 69-85.

[53] Nauges, C. and A. Thomas (2003), "Consistent Estimation of Dynamic Panel Data Models with Time-Varying Individual Effects," Annales d'Economie et de Statistique, 70:53-75.

[54] Nickell, S.J. (1981), "Biases in Dynamic Models with Fixed Effects," Econometrica, 49, 1417-1426.

[55] Palm, F.C. and T.E. Nijman (1984), "Missing Observations in the Dynamic Regression Model," Econometrica, $52,1415-1435$.

[56] Pesaran, M.H. (2006), "Estimation and Inference in Large heterogeneous Panels with a Multifactor Error Structure," Econometrica, 74, 967-1012.

[57] Pitman, E.J.G. (1937), "The 'Closest' Estimates of Statistical Parameters," Mathematical Proceedings of the Cambridge Philosophical Society, 33, 212-222.

[58] Robinson, P.M. (1985), "Testing for Serial Correlation in Regression with Missing Observations," Journal of the Royal Statistical Society, Series B, 47, 429-437.

[59] Robinson, P.M. (2009), "On Discrete Sampling of Time-Varying Continuous-Time Systems," Econometric Theory, 25, 985-994

[60] Rosner, B. and A. Munoz (1988), "Autoregressive Modelling for the Analysis of Longitudinal Data with Unequally Spaced Examinations," Statistics in Medicine, 7, 59-71.

[61] Ryan, K.F. and D.E.A. Giles (1998), "Testing for Unit Roots in Economic Time-Series with Missing observations," in T. B. Fomby and R. C. Hill (eds.) Advances in Econometrics, 13, 203-242.

[62] Savin, N.E. and K.T. White (1978), "Testing for Autocorrelation with Missing Observations," Econometrica, $46,59-67$.

[63] Shin, D.W. and S. Sarkar (1994a), "Unit Roots for ARIMA(0,1,q) Models with Irregularly Observed Samples," Statistics and Pobability Letters, 19, 188-194.

[64] Shin, D.W. and S. Sarkar (1994b), "Likelihood Ratio Type Unit Root Tests for AR(1) Models with Nonconsecutive Observations," Comunications in Statistics: Theory and Methods, 23, 1387-1397 
[65] Shively, T.S. (1993), "Testing for Autoregressive Disturbances in a Time Series Regression with Missing Observations," Journal of Econometrics, 57, 233-255.

[66] Strauss, J. and D. Thomas (2008), "Health Over the Life Course," in T.P. Schultz and J. Strauss (eds.) Handbook of Development Economics, Vol. 4, North-Holland, 3375-3474

[67] Todd, P.E. and K.I. Wolpin (2003), "On the Specification and Estimation of the Production Function for Cognitive Achievement," Economic Journal, 113, F3-F33. 
Table A1. Simulation Results: $\gamma=0.2, \beta=0.8$.

\begin{tabular}{|c|c|c|c|c|c|c|c|c|c|c|}
\hline \multirow[t]{2}{*}{ Estimator } & \multicolumn{5}{|c|}{$\gamma$} & \multicolumn{5}{|c|}{$\beta$} \\
\hline & DGP1 & DGP2 & DGP3 & DGP4 & DGP5 & DGP1 & DGP2 & DGP3 & DGP4 & DGP5 \\
\hline \multicolumn{11}{|c|}{ Panel I. Mean Absolute Percentage Error } \\
\hline $\mathrm{AH}$ & 4.489 & 3.391 & 3.740 & 3.818 & 11.185 & 2.083 & 1.571 & 5.069 & 3.293 & 5.527 \\
\hline $\mathrm{AB}$ & 3.957 & 3.360 & 3.129 & 3.657 & 10.488 & 2.202 & 1.459 & 5.607 & 3.424 & 6.473 \\
\hline $\mathrm{BB}$ & 5.277 & 4.271 & 4.130 & 4.568 & 10.768 & 1.779 & 1.241 & 5.758 & 3.571 & 7.596 \\
\hline NLS-IV & 1.220 & 6.778 & 1.039 & 2.276 & 5.571 & 1.213 & 18.967 & 2.671 & 18.136 & 42.255 \\
\hline NLS-CRE-IV & 1.220 & 1.149 & 1.031 & 1.935 & 5.944 & 1.000 & 1.000 & 2.573 & 1.589 & 4.308 \\
\hline FD-NLS-IV & 3.067 & 3.198 & 2.412 & 3.659 & 9.985 & 1.470 & 1.950 & 2.303 & 1.390 & 2.305 \\
\hline FD-NLS-CRE-IV & 3.151 & 2.625 & 2.420 & 2.291 & 6.047 & 1.483 & 1.759 & 2.299 & 1.585 & 2.981 \\
\hline QD-LS-MD & 2.497 & 2.849 & 2.619 & 11.368 & 2.175 & 1.555 & 1.668 & 2.652 & 1.018 & 3.030 \\
\hline QD-GMM & 1.270 & 1.000 & 1.000 & 1.000 & 1.000 & 1.230 & 1.249 & 2.626 & 1.599 & 3.726 \\
\hline E-NLS-IV & 4.632 & 3.199 & 6.589 & 6.950 & 1.477 & 1.446 & 1.083 & 4.101 & 2.728 & 4.045 \\
\hline E-NLS-CRE-IV & 1.685 & 4.006 & 1.442 & 5.456 & 4.932 & 1.128 & 1.271 & 3.361 & 2.289 & 4.326 \\
\hline E-NLS-IV-L & 3.896 & 2.577 & 2.018 & 6.820 & 10.881 & 1.404 & 4.190 & 5.229 & 7.313 & 6.118 \\
\hline E-NLS-CRE-IV-L & 6.705 & 6.627 & 4.692 & 6.517 & 10.403 & 1.068 & 1.519 & 4.006 & 2.517 & 5.086 \\
\hline E-NLS-IV-A & 1.070 & 9.347 & 2.752 & 15.400 & 28.541 & 2.676 & 3.445 & 1.024 & 1.390 & 11.182 \\
\hline E-NLS-CRE-IV-A & 3.747 & 5.140 & 1.598 & 4.242 & 4.694 & 3.016 & 2.688 & 1.000 & 1.047 & 1.000 \\
\hline E-NLS-IV-C & 1.000 & 7.753 & 2.409 & 17.904 & 31.570 & 7.926 & 14.260 & 7.438 & 14.847 & 31.180 \\
\hline E-NLS-CRE-IV-C & 4.505 & 5.445 & 1.694 & 4.340 & 4.511 & 6.281 & 4.502 & 4.467 & 1.000 & 6.403 \\
\hline E-NLS-IV-AR1 & 10.731 & 16.930 & 4.689 & 6.485 & 15.654 & 1.094 & 3.759 & 4.612 & 4.549 & 6.709 \\
\hline E-NLS-CRE-IV-AR1 & 2.152 & 3.387 & 1.763 & 4.466 & 3.625 & 1.061 & 1.303 & 2.834 & 2.299 & 4.232 \\
\hline \multicolumn{11}{|c|}{ Panel II. Root Mean Squared Error } \\
\hline $\mathrm{AH}$ & 3.723 & 2.803 & 3.120 & 3.145 & 8.979 & 2.003 & 1.588 & 4.305 & 2.772 & 4.686 \\
\hline $\mathrm{AB}$ & 3.225 & 2.721 & 2.573 & 2.957 & 8.396 & 2.060 & 1.461 & 4.724 & 2.871 & 5.463 \\
\hline $\mathrm{BB}$ & 4.246 & 3.418 & 3.356 & 3.650 & 8.621 & 1.729 & 1.278 & 4.854 & 2.994 & 6.397 \\
\hline NLS-IV & 1.216 & 5.402 & 1.062 & 1.888 & 4.492 & 1.195 & 15.361 & 2.441 & 14.648 & 35.374 \\
\hline NLS-CRE-IV & 1.199 & 1.068 & 1.050 & 1.658 & 4.799 & 1.000 & 1.000 & 2.295 & 1.414 & 3.660 \\
\hline FD-NLS-IV & 2.518 & 2.563 & 1.999 & 2.921 & 7.997 & 1.447 & 1.853 & 2.164 & 1.308 & 2.069 \\
\hline FD-NLS-CRE-IV & 2.582 & 2.128 & 2.006 & 1.883 & 4.870 & 1.456 & 1.699 & 2.161 & 1.461 & 2.609 \\
\hline QD-LS-MD & 2.478 & 2.809 & 2.581 & 9.421 & 2.115 & 1.557 & 1.687 & 2.450 & 1.021 & 2.650 \\
\hline QD-GMM & 1.254 & 1.000 & 1.000 & 1.000 & 1.000 & 1.232 & 1.260 & 2.405 & 1.467 & 3.210 \\
\hline E-NLS-IV & 3.963 & 2.845 & 5.441 & 5.779 & 1.447 & 1.410 & 1.097 & 3.477 & 2.286 & 3.449 \\
\hline E-NLS-CRE-IV & 1.619 & 3.295 & 1.382 & 4.378 & 3.985 & 1.117 & 1.259 & 2.897 & 1.945 & 3.674 \\
\hline E-NLS-IV-L & 3.174 & 2.117 & 1.707 & 5.409 & 8.756 & 1.377 & 3.554 & 4.376 & 5.948 & 5.167 \\
\hline E-NLS-CRE-IV-L & 5.369 & 5.266 & 3.803 & 5.176 & 8.326 & 1.036 & 1.465 & 3.404 & 2.124 & 4.301 \\
\hline E-NLS-IV-A & 1.053 & 7.422 & 2.321 & 12.163 & 22.848 & 2.329 & 2.950 & 1.025 & 1.266 & 9.373 \\
\hline E-NLS-CRE-IV-A & 3.093 & 4.118 & 1.456 & 3.425 & 3.787 & 2.580 & 2.350 & 1.000 & 1.005 & 1.000 \\
\hline E-NLS-IV-C & 1.000 & 6.201 & 2.089 & 14.145 & 25.279 & 6.388 & 11.604 & 6.207 & 11.991 & 26.093 \\
\hline E-NLS-CRE-IV-C & 3.666 & 4.345 & 1.529 & 3.500 & 3.649 & 5.101 & 3.772 & 3.863 & 1.000 & 5.406 \\
\hline E-NLS-IV-AR1 & 8.815 & 13.537 & 3.872 & 5.121 & 12.516 & 1.065 & 3.246 & 3.888 & 3.737 & 5.652 \\
\hline E-NLS-CRE-IV-AR1 & 2.008 & 2.839 & 1.647 & 3.625 & 2.955 & 1.050 & 1.285 & 2.507 & 1.957 & 3.596 \\
\hline
\end{tabular}

Notes: Results obtaining using 250 simulations with N=500 and M=6 (DGP1-DGP4) or M=36 (DGP5). DGP1: Mean Corr(Xt,Xt-1)=0.00; Mean $\operatorname{Corr}(X t, \alpha)=0.00$. DGP2: Mean Corr $(X t, X t-1)=0.03$; Mean $\operatorname{Corr}(X t, \alpha)=0.24$. DGP3: Mean $\operatorname{Corr}(X t, X t-1)=0.30 ;$ Mean Corr $(X t, \alpha)=0.00$. DGP4 \& DGP5: Mean $\operatorname{Corr}(\mathrm{Xt}, \mathrm{Xt}-1)=0.42$; Mean $\operatorname{Corr}(\mathrm{Xt}, \alpha)=0.39$. Gray shading denotes lowest value. Green shading denotes values within 1.5 times the lowest value. See text for further details. 
Table A2. Simulation Results: $\gamma=0.5, \beta=0.5$.

\begin{tabular}{|c|c|c|c|c|c|c|c|c|c|c|}
\hline \multirow[t]{2}{*}{ Estimator } & \multicolumn{5}{|c|}{$\gamma$} & \multicolumn{5}{|c|}{$\boldsymbol{\beta}$} \\
\hline & DGP1 & DGP2 & DGP3 & DGP4 & DGP5 & DGP1 & DGP2 & DGP3 & DGP4 & DGP5 \\
\hline \multicolumn{11}{|c|}{ Panel I. Mean Absolute Percentage Error } \\
\hline $\mathrm{AH}$ & 8.616 & 6.445 & 6.673 & 9.262 & 23.639 & 3.154 & 2.123 & 8.595 & 9.568 & 5.000 \\
\hline $\mathrm{AB}$ & 7.496 & 6.003 & 5.824 & 8.874 & 22.303 & 3.646 & 2.212 & 9.322 & 10.015 & 5.912 \\
\hline $\mathrm{BB}$ & 11.001 & 8.611 & 8.686 & 12.956 & 23.337 & 2.410 & 1.341 & 9.279 & 9.857 & 6.821 \\
\hline NLS-IV & 1.181 & 4.880 & 1.121 & 10.560 & 19.798 & 1.046 & 6.661 & 4.331 & 12.713 & 9.576 \\
\hline NLS-CRE-IV & 1.208 & 1.105 & 1.136 & 2.084 & 5.125 & 1.000 & 1.031 & 3.909 & 3.692 & 3.432 \\
\hline FD-NLS-IV & 10.669 & 9.152 & 8.860 & 14.698 & 27.322 & 3.576 & 4.690 & 2.162 & 2.184 & 1.000 \\
\hline FD-NLS-CRE-IV & 10.899 & 8.997 & 8.936 & 13.396 & 23.973 & 3.638 & 4.637 & 2.133 & 2.434 & 1.274 \\
\hline QD-LS-MD & 2.201 & 1.735 & 2.395 & 5.370 & 2.003 & 1.534 & 1.588 & 3.208 & 3.060 & 1.844 \\
\hline QD-GMM & 1.000 & 1.000 & 1.000 & 1.000 & 1.000 & 1.187 & 1.374 & 3.687 & 3.718 & 3.002 \\
\hline E-NLS-IV & 4.852 & 3.557 & 4.976 & 7.173 & 2.884 & 2.043 & 1.253 & 6.939 & 7.852 & 3.796 \\
\hline E-NLS-CRE-IV & 3.393 & 1.633 & 3.135 & 7.533 & 2.426 & 1.307 & 1.142 & 5.006 & 5.557 & 3.468 \\
\hline E-NLS-IV-L & 12.054 & 7.225 & 8.601 & 6.965 & 14.222 & 1.071 & 1.000 & 7.104 & 10.521 & 3.615 \\
\hline E-NLS-CRE-IV-L & 14.368 & 11.968 & 10.681 & 17.299 & 22.748 & 1.626 & 2.654 & 5.685 & 6.629 & 3.257 \\
\hline E-NLS-IV-A & 5.292 & 1.524 & 2.007 & 3.651 & 1.727 & 6.054 & 6.336 & 1.000 & 1.000 & 3.670 \\
\hline E-NLS-CRE-IV-A & 8.259 & 8.306 & 4.206 & 9.570 & 10.395 & 6.844 & 6.195 & 1.843 & 1.055 & 2.760 \\
\hline E-NLS-IV-C & 6.668 & 2.268 & 1.399 & 7.105 & 7.002 & 13.228 & 14.993 & 10.051 & 15.709 & 12.546 \\
\hline E-NLS-CRE-IV-C & 9.546 & 9.457 & 3.458 & 10.706 & 7.451 & 12.708 & 10.364 & 9.912 & 5.699 & 9.199 \\
\hline E-NLS-IV-AR1 & 8.388 & 14.701 & 8.426 & 20.042 & 24.648 & 1.576 & 2.023 & 6.201 & 8.712 & 3.272 \\
\hline E-NLS-CRE-IV-AR1 & 4.139 & 1.133 & 2.961 & 5.165 & 2.140 & 1.032 & 1.298 & 4.367 & 5.601 & 3.552 \\
\hline \multicolumn{11}{|c|}{ Panel II. Root Mean Squared Error } \\
\hline $\mathrm{AH}$ & 7.171 & 5.339 & 5.789 & 7.564 & 18.980 & 2.941 & 2.097 & 7.106 & 7.760 & 4.550 \\
\hline $\mathrm{AB}$ & 6.084 & 4.857 & 4.883 & 7.006 & 17.861 & 3.218 & 2.104 & 7.665 & 8.085 & 5.369 \\
\hline $\mathrm{BB}$ & 8.869 & 6.920 & 7.231 & 10.145 & 18.689 & 2.307 & 1.384 & 7.637 & 7.968 & 6.190 \\
\hline NLS-IV & 1.170 & 3.969 & 1.162 & 8.318 & 15.899 & 1.032 & 5.428 & 3.640 & 10.191 & 8.680 \\
\hline NLS-CRE-IV & 1.180 & 1.062 & 1.189 & 2.030 & 4.241 & 1.000 & 1.026 & 3.295 & 3.097 & 3.130 \\
\hline FD-NLS-IV & 8.575 & 7.328 & 7.352 & 11.464 & 21.878 & 3.084 & 3.914 & 2.041 & 2.052 & 1.000 \\
\hline FD-NLS-CRE-IV & 8.759 & 7.203 & 7.415 & 10.451 & 19.198 & 3.130 & 3.873 & 2.020 & 2.251 & 1.234 \\
\hline QD-LS-MD & 2.240 & 1.724 & 2.365 & 4.613 & 1.929 & 1.582 & 1.604 & 2.875 & 2.781 & 1.729 \\
\hline QD-GMM & 1.000 & 1.000 & 1.000 & 1.000 & 1.000 & 1.209 & 1.358 & 3.191 & 3.193 & 2.754 \\
\hline E-NLS-IV & 3.980 & 2.918 & 4.165 & 5.645 & 2.405 & 1.883 & 1.246 & 5.706 & 6.330 & 3.455 \\
\hline E-NLS-CRE-IV & 2.917 & 1.630 & 2.748 & 6.234 & 2.055 & 1.296 & 1.124 & 4.158 & 4.535 & 3.160 \\
\hline E-NLS-IV-L & 9.693 & 5.799 & 7.143 & 5.466 & 11.398 & 1.063 & 1.000 & 5.855 & 8.452 & 3.298 \\
\hline E-NLS-CRE-IV-L & 11.550 & 9.589 & 8.867 & 13.507 & 18.214 & 1.556 & 2.312 & 4.715 & 5.381 & 2.975 \\
\hline E-NLS-IV-A & 4.315 & 1.346 & 1.763 & 2.913 & 1.519 & 4.944 & 5.161 & 1.000 & 1.000 & 3.339 \\
\hline E-NLS-CRE-IV-A & 6.683 & 6.678 & 3.564 & 7.533 & 8.336 & 5.563 & 5.044 & 1.713 & 1.070 & 2.526 \\
\hline E-NLS-IV-C & 5.435 & 1.986 & 1.416 & 5.608 & 5.654 & 10.654 & 12.085 & 8.266 & 12.534 & 11.355 \\
\hline E-NLS-CRE-IV-C & 7.713 & 7.591 & 3.095 & 8.439 & 6.001 & 10.232 & 8.364 & 8.175 & 4.727 & 8.332 \\
\hline E-NLS-IV-AR1 & 9.041 & 12.472 & 7.042 & 15.641 & 19.748 & 1.523 & 3.544 & 5.137 & 7.030 & 2.994 \\
\hline E-NLS-CRE-IV-AR1 & 3.507 & 1.139 & 2.634 & 4.338 & 1.825 & 1.030 & 1.269 & 3.667 & 4.578 & 3.236 \\
\hline
\end{tabular}

Notes: See Table A1 for details. 
Table A3. Simulation Results: $\gamma=0.8, \beta=0.2$.

\begin{tabular}{|c|c|c|c|c|c|c|c|c|c|c|}
\hline \multirow[t]{2}{*}{ Estimator } & \multicolumn{5}{|c|}{$\gamma$} & \multicolumn{5}{|c|}{$\boldsymbol{\beta}$} \\
\hline & DGP1 & DGP2 & DGP3 & DGP4 & DGP5 & DGP1 & DGP2 & DGP3 & DGP4 & DGP5 \\
\hline \multicolumn{11}{|c|}{ Panel I. Mean Absolute Percentage Error } \\
\hline $\mathrm{AH}$ & 32.945 & 32.069 & 100.643 & 82.399 & 37.812 & 3.067 & 2.721 & 6.314 & 7.069 & 5.159 \\
\hline $\mathrm{AB}$ & 3.597 & 4.043 & 3.545 & 3.617 & 46.769 & 2.035 & 1.797 & 2.373 & 2.976 & 3.448 \\
\hline $\mathrm{BB}$ & 15.671 & 17.056 & 16.066 & 15.764 & 48.829 & 1.546 & 1.341 & 2.136 & 2.650 & 3.959 \\
\hline NLS-IV & 4.222 & 7.371 & 5.874 & 12.778 & 33.447 & 1.000 & 1.800 & 1.238 & 2.168 & 3.810 \\
\hline NLS-CRE-IV & 5.172 & 4.465 & 5.585 & 4.996 & 13.976 & 1.068 & 1.024 & 1.170 & 1.308 & 2.262 \\
\hline FD-NLS-IV & 50.319 & 53.542 & 53.077 & 50.333 & 131.938 & 3.220 & 3.521 & 1.063 & 1.354 & 2.493 \\
\hline FD-NLS-CRE-IV & 50.320 & 53.271 & 53.002 & 49.456 & 129.145 & 3.220 & 3.519 & 1.049 & 1.291 & 2.387 \\
\hline QD-LS-MD & 9.693 & 10.093 & 7.607 & 7.034 & 6.413 & 1.852 & 1.859 & 1.189 & 1.456 & 1.000 \\
\hline QD-GMM & 1.528 & 1.773 & 1.579 & 1.489 & 1.495 & 1.173 & 1.137 & 1.000 & 1.219 & 1.538 \\
\hline E-NLS-IV & 1.364 & 1.508 & 1.571 & 1.584 & 3.306 & 1.174 & 1.069 & 1.761 & 2.292 & 2.917 \\
\hline E-NLS-CRE-IV & 1.364 & 1.228 & 1.537 & 1.073 & 1.326 & 1.027 & 1.000 & 1.233 & 1.386 & 2.504 \\
\hline E-NLS-IV-L & 1.501 & 1.960 & 1.360 & 1.857 & 1.282 & 9.378 & 7.667 & 4.055 & 1.438 & 6.411 \\
\hline E-NLS-CRE-IV-L & 1.388 & 1.946 & 1.259 & 1.869 & 2.223 & 10.031 & 10.108 & 4.677 & 5.511 & 10.741 \\
\hline E-NLS-IV-A & 1.014 & 1.000 & 1.000 & 1.000 & 1.739 & 5.975 & 4.560 & 2.020 & 1.000 & 2.927 \\
\hline E-NLS-CRE-IV-A & 1.000 & 1.232 & 1.050 & 1.100 & 1.036 & 6.462 & 6.668 & 2.602 & 3.097 & 7.238 \\
\hline E-NLS-IV-C & 1.132 & 1.340 & 1.440 & 1.745 & 3.511 & 8.568 & 7.962 & 3.940 & 3.291 & 7.627 \\
\hline E-NLS-CRE-IV-C & 1.143 & 1.095 & 1.400 & 1.022 & 1.120 & 8.896 & 9.110 & 4.277 & 5.351 & 10.178 \\
\hline E-NLS-IV-AR1 & 1.372 & 1.465 & 1.188 & 1.199 & 1.021 & 5.512 & 10.931 & 3.352 & 7.704 & 13.175 \\
\hline E-NLS-CRE-IV-AR1 & 1.391 & 1.275 & 1.436 & 1.048 & 1.000 & 1.016 & 1.017 & 1.254 & 1.465 & 2.584 \\
\hline \multicolumn{11}{|c|}{ Panel II. Root Mean Squared Error } \\
\hline $\mathrm{AH}$ & 35.359 & 33.235 & 239.823 & 145.001 & 38.655 & 3.375 & 2.979 & 13.475 & 10.347 & 4.461 \\
\hline $\mathrm{AB}$ & 3.552 & 3.953 & 3.521 & 3.543 & 37.897 & 1.945 & 1.771 & 2.118 & 2.711 & 2.902 \\
\hline $\mathrm{BB}$ & 12.829 & 13.909 & 13.039 & 12.715 & 39.568 & 1.549 & 1.390 & 1.939 & 2.457 & 3.301 \\
\hline NLS-IV & 4.530 & 6.310 & 5.410 & 10.206 & 27.126 & 1.000 & 1.689 & 1.149 & 2.011 & 3.159 \\
\hline NLS-CRE-IV & 5.341 & 4.461 & 5.493 & 4.842 & 12.037 & 1.083 & 1.067 & 1.098 & 1.262 & 1.914 \\
\hline FD-NLS-IV & 40.395 & 42.852 & 42.195 & 39.813 & 106.839 & 2.726 & 2.982 & 1.011 & 1.311 & 2.112 \\
\hline FD-NLS-CRE-IV & 40.396 & 42.635 & 42.136 & 39.119 & 104.577 & 2.726 & 2.981 & 1.000 & 1.258 & 2.033 \\
\hline QD-LS-MD & 9.942 & 10.239 & 7.448 & 6.802 & 6.401 & 1.779 & 1.795 & 1.182 & 1.483 & 1.000 \\
\hline QD-GMM & 1.519 & 1.753 & 1.569 & 1.462 & 1.600 & 1.163 & 1.146 & 1.003 & 1.246 & 1.436 \\
\hline E-NLS-IV & 1.315 & 1.440 & 1.478 & 1.466 & 2.784 & 1.142 & 1.060 & 1.578 & 2.084 & 2.416 \\
\hline E-NLS-CRE-IV & 1.319 & 1.211 & 1.454 & 1.058 & 1.266 & 1.001 & 1.000 & 1.152 & 1.337 & 2.096 \\
\hline E-NLS-IV-L & 1.512 & 1.933 & 1.349 & 1.775 & 1.267 & 7.462 & 6.234 & 3.293 & 1.427 & 5.131 \\
\hline E-NLS-CRE-IV-L & 1.398 & 1.933 & 1.247 & 1.813 & 2.012 & 7.962 & 8.152 & 3.766 & 4.540 & 8.560 \\
\hline E-NLS-IV-A & 1.011 & 1.000 & 1.000 & 1.002 & 1.577 & 4.782 & 3.745 & 1.699 & 1.000 & 2.385 \\
\hline E-NLS-CRE-IV-A & 1.000 & 1.224 & 1.051 & 1.069 & 1.044 & 5.153 & 5.397 & 2.133 & 2.600 & 5.776 \\
\hline E-NLS-IV-C & 1.134 & 1.312 & 1.378 & 1.579 & 2.941 & 6.777 & 6.401 & 3.152 & 2.712 & 6.080 \\
\hline E-NLS-CRE-IV-C & 1.139 & 1.090 & 1.350 & 1.000 & 1.107 & 7.033 & 7.316 & 3.417 & 4.356 & 8.105 \\
\hline E-NLS-IV-AR1 & 1.352 & 1.432 & 1.192 & 1.193 & 1.035 & 5.506 & 9.463 & 2.798 & 6.392 & 10.498 \\
\hline E-NLS-CRE-IV-AR1 & 1.345 & 1.254 & 1.376 & 1.025 & 1.000 & 1.006 & 1.034 & 1.166 & 1.395 & 2.156 \\
\hline
\end{tabular}

Notes: See Table A1 for details. 
Table A4. Simulation Results: $\gamma=0.2, \beta=0.2$.

\begin{tabular}{|c|c|c|c|c|c|c|c|c|c|c|}
\hline \multirow[t]{2}{*}{ Estimator } & \multicolumn{5}{|c|}{$\gamma$} & \multicolumn{5}{|c|}{$\beta$} \\
\hline & DGP1 & DGP2 & DGP3 & DGP4 & DGP5 & DGP1 & DGP2 & DGP3 & DGP4 & DGP5 \\
\hline \multicolumn{11}{|c|}{ Panel I. Mean Absolute Percentage Error } \\
\hline $\mathrm{AH}$ & 4.489 & 3.933 & 3.740 & 6.316 & 15.176 & 2.083 & 1.662 & 5.069 & 4.226 & 5.172 \\
\hline $\mathrm{AB}$ & 3.957 & 3.589 & 3.129 & 5.451 & 14.052 & 2.202 & 1.647 & 5.607 & 4.613 & 6.108 \\
\hline $\mathrm{BB}$ & 5.277 & 4.741 & 4.130 & 7.131 & 14.548 & 1.779 & 1.331 & 5.758 & 4.739 & 7.040 \\
\hline NLS-IV & 1.220 & 3.080 & 1.039 & 3.174 & 6.713 & 1.213 & 6.064 & 2.671 & 9.157 & 15.401 \\
\hline NLS-CRE-IV & 1.220 & 1.407 & 1.031 & 1.601 & 3.055 & 1.000 & 1.000 & 2.573 & 2.085 & 3.779 \\
\hline FD-NLS-IV & 3.067 & 3.052 & 2.412 & 4.703 & 9.486 & 1.470 & 1.856 & 2.303 & 1.876 & 2.597 \\
\hline FD-NLS-CRE-IV & 3.151 & 3.039 & 2.420 & 4.347 & 8.467 & 1.483 & 1.852 & 2.299 & 1.936 & 2.755 \\
\hline QD-LS-MD & 2.497 & 2.231 & 2.619 & 4.841 & 2.083 & 1.555 & 1.598 & 2.652 & 2.211 & 3.338 \\
\hline QD-GMM & 1.270 & 1.120 & 1.000 & 1.624 & 1.391 & 1.230 & 1.268 & 2.626 & 2.162 & 3.542 \\
\hline E-NLS-IV & 4.632 & 3.566 & 6.589 & 11.424 & 2.147 & 1.446 & 1.113 & 4.101 & 3.453 & 3.653 \\
\hline E-NLS-CRE-IV & 1.685 & 1.538 & 1.442 & 3.080 & 2.183 & 1.128 & 1.054 & 3.361 & 2.918 & 3.942 \\
\hline E-NLS-IV-L & 3.896 & 2.391 & 2.018 & 1.000 & 7.393 & 1.404 & 1.291 & 5.229 & 5.022 & 4.360 \\
\hline E-NLS-CRE-IV-L & 6.705 & 6.734 & 4.692 & 9.453 & 13.861 & 1.068 & 1.415 & 4.006 & 3.294 & 4.714 \\
\hline E-NLS-IV-A & 1.070 & 2.026 & 2.752 & 9.772 & 4.728 & 2.676 & 3.082 & 1.024 & 1.160 & 3.895 \\
\hline E-NLS-CRE-IV-A & 3.747 & 4.630 & 1.598 & 4.950 & 6.034 & 3.016 & 3.138 & 1.000 & 1.000 & 1.000 \\
\hline E-NLS-IV-C & 1.000 & 1.000 & 2.409 & 9.835 & 5.908 & 7.926 & 8.953 & 7.438 & 9.275 & 12.377 \\
\hline E-NLS-CRE-IV-C & 4.505 & 5.194 & 1.694 & 5.166 & 5.935 & 6.281 & 5.664 & 4.467 & 2.224 & 6.151 \\
\hline E-NLS-IV-AR1 & 10.256 & 11.755 & 4.689 & 10.970 & 13.005 & 1.092 & 1.051 & 4.612 & 4.325 & 4.676 \\
\hline E-NLS-CRE-IV-AR1 & 2.152 & 1.227 & 1.763 & 2.123 & 1.000 & 1.061 & 1.140 & 2.834 & 2.609 & 3.765 \\
\hline \multicolumn{11}{|c|}{ Panel II. Root Mean Squared Error } \\
\hline $\mathrm{AH}$ & 3.723 & 3.271 & 3.120 & 5.122 & 12.261 & 2.003 & 1.655 & 4.305 & 3.610 & 4.422 \\
\hline $\mathrm{AB}$ & 3.225 & 2.931 & 2.573 & 4.357 & 11.321 & 2.060 & 1.617 & 4.724 & 3.913 & 5.197 \\
\hline $\mathrm{BB}$ & 4.246 & 3.822 & 3.356 & 5.631 & 11.721 & 1.729 & 1.355 & 4.854 & 4.022 & 5.979 \\
\hline NLS-IV & 1.216 & 2.647 & 1.062 & 2.846 & 5.553 & 1.195 & 4.990 & 2.441 & 7.565 & 13.027 \\
\hline NLS-CRE-IV & 1.199 & 1.363 & 1.050 & 1.556 & 2.704 & 1.000 & 1.000 & 2.295 & 1.879 & 3.244 \\
\hline FD-NLS-IV & 2.518 & 2.488 & 1.999 & 3.749 & 7.670 & 1.447 & 1.773 & 2.164 & 1.780 & 2.306 \\
\hline FD-NLS-CRE-IV & 2.582 & 2.480 & 2.006 & 3.486 & 6.861 & 1.456 & 1.768 & 2.161 & 1.828 & 2.434 \\
\hline QD-LS-MD & 2.478 & 2.202 & 2.581 & 4.639 & 2.056 & 1.557 & 1.627 & 2.450 & 2.054 & 2.912 \\
\hline QD-GMM & 1.254 & 1.113 & 1.000 & 1.572 & 1.424 & 1.232 & 1.271 & 2.405 & 1.996 & 3.073 \\
\hline E-NLS-IV & 3.963 & 3.128 & 5.441 & 9.205 & 1.992 & 1.410 & 1.121 & 3.477 & 2.942 & 3.139 \\
\hline E-NLS-CRE-IV & 1.619 & 1.559 & 1.382 & 2.870 & 2.005 & 1.117 & 1.042 & 2.897 & 2.519 & 3.378 \\
\hline E-NLS-IV-L & 3.174 & 2.008 & 1.707 & 1.000 & 5.984 & 1.377 & 1.292 & 4.376 & 4.202 & 3.728 \\
\hline E-NLS-CRE-IV-L & 5.369 & 5.397 & 3.803 & 7.431 & 11.166 & 1.036 & 1.378 & 3.404 & 2.818 & 4.021 \\
\hline E-NLS-IV-A & 1.053 & 1.809 & 2.321 & 7.713 & 3.919 & 2.329 & 2.649 & 1.025 & 1.152 & 3.351 \\
\hline E-NLS-CRE-IV-A & 3.093 & 3.765 & 1.456 & 4.040 & 4.913 & 2.580 & 2.682 & 1.000 & 1.000 & 1.000 \\
\hline E-NLS-IV-C & 1.000 & 1.000 & 2.089 & 7.815 & 4.869 & 6.388 & 7.253 & 6.207 & 7.701 & 10.469 \\
\hline E-NLS-CRE-IV-C & 3.666 & 4.194 & 1.529 & 4.206 & 4.849 & 5.101 & 4.652 & 3.863 & 2.085 & 5.241 \\
\hline E-NLS-IV-AR1 & 8.505 & 9.378 & 3.872 & 8.657 & 10.526 & 1.067 & 1.023 & 3.889 & 3.645 & 3.993 \\
\hline E-NLS-CRE-IV-AR1 & 2.008 & 1.247 & 1.647 & 2.101 & 1.000 & 1.050 & 1.125 & 2.507 & 2.287 & 3.230 \\
\hline
\end{tabular}

Notes: See Table A1 for details. 
Table A5. Simulation Results: $\gamma=0.8, \beta=0.8$.

\begin{tabular}{|c|c|c|c|c|c|c|c|c|c|c|}
\hline \multirow[t]{2}{*}{ Estimator } & \multicolumn{5}{|c|}{$\gamma$} & \multicolumn{5}{|c|}{$\beta$} \\
\hline & DGP1 & DGP2 & DGP3 & DGP4 & DGP5 & DGP1 & DGP2 & DGP3 & DGP4 & DGP5 \\
\hline \multicolumn{11}{|c|}{ Panel I. Mean Absolute Percentage Error } \\
\hline $\mathrm{AH}$ & 32.945 & 27.309 & 100.643 & 140.775 & 47.535 & 3.067 & 2.628 & 6.314 & 13.476 & 6.437 \\
\hline $\mathrm{AB}$ & 3.597 & 4.139 & 3.545 & 4.217 & 59.490 & 2.035 & 1.602 & 2.373 & 3.356 & 4.233 \\
\hline BB & 15.671 & 15.479 & 16.066 & 15.123 & 61.793 & 1.546 & 1.182 & 2.136 & 2.962 & 5.034 \\
\hline NLS-IV & 4.222 & 10.543 & 5.874 & 12.297 & 49.400 & 1.000 & 1.734 & 1.238 & 2.604 & 5.333 \\
\hline NLS-CRE-IV & 5.172 & 3.212 & 5.585 & 6.648 & 9.831 & 1.068 & 1.273 & 1.170 & 1.519 & 1.970 \\
\hline FD-NLS-IV & 50.319 & 45.126 & 53.077 & 43.177 & 177.800 & 3.220 & 3.296 & 1.063 & 1.596 & 3.280 \\
\hline FD-NLS-CRE-IV & 50.320 & 43.224 & 53.002 & 39.346 & 159.253 & 3.220 & 3.233 & 1.049 & 1.480 & 2.926 \\
\hline QD-LS-MD & 9.693 & 7.706 & 7.607 & 7.258 & 8.008 & 1.852 & 1.648 & 1.189 & 2.163 & 4.155 \\
\hline QD-GMM & 1.528 & 2.084 & 1.579 & 1.672 & 2.908 & 1.173 & 1.084 & 1.000 & 1.179 & 1.285 \\
\hline E-NLS-IV & 1.364 & 1.425 & 1.571 & 1.488 & 4.461 & 1.174 & 1.000 & 1.761 & 2.882 & 3.691 \\
\hline E-NLS-CRE-IV & 1.364 & 1.000 & 1.537 & 1.051 & 1.000 & 1.027 & 1.254 & 1.233 & 1.376 & 1.700 \\
\hline E-NLS-IV-L & 1.501 & 2.674 & 1.360 & 2.451 & 4.091 & 9.378 & 1.500 & 4.055 & 15.911 & 17.603 \\
\hline E-NLS-CRE-IV-L & 1.388 & 3.470 & 1.259 & 3.020 & 3.888 & 10.031 & 8.453 & 4.677 & 5.605 & 12.993 \\
\hline E-NLS-IV-A & 1.014 & 1.384 & 1.000 & 2.730 & 8.242 & 5.975 & 2.572 & 2.020 & 14.887 & 19.056 \\
\hline E-NLS-CRE-IV-A & 1.000 & 1.868 & 1.050 & 1.441 & 1.944 & 6.462 & 5.814 & 2.602 & 3.328 & 8.787 \\
\hline E-NLS-IV-C & 1.132 & 2.085 & 1.440 & 3.318 & 9.637 & 8.568 & 3.653 & 3.940 & 4.720 & 5.236 \\
\hline E-NLS-CRE-IV-C & 1.143 & 1.204 & 1.400 & 1.000 & 1.019 & 8.896 & 8.210 & 4.277 & 6.141 & 12.530 \\
\hline E-NLS-IV-AR1 & 1.672 & 1.895 & 1.188 & 3.130 & 4.479 & 5.272 & 16.804 & 3.352 & 7.616 & 16.996 \\
\hline E-NLS-CRE-IV-AR1 & 1.391 & 1.025 & 1.436 & 1.280 & 1.217 & 1.016 & 1.213 & 1.254 & 1.000 & 1.000 \\
\hline \multicolumn{11}{|c|}{ Panel II. Root Mean Squared Error } \\
\hline $\mathrm{AH}$ & 35.359 & 30.572 & 239.823 & 674.922 & 47.912 & 3.375 & 3.071 & 13.475 & 49.306 & 5.617 \\
\hline $\mathrm{AB}$ & & & 3.521 & & 47.052 & 1.945 & 1.602 & 2.118 & 957 & 3.586 \\
\hline BB & 12.829 & 12.637 & 13.039 & 12.127 & 48.875 & 1.549 & 1.239 & 1.939 & 2.657 & 4.213 \\
\hline NLS-IV & 4.530 & 8.495 & 5.410 & 9.709 & 39.048 & 1.000 & 1.691 & 1.149 & 2.324 & 4.419 \\
\hline NLS-CRE-IV & 5.341 & 3.391 & 5.493 & 8.262 & 11.231 & 1.083 & 1.266 & 1.098 & 1.402 & 1.793 \\
\hline FD-NLS-IV & 40.395 & 36.225 & 42.195 & 34.049 & 140.521 & 2.726 & 2.811 & 1.011 & 1.487 & 2.775 \\
\hline FD-NLS-CRE-IV & 40.396 & 34.698 & 42.136 & 31.029 & 125.864 & 2.726 & 2.764 & 1.000 & 1.383 & 2.510 \\
\hline QD-LS-MD & 9.942 & 7.830 & 7.448 & 6.619 & 7.959 & 1.779 & 1.597 & 1.182 & 1.966 & 3.467 \\
\hline QD-GMM & 1.519 & 2.025 & 1.569 & 1.603 & 2.767 & 1.163 & 1.102 & 1.003 & 1.137 & 1.262 \\
\hline E-NLS-IV & 1.315 & 1.342 & 1.478 & 1.356 & 3.665 & 1.142 & 1.000 & 1.578 & 2.487 & 3.074 \\
\hline E-NLS-CRE-IV & 1.319 & 1.000 & 1.454 & 1.051 & 1.000 & 1.001 & 1.242 & 1.152 & 1.292 & 1.540 \\
\hline E-NLS-IV-L & 1.512 & 2.352 & 1.349 & 2.049 & 3.387 & 7.462 & 1.478 & 3.293 & 12.450 & 14.173 \\
\hline E-NLS-CRE-IV-L & 1.398 & 3.237 & 1.247 & 2.771 & 3.293 & 7.962 & 6.917 & 3.766 & 4.493 & 10.420 \\
\hline E-NLS-IV-A & 1.011 & 1.277 & 1.000 & 2.209 & 6.578 & 4.782 & 2.246 & 1.699 & 11.623 & 15.314 \\
\hline E-NLS-CRE-IV-A & 1.000 & 1.793 & 1.051 & 1.387 & 1.794 & 5.153 & 4.759 & 2.133 & 2.707 & 7.057 \\
\hline E-NLS-IV-C & 1.134 & 1.808 & 1.378 & 2.670 & 7.672 & 6.777 & 3.012 & 3.152 & 3.752 & 4.298 \\
\hline E-NLS-CRE-IV-C & 1.139 & 1.219 & 1.350 & 1.000 & 1.016 & 7.033 & 6.659 & 3.417 & 4.806 & 10.040 \\
\hline E-NLS-IV-AR1 & 4.020 & 1.752 & 1.192 & 3.060 & 3.746 & 5.269 & 13.619 & 2.798 & 5.935 & 13.609 \\
\hline E-NLS-CRE-IV-AR1 & 1.345 & 1.031 & 1.376 & 1.263 & 1.222 & 1.006 & 1.218 & 1.166 & 1.000 & 1.000 \\
\hline
\end{tabular}

Notes: See Table A1 for details. 
Table A6. Simulation Results: Long-run Coefficient.

\begin{tabular}{|c|c|c|c|c|c|c|c|c|c|c|}
\hline \multirow[t]{3}{*}{ Estimator } & \multicolumn{10}{|c|}{$\beta /(1-\gamma)$} \\
\hline & \multicolumn{2}{|c|}{$\gamma=0.2, \beta=0.8$} & \multicolumn{2}{|c|}{$\gamma=0.5, \beta=0.5$} & \multicolumn{2}{|c|}{$\gamma=0.8, \beta=0.2$} & \multicolumn{2}{|c|}{$\gamma=0.2, \beta=0.2$} & \multicolumn{2}{|c|}{$\gamma=0.8, \beta=0.8$} \\
\hline & DGP2 & DGP4 & DGP2 & DGP4 & DGP2 & DGP4 & DGP2 & DGP4 & DGP2 & DGP4 \\
\hline \multicolumn{11}{|c|}{ Panel I. Mean Absolute Percentage Error } \\
\hline $\mathrm{AH}$ & 2.273 & 1.698 & 3.690 & 3.023 & 21.840 & 28.498 & 2.781 & 1.564 & 26.231 & 21.288 \\
\hline $\mathrm{AB}$ & 2.295 & 1.403 & 3.481 & 2.513 & 1.731 & 1.604 & 2.502 & 1.000 & 2.016 & 1.851 \\
\hline $\mathrm{BB}$ & 3.127 & 2.006 & 4.958 & 4.674 & 4.723 & 2.412 & 3.627 & 1.603 & 5.121 & 3.403 \\
\hline NLS-IV & 15.201 & 16.103 & 8.277 & 24.387 & 10.704 & 56.347 & 5.589 & 6.870 & 35.360 & 166.632 \\
\hline NLS-CRE-IV & 1.000 & 1.000 & 1.000 & 1.146 & 3.200 & 5.042 & 1.402 & 1.179 & 2.355 & 2.869 \\
\hline FD-NLS-IV & 3.036 & 2.604 & 6.050 & 7.606 & 8.205 & 5.389 & 3.120 & 1.711 & 8.364 & 6.640 \\
\hline FD-NLS-CRE-IV & 2.553 & 1.300 & 5.986 & 7.019 & 8.197 & 5.350 & 3.108 & 1.514 & 8.291 & 6.471 \\
\hline QD-LS-MD & 3.200 & 19.842 & 1.828 & 7.855 & 9.007 & 7.015 & 2.443 & 4.133 & 11.696 & 10.744 \\
\hline QD-GMM & 1.062 & 1.100 & 1.029 & 1.575 & 1.276 & 1.101 & 1.238 & 1.458 & 1.617 & 1.130 \\
\hline E-NLS-IV & 3.373 & 11.857 & 4.247 & 13.140 & 1.402 & 2.494 & 3.901 & 10.829 & 1.646 & 3.421 \\
\hline E-NLS-CRE-IV & 3.339 & 3.513 & 1.418 & 3.140 & 1.015 & 1.334 & 1.504 & 1.060 & 1.218 & 1.280 \\
\hline E-NLS-IV-L & 3.917 & 15.362 & 4.462 & 1.234 & 5.704 & 1.440 & 1.687 & 2.200 & 1.000 & 8.568 \\
\hline E-NLS-CRE-IV-L & 5.100 & 4.224 & 6.627 & 7.333 & 7.220 & 4.137 & 5.543 & 3.320 & 7.165 & 4.896 \\
\hline E-NLS-IV-A & 9.489 & 28.043 & 2.698 & 3.758 & 3.122 & 1.000 & 1.000 & 6.417 & 3.268 & 15.848 \\
\hline E-NLS-CRE-IV-A & 4.574 & 3.323 & 6.001 & 5.968 & 4.741 & 2.278 & 4.790 & 2.341 & 5.015 & 2.920 \\
\hline E-NLS-IV-C & 2.448 & 18.035 & 5.138 & 1.000 & 5.124 & 1.749 & 2.878 & 1.412 & 1.502 & 7.386 \\
\hline E-NLS-CRE-IV-C & 5.291 & 4.459 & 7.106 & 8.320 & 6.152 & 3.656 & 6.043 & 3.771 & 6.411 & 4.608 \\
\hline E-NLS-IV-AR1 & 8.738 & 3.025 & 7.051 & 7.750 & 7.423 & 5.435 & 8.074 & 3.552 & 13.144 & 6.081 \\
\hline E-NLS-CRE-IV-AR1 & 2.915 & 2.681 & 1.073 & 1.826 & 1.000 & 1.269 & 1.276 & 1.165 & 1.181 & 1.000 \\
\hline \multicolumn{11}{|c|}{ Panel II. Root Mean Squared Error } \\
\hline $\mathrm{AH}$ & 2.051 & 1.644 & 3.085 & 2.845 & 52.158 & 134.690 & 2.395 & 1.511 & 66.371 & 70.899 \\
\hline $\mathrm{AB}$ & 1.997 & 1.355 & 2.832 & 2.261 & 1.834 & 1.862 & 2.106 & 1.000 & 2.098 & 2.113 \\
\hline BB & 2.632 & 1.801 & 3.988 & 3.934 & 3.862 & 2.098 & 2.929 & 1.476 & 4.270 & 2.782 \\
\hline NLS-IV & 12.516 & 13.107 & 6.761 & 20.458 & 10.014 & 123.614 & 4.573 & 5.738 & 30.289 & 479.613 \\
\hline NLS-CRE-IV & 1.000 & 1.000 & 1.003 & 1.198 & 3.673 & 8.538 & 1.367 & 1.164 & 2.483 & 3.093 \\
\hline FD-NLS-IV & 2.542 & 2.215 & 4.848 & 6.316 & 6.616 & 4.490 & 2.532 & 1.529 & 6.900 & 5.276 \\
\hline FD-NLS-CRE-IV & 2.164 & 1.236 & 4.797 & 5.832 & 6.610 & 4.457 & 2.524 & 1.378 & 6.840 & 5.143 \\
\hline QD-LS-MD & 3.494 & 17.583 & 1.895 & 7.414 & 10.867 & 8.967 & 2.460 & 4.279 & 13.731 & 10.967 \\
\hline QD-GMM & 1.074 & 1.097 & 1.000 & 1.573 & 1.260 & 1.153 & 1.195 & 1.455 & 1.587 & 1.094 \\
\hline E-NLS-IV & 3.171 & 10.185 & 3.544 & 11.029 & 1.373 & 2.295 & 3.428 & 9.169 & 1.628 & 2.962 \\
\hline E-NLS-CRE-IV & 2.838 & 2.949 & 1.366 & 2.874 & 1.014 & 1.318 & 1.469 & 1.092 & 1.220 & 1.203 \\
\hline E-NLS-IV-L & 3.320 & 12.558 & 3.583 & 1.171 & 4.631 & 1.308 & 1.476 & 1.959 & 1.000 & 6.862 \\
\hline E-NLS-CRE-IV-L & 4.208 & 3.490 & 5.309 & 6.092 & 5.843 & 3.477 & 4.388 & 2.783 & 5.931 & 3.924 \\
\hline E-NLS-IV-A & 7.870 & 22.863 & 2.193 & 3.226 & 2.589 & 1.000 & 1.000 & 5.340 & 2.882 & 12.675 \\
\hline E-NLS-CRE-IV-A & 3.779 & 2.769 & 4.810 & 4.969 & 3.858 & 1.959 & 3.803 & 2.006 & 4.168 & 2.385 \\
\hline E-NLS-IV-C & 2.166 & 14.763 & 4.122 & 1.000 & 4.155 & 1.531 & 2.322 & 1.326 & 1.398 & 5.979 \\
\hline E-NLS-CRE-IV-C & 4.347 & 3.647 & 5.690 & 6.901 & 4.975 & 3.067 & 4.759 & 3.111 & 5.302 & 3.683 \\
\hline E-NLS-IV-AR1 & 7.216 & 2.498 & 5.769 & 6.432 & 6.538 & 4.640 & 6.350 & 2.967 & 10.875 & 4.832 \\
\hline E-NLS-CRE-IV-AR1 & 2.521 & 2.335 & 1.047 & 1.779 & 1.000 & 1.257 & 1.259 & 1.170 & 1.196 & 1.000 \\
\hline
\end{tabular}

Notes: See Table A1 for details. 
Table 1. Examples of Irregularly Spaced Longitudinal Surveys in Developed Countries

\begin{tabular}{|c|c|c|}
\hline Country & Survey & Structure \\
\hline \multirow[t]{3}{*}{ Australia } & $\begin{array}{l}\text { Australian Longitudinal Study on Women's Health } \\
\text { (ALSWH) }\end{array}$ & Waves for different cohorts are separated by $2-4$ years \\
\hline & Longitudinal Study of Australian Children (LSAC) & Biennial from 2003-present \\
\hline & Longitudinal Survey of Immigrants to Australia & $\begin{array}{l}\text { Wave } 1 \text { covers first } 6 \text { months post-immigration, Wave } 2 \text { covers } \\
6 \text { - } 18 \text { months post-immigration, Wave } 3 \text { covers } 18-42 \text { months } \\
\text { post-immigration }\end{array}$ \\
\hline Canada & $\begin{array}{l}\text { National Longitudinal Survey of Children and Youth } \\
\text { (NLSCY) }\end{array}$ & Biennial from 1994-2009 \\
\hline France & French Longitudinal Study of Children (ELFE) & $\begin{array}{l}\text { Individuals at birth, } 2 \text { months old, } 10 \text { months old, annual until } 5 \\
\text { years old, then every 2-3 years thereafter }\end{array}$ \\
\hline Japan & $\begin{array}{l}\text { Nihon University Japanese Longitudinal Study of } \\
\text { Aging (NUJLSOA) }\end{array}$ & $\begin{array}{l}\text { Biennial for first three waves, Waves } 3 \text { and } 4 \text { separated by } 3 \\
\text { years }\end{array}$ \\
\hline \multirow[t]{4}{*}{ UK } & 1958 National Child Development Study (NCDS) & $\begin{array}{l}\text { Individuals at birth, } 7 \text { years old, } 11 \text { years old, } 16 \text { years old, } 23 \\
\text { years old, } 33 \text { years old, } 42 \text { years old, } 46 \text { years old, } 50 \text { years old, } \\
\text { and } 55 \text { years old }\end{array}$ \\
\hline & 1970 British Cohort Study (BCS70) & $\begin{array}{l}\text { Individuals at birth, } 5 \text { years old, } 10 \text { years old, } 16 \text { years old, } 26 \\
\text { years old, } 30 \text { years old, } 34 \text { years old, } 38 \text { years old, and } 42 \text { years } \\
\text { old }\end{array}$ \\
\hline & Millennium Cohort Study (MCS) & $\begin{array}{l}\text { Individuals at birth, } 9 \text { months old, } 3 \text { years old, } 5 \text { years old, and } \\
7 \text { years old }\end{array}$ \\
\hline & National Pupil Database (NPD) & $\begin{array}{l}\text { Annual data on all students attending state primary and } \\
\text { secondary schools, but national achievement assessments are } \\
\text { only for ages } 7,11,14 \text {, and } 16\end{array}$ \\
\hline
\end{tabular}

USA Current Populaton Survey

Early Childhood Longitudinal Survey-Kindergarten Cohort (ECLS-K)

Early Childhood Longitudinal Survey-Birth Cohort (ECLS-B)

Education Longitudinal Study of 2002 (ELS:2002)

General Social Survey (GSS)

Health and Retirement Study (HRS)

High School \& Beyond (HS\&B)

High School Longitudinal Study of 2009 (HSLS:09)

National Education Longitudinal Study of 1988

(NELS:88)

National Longitudinal Study of Adolescent Health

(Add Health)

National Longitudinal Survey of Youth 1979

(NLSY79)

Panel Study of Income Dynamics (PSID)

Second Longitudinal Study of Aging (LSOAII)

Survey of Income and Program Participation
4 consecutive months, 8 month gap, 4 consecutive months

Fall \& Spring Kindergarten, Fall \& Spring 1st Grade, Spring 3rd Grade, Spring 5th Grade, Spring 8th Grade

Children at 9 months of age, 2 years old, 4 years old, Fall Kindergarten (either age 5 or 6 )

Tenth Grade, Twelfth Grade, 4 years post baseline, 10 years post baseline

Biennial

Biennial

2 cohorts surveyed every two years for 6 years with the younger cohort also surveyed 12 years post baseline

Fall 9th Grade, Spring 11th Grade, Spring 12th Grade, 6 years post baseline, 12 years post baseline

8th Grade, 10th Grade, 12th Grade, 6 years post baseline, 12 years post baseline

Waves 1 and 2 are separated by 1 year, Wave 3 is 6 years post baseline, Wave 4 is 13 years post baseline

Annual from 1979-1994, biennial thereafter

Annual from 1968-1997, biennial thereafter

Waves 1 and 2 are separated by 3 years, Waves 2 and 3 are separated by 2 years

Variable design, but 8 equally-spaced waves are administered over a 32 month window

Note: As some of these surveys are on-going, the reported structure refers to the intended collection design. See McKenzie (2001) for data examples from developing countries. 
Table 2. Hypothetical Values of $\phi_{\mathrm{m}}$.

\begin{tabular}{cccc}
\hline & \multicolumn{3}{c}{ Period $\boldsymbol{m}$} \\
\cline { 2 - 4 } $\boldsymbol{\gamma}$ & 2 & 3 & 4 \\
\hline 0.9 & 1 & 0.53 & 2.71 \\
0.8 & 1 & 0.56 & 2.44 \\
0.7 & 1 & 0.59 & 2.19 \\
0.6 & 1 & 0.63 & 1.96 \\
0.5 & 1 & 0.67 & 1.75 \\
0.4 & 1 & 0.71 & 1.56 \\
0.3 & 1 & 0.77 & 1.39 \\
0.2 & 1 & 0.83 & 1.24 \\
0.1 & 1 & 0.91 & 1.11 \\
0 & 1 & 1 & 1 \\
\hline
\end{tabular}

Note: See text for details. 
Table 3. Requirements for Consistency as $\mathbf{N} \rightarrow \infty$ with Irregularly Spaced Panel Data when $\gamma, \boldsymbol{\beta} \neq \mathbf{0}$.

\begin{tabular}{lll}
\hline Estimator & & $\boldsymbol{\gamma}$ \\
\hline POLS & Never. & $x$ is uncorrelated with $\alpha$ and serially uncorrelated. \\
NLS & $\alpha_{\mathrm{i}}=\alpha$ for all $i, x$ is strictly exogenous and serially uncorrelated, and & $\alpha_{\mathrm{i}}=\alpha$ for all $i, x$ is strictly exogenous and serially uncorrelated, and \\
& $\varepsilon$ is serially uncorrelated. & $\varepsilon$ is serially uncorrelated.
\end{tabular}

NLS-IV

NLS-CRE-IV

FD

$\mathrm{AH}$

FD-NLS

FD-NLS-IV

FD-NLS-CRE-IV

$\mathrm{AB}$

$\mathrm{BB}$

QD-UCI

QD-LS-MD

QD-GMM

E-NLS-IV

E-NLS-CRE-IV

E-NLS-IV-AR1

serially uncorrelated.

E-NLS-CRE-IV-AR1 $\mathrm{T} \rightarrow \infty, \mathrm{x}$ is strictly exogenous and follows an $\mathrm{AR}(1)$ process, and $\varepsilon$ is serially uncorrelated.

$x$ is uncorrelated with $\alpha$, predetermined, and serially uncorrelated.

$x$ is strictly exogenous and serially uncorrelated.

Never.

Never.

$\alpha_{\mathrm{i}}=\alpha$ for all $i, x$ is strictly exogenous and serially uncorrelated, and $\varepsilon$ is serially uncorrelated. and $\varepsilon$ is serially uncorrelated.

$x$ is strictly exogenous and serially uncorrelated, and $\varepsilon$ is serially uncorrelated.

Never.

Never.

$x$ is strictly exogenous and serially uncorrelated, and $\varepsilon$ is serially uncorrelated.

$x$ is strictly exogenous and serially uncorrelated, and $\varepsilon$ is serially uncorrelated.

$x$ is strictly exogenous and serially uncorrelated, and $\varepsilon$ is serially uncorrelated.

$\mathrm{T} \rightarrow \infty, \mathrm{x}$ is strictly exogenous and serially uncorrelated, and $\varepsilon$ is serially uncorrelated.

$\mathrm{T} \rightarrow \infty, \mathrm{x}$ is strictly exogenous and serially uncorrelated, and $\varepsilon$ is serially uncorrelated.

$\mathrm{T} \rightarrow \infty, \mathrm{x}$ is strictly exogenous and follows an $\mathrm{AR}(1)$ process, and $\varepsilon$ is $x$ is uncorrelated with $\alpha$, strictly exogenous, and serially uncorrelated.

$x$ is strictly exogenous and serially uncorrelated.

Never.

Never.

$\alpha_{\mathrm{i}}=\alpha$ for all $i, x$ is strictly exogenous and serially uncorrelated, and $\varepsilon$ is serially uncorrelated.

d, $x$ is uncorrelated with $\alpha$, strictly exogenous, and serially uncorrelated, and $\varepsilon$ is serially uncorrelated.

$x$ is strictly exogenous and serially uncorrelated, and $\varepsilon$ is serially uncorrelated.

Never.

Never.

$x$ is strictly exogenous and serially uncorrelated, and $\varepsilon$ is serially uncorrelated.

$x$ is strictly exogenous and serially uncorrelated, and $\varepsilon$ is serially uncorrelated.

$x$ is strictly exogenous and serially uncorrelated, and $\varepsilon$ is serially uncorrelated.

$\mathrm{T} \rightarrow \infty$, $\mathrm{x}$ is strictly exogenous and serially uncorrelated, and $\varepsilon$ is serially uncorrelated.

$\mathrm{T} \rightarrow \infty, \mathrm{x}$ is strictly exogenous and serially uncorrelated, and $\varepsilon$ is serially uncorrelated.

$\mathrm{T} \rightarrow \infty, \mathrm{x}$ is strictly exogenous and follows an $\mathrm{AR}(1)$ process, and $\varepsilon$ is serially uncorrelated.

$\mathrm{T} \rightarrow \infty, \mathrm{x}$ is strictly exogenous and follows an $\mathrm{AR}(1)$ process, and $\varepsilon$ is serially uncorrelated.

Notes: POLS = Pooled Ordinary Least Squares; NLS = Nonlinear Least Squares; CRE = Correlated Random Effects; IV = Instrumental Variables; FD = First-

Differencing; AB = Arellano-Bond; BB = Blundell-Bond; QD = Quasi-Differencing; UCI = Union of Confidence Intervals; MD = Distance Minimization; GMM =

Generalized Method of Moments; E = Everaert; AR1 = First-Order Autoregressive. 
Table 4. Simulation Results: $\gamma=0.2, \beta=0.8$.

\begin{tabular}{|c|c|c|c|c|c|c|c|c|c|c|}
\hline \multirow[t]{2}{*}{ Estimator } & \multicolumn{5}{|c|}{$\gamma$} & \multicolumn{5}{|c|}{$\boldsymbol{\beta}$} \\
\hline & DGP1 & DGP2 & DGP3 & DGP4 & DGP5 & DGP1 & DGP2 & DGP3 & DGP4 & DGP5 \\
\hline \multicolumn{11}{|c|}{ Panel I. Mean Absolute Percentage Error } \\
\hline $\mathrm{AH}$ & 0.406 & 0.401 & 0.456 & 0.454 & 0.545 & 0.022 & 0.018 & 0.065 & 0.065 & 0.047 \\
\hline $\mathrm{AB}$ & 0.358 & 0.397 & 0.381 & 0.435 & 0.511 & 0.024 & 0.017 & 0.072 & 0.068 & 0.055 \\
\hline $\mathrm{BB}$ & 0.477 & 0.505 & 0.503 & 0.544 & 0.525 & 0.019 & 0.014 & 0.074 & 0.071 & 0.064 \\
\hline NLS-IV & 0.110 & 0.802 & 0.127 & 0.271 & 0.272 & 0.013 & 0.219 & 0.034 & 0.359 & 0.358 \\
\hline NLS-CRE-IV & 0.110 & 0.136 & 0.126 & 0.230 & 0.290 & 0.011 & 0.012 & 0.033 & 0.031 & 0.037 \\
\hline FD-NLS-IV & 0.277 & 0.378 & 0.294 & 0.435 & 0.487 & 0.016 & 0.023 & 0.030 & 0.028 & 0.020 \\
\hline FD-NLS-CRE-IV & 0.285 & 0.311 & 0.295 & 0.273 & 0.295 & 0.016 & 0.020 & 0.030 & 0.031 & 0.025 \\
\hline QD-LS-MD & 0.226 & 0.337 & 0.319 & 1.353 & 0.106 & 0.017 & 0.019 & 0.034 & 0.020 & 0.026 \\
\hline QD-GMM & 0.115 & 0.118 & 0.122 & 0.119 & 0.049 & 0.013 & 0.014 & 0.034 & 0.032 & 0.032 \\
\hline E-NLS-IV & 0.419 & 0.378 & 0.803 & 0.827 & 0.072 & 0.016 & 0.013 & 0.053 & 0.054 & 0.034 \\
\hline E-NLS-CRE-IV & 0.152 & 0.474 & 0.176 & 0.649 & 0.240 & 0.012 & 0.015 & 0.043 & 0.045 & 0.037 \\
\hline E-NLS-IV-L & 0.352 & 0.305 & 0.246 & 0.812 & 0.530 & 0.015 & 0.048 & 0.067 & 0.145 & 0.052 \\
\hline E-NLS-CRE-IV-L & 0.606 & 0.784 & 0.572 & 0.776 & 0.507 & 0.012 & 0.018 & 0.051 & 0.050 & 0.043 \\
\hline E-NLS-IV-A & 0.097 & 1.106 & 0.335 & 1.833 & 1.391 & 0.029 & 0.040 & 0.013 & 0.028 & 0.095 \\
\hline E-NLS-CRE-IV-A & 0.339 & 0.608 & 0.195 & 0.505 & 0.229 & 0.032 & 0.031 & 0.013 & 0.021 & 0.008 \\
\hline E-NLS-IV-C & 0.090 & 0.917 & 0.294 & 2.131 & 1.539 & 0.085 & 0.165 & 0.096 & 0.294 & 0.264 \\
\hline E-NLS-CRE-IV-C & 0.407 & 0.644 & 0.206 & 0.517 & 0.220 & 0.068 & 0.052 & 0.057 & 0.020 & 0.054 \\
\hline E-NLS-IV-AR1 & 0.970 & 2.003 & 0.571 & 0.772 & 0.763 & 0.012 & 0.043 & 0.059 & 0.090 & 0.057 \\
\hline E-NLS-CRE-IV-AR1 & 0.194 & 0.401 & 0.215 & 0.531 & 0.177 & 0.011 & 0.015 & 0.036 & 0.046 & 0.036 \\
\hline \multicolumn{11}{|c|}{ Panel II. Root Mean Squared Error } \\
\hline $\mathrm{AH}$ & 0.085 & 0.084 & 0.095 & 0.095 & 0.110 & 0.022 & 0.018 & 0.054 & 0.055 & 0.038 \\
\hline $\mathrm{AB}$ & 0.073 & 0.082 & 0.078 & 0.089 & 0.102 & 0.022 & 0.017 & 0.060 & 0.056 & 0.044 \\
\hline $\mathrm{BB}$ & 0.097 & 0.102 & 0.102 & 0.110 & 0.105 & 0.019 & 0.015 & 0.061 & 0.059 & 0.052 \\
\hline NLS-IV & 0.028 & 0.162 & 0.032 & 0.057 & 0.055 & 0.013 & 0.176 & 0.031 & 0.288 & 0.287 \\
\hline NLS-CRE-IV & 0.027 & 0.032 & 0.032 & 0.050 & 0.059 & 0.011 & 0.011 & 0.029 & 0.028 & 0.030 \\
\hline FD-NLS-IV & 0.057 & 0.077 & 0.061 & 0.088 & 0.098 & 0.016 & 0.021 & 0.027 & 0.026 & 0.017 \\
\hline FD-NLS-CRE-IV & 0.059 & 0.064 & 0.061 & 0.057 & 0.059 & 0.016 & 0.019 & 0.027 & 0.029 & 0.021 \\
\hline QD-LS-MD & 0.056 & 0.084 & 0.078 & 0.284 & 0.026 & 0.017 & 0.019 & 0.031 & 0.020 & 0.021 \\
\hline QD-GMM & 0.029 & 0.030 & 0.030 & 0.030 & 0.012 & 0.013 & 0.014 & 0.030 & 0.029 & 0.026 \\
\hline E-NLS-IV & 0.090 & 0.085 & 0.165 & 0.174 & 0.018 & 0.015 & 0.013 & 0.044 & 0.045 & 0.028 \\
\hline E-NLS-CRE-IV & 0.037 & 0.099 & 0.042 & 0.132 & 0.049 & 0.012 & 0.014 & 0.037 & 0.038 & 0.030 \\
\hline E-NLS-IV-L & 0.072 & 0.063 & 0.052 & 0.163 & 0.107 & 0.015 & 0.041 & 0.055 & 0.117 & 0.042 \\
\hline E-NLS-CRE-IV-L & 0.122 & 0.158 & 0.116 & 0.156 & 0.102 & 0.011 & 0.017 & 0.043 & 0.042 & 0.035 \\
\hline E-NLS-IV-A & 0.024 & 0.222 & 0.071 & 0.367 & 0.279 & 0.025 & 0.034 & 0.013 & 0.025 & 0.076 \\
\hline E-NLS-CRE-IV-A & 0.070 & 0.123 & 0.044 & 0.103 & 0.046 & 0.028 & 0.027 & 0.013 & 0.020 & 0.008 \\
\hline E-NLS-IV-C & 0.023 & 0.186 & 0.063 & 0.427 & 0.308 & 0.070 & 0.133 & 0.078 & 0.236 & 0.212 \\
\hline E-NLS-CRE-IV-C & 0.083 & 0.130 & 0.046 & 0.106 & 0.044 & 0.055 & 0.043 & 0.049 & 0.020 & 0.044 \\
\hline E-NLS-IV-AR1 & 0.201 & 0.405 & 0.118 & 0.154 & 0.153 & 0.012 & 0.037 & 0.049 & 0.073 & 0.046 \\
\hline E-NLS-CRE-IV-AR1 & 0.046 & 0.085 & 0.050 & 0.109 & 0.036 & 0.011 & 0.015 & 0.032 & 0.038 & 0.029 \\
\hline
\end{tabular}

Notes: Results obtaining using 250 simulations with $\mathrm{N}=500$ and $\mathrm{M}=6$ (DGP1-DGP4) or $\mathrm{M}=36$ (DGP5). DGP1: Mean Corr $\left(\mathrm{X}_{\mathrm{t}}, \mathrm{X}_{\mathrm{t}-1}\right)=0.00$; Mean $\operatorname{Corr}\left(X_{t}, \alpha\right)=0.00$. DGP2: Mean Corr $\left(X_{t}, X_{t-1}\right)=-0.01 ;$ Mean $\operatorname{Corr}\left(X_{t}, \alpha\right)=0.20$. DGP3: Mean Corr $\left(X_{t}, X_{t-1}\right)=0.30 ;$ Mean Corr $\left(X_{t}, \alpha\right)=0.00$. DGP4 \& DGP5: Mean $\operatorname{Corr}\left(\mathrm{X}_{\mathrm{t}}, \mathrm{X}_{\mathrm{t}-1}\right)=0.38$; Mean $\operatorname{Corr}\left(\mathrm{X}_{\mathrm{t}}, \alpha\right)=0.35$. Gray shading denotes lowest value. Green shading denotes values within 1.5 times the lowest value. See text for further details. 
Table 5. Simulation Results: $\gamma=0.5, \beta=0.5$.

\begin{tabular}{|c|c|c|c|c|c|c|c|c|c|c|}
\hline \multirow[t]{2}{*}{ Estimator } & \multicolumn{5}{|c|}{$\gamma$} & \multicolumn{5}{|c|}{$\beta$} \\
\hline & DGP1 & DGP2 & DGP3 & DGP4 & DGP5 & DGP1 & DGP2 & DGP3 & DGP4 & DGP5 \\
\hline \multicolumn{11}{|c|}{ Panel I. Mean Absolute Percentage Error } \\
\hline $\mathrm{AH}$ & 0.356 & 0.360 & 0.347 & 0.346 & 0.478 & 0.049 & 0.035 & 0.177 & 0.177 & 0.121 \\
\hline $\mathrm{AB}$ & 0.310 & 0.335 & 0.303 & 0.332 & 0.451 & 0.057 & 0.036 & 0.192 & 0.185 & 0.143 \\
\hline $\mathrm{BB}$ & 0.455 & 0.480 & 0.451 & 0.485 & 0.472 & 0.038 & 0.022 & 0.191 & 0.182 & 0.165 \\
\hline NLS-IV & 0.049 & 0.272 & 0.058 & 0.395 & 0.401 & 0.016 & 0.110 & 0.089 & 0.235 & 0.231 \\
\hline NLS-CRE-IV & 0.050 & 0.062 & 0.059 & 0.078 & 0.104 & 0.016 & 0.017 & 0.080 & 0.068 & 0.083 \\
\hline FD-NLS-IV & 0.441 & 0.511 & 0.460 & 0.550 & 0.553 & 0.056 & 0.077 & 0.045 & 0.040 & 0.024 \\
\hline FD-NLS-CRE-IV & 0.451 & 0.502 & 0.464 & 0.501 & 0.485 & 0.057 & 0.076 & 0.044 & 0.045 & 0.031 \\
\hline QD-LS-MD & 0.091 & 0.097 & 0.124 & 0.201 & 0.041 & 0.024 & 0.026 & 0.066 & 0.057 & 0.045 \\
\hline QD-GMM & 0.041 & 0.056 & 0.052 & 0.037 & 0.020 & 0.019 & 0.023 & 0.076 & 0.069 & 0.072 \\
\hline E-NLS-IV & 0.201 & 0.198 & 0.258 & 0.268 & 0.058 & 0.032 & 0.021 & 0.143 & 0.145 & 0.092 \\
\hline E-NLS-CRE-IV & 0.140 & 0.091 & 0.163 & 0.282 & 0.049 & 0.020 & 0.019 & 0.103 & 0.103 & 0.084 \\
\hline E-NLS-IV-L & 0.498 & 0.403 & 0.447 & 0.261 & 0.288 & 0.017 & 0.016 & 0.146 & 0.195 & 0.087 \\
\hline E-NLS-CRE-IV-L & 0.594 & 0.668 & 0.555 & 0.647 & 0.460 & 0.025 & 0.044 & 0.117 & 0.123 & 0.079 \\
\hline E-NLS-IV-A & 0.219 & 0.085 & 0.104 & 0.137 & 0.035 & 0.095 & 0.104 & 0.021 & 0.018 & 0.089 \\
\hline E-NLS-CRE-IV-A & 0.341 & 0.463 & 0.219 & 0.358 & 0.210 & 0.107 & 0.102 & 0.038 & 0.020 & 0.067 \\
\hline E-NLS-IV-C & 0.276 & 0.127 & 0.073 & 0.266 & 0.142 & 0.207 & 0.247 & 0.207 & 0.291 & 0.303 \\
\hline E-NLS-CRE-IV-C & 0.395 & 0.528 & 0.180 & 0.400 & 0.151 & 0.199 & 0.171 & 0.204 & 0.105 & 0.222 \\
\hline E-NLS-IV-AR1 & 0.347 & 0.820 & 0.438 & 0.750 & 0.499 & 0.025 & 0.033 & 0.128 & 0.161 & 0.079 \\
\hline E-NLS-CRE-IV-AR1 & 0.171 & 0.063 & 0.154 & 0.193 & 0.043 & 0.016 & 0.021 & 0.090 & 0.104 & 0.086 \\
\hline \multicolumn{11}{|c|}{ Panel II. Root Mean Squared Error } \\
\hline $\mathrm{AH}$ & 0.185 & 0.186 & 0.182 & 0.182 & 0.240 & 0.029 & 0.022 & 0.090 & 0.090 & 0.061 \\
\hline $\mathrm{AB}$ & 0.157 & 0.169 & 0.153 & 0.168 & 0.226 & 0.031 & 0.022 & 0.097 & 0.094 & 0.072 \\
\hline $\mathrm{BB}$ & 0.229 & 0.241 & 0.227 & 0.244 & 0.236 & 0.023 & 0.014 & 0.097 & 0.093 & 0.083 \\
\hline NLS-IV & 0.030 & 0.138 & 0.036 & 0.200 & 0.201 & 0.010 & 0.056 & 0.046 & 0.119 & 0.116 \\
\hline NLS-CRE-IV & 0.030 & 0.037 & 0.037 & 0.049 & 0.054 & 0.010 & 0.011 & 0.042 & 0.036 & 0.042 \\
\hline FD-NLS-IV & 0.221 & 0.256 & 0.231 & 0.275 & 0.276 & 0.030 & 0.040 & 0.026 & 0.024 & 0.013 \\
\hline FD-NLS-CRE-IV & 0.226 & 0.251 & 0.233 & 0.251 & 0.243 & 0.031 & 0.040 & 0.026 & 0.026 & 0.016 \\
\hline QD-LS-MD & 0.058 & 0.060 & 0.074 & 0.111 & 0.024 & 0.015 & 0.016 & 0.036 & 0.032 & 0.023 \\
\hline QD-GMM & 0.026 & 0.035 & 0.031 & 0.024 & 0.013 & 0.012 & 0.014 & 0.041 & 0.037 & 0.037 \\
\hline E-NLS-IV & 0.103 & 0.102 & 0.131 & 0.136 & 0.030 & 0.018 & 0.013 & 0.072 & 0.074 & 0.046 \\
\hline E-NLS-CRE-IV & 0.075 & 0.057 & 0.086 & 0.150 & 0.026 & 0.013 & 0.012 & 0.053 & 0.053 & 0.042 \\
\hline E-NLS-IV-L & 0.250 & 0.202 & 0.224 & 0.131 & 0.144 & 0.010 & 0.010 & 0.074 & 0.098 & 0.044 \\
\hline E-NLS-CRE-IV-L & 0.298 & 0.334 & 0.278 & 0.324 & 0.230 & 0.015 & 0.024 & 0.060 & 0.063 & 0.040 \\
\hline E-NLS-IV-A & 0.111 & 0.047 & 0.055 & 0.070 & 0.019 & 0.048 & 0.053 & 0.013 & 0.012 & 0.045 \\
\hline E-NLS-CRE-IV-A & 0.172 & 0.233 & 0.112 & 0.181 & 0.105 & 0.054 & 0.052 & 0.022 & 0.012 & 0.034 \\
\hline E-NLS-IV-C & 0.140 & 0.069 & 0.044 & 0.135 & 0.071 & 0.104 & 0.124 & 0.105 & 0.146 & 0.151 \\
\hline E-NLS-CRE-IV-C & 0.199 & 0.265 & 0.097 & 0.203 & 0.076 & 0.100 & 0.086 & 0.104 & 0.055 & 0.111 \\
\hline E-NLS-IV-AR1 & 0.233 & 0.435 & 0.221 & 0.375 & 0.250 & 0.015 & 0.036 & 0.065 & 0.082 & 0.040 \\
\hline E-NLS-CRE-IV-AR1 & 0.090 & 0.040 & 0.083 & 0.104 & 0.023 & 0.010 & 0.013 & 0.047 & 0.053 & 0.043 \\
\hline
\end{tabular}

Notes: Green shading denotes values within 1.5 times the lowest value. See Table 4 and text for further details. 
Table 6. Simulation Results: $\gamma=0.8, \beta=0.2$.

\begin{tabular}{|c|c|c|c|c|c|c|c|c|c|c|}
\hline \multirow[t]{2}{*}{ Estimator } & \multicolumn{5}{|c|}{$\gamma$} & \multicolumn{5}{|c|}{$\boldsymbol{\beta}$} \\
\hline & DGP1 & DGP2 & DGP3 & DGP4 & DGP5 & DGP1 & DGP2 & DGP3 & DGP4 & DGP5 \\
\hline \multicolumn{11}{|c|}{ Panel I. Mean Absolute Percentage Error } \\
\hline $\mathrm{AH}$ & 0.484 & 0.453 & 1.408 & 1.251 & 0.218 & 0.211 & 0.184 & 0.809 & 0.716 & 0.278 \\
\hline $\mathrm{AB}$ & 0.053 & 0.057 & 0.050 & 0.055 & 0.270 & 0.140 & 0.122 & 0.304 & 0.301 & 0.186 \\
\hline $\mathrm{BB}$ & 0.230 & 0.241 & 0.225 & 0.239 & 0.282 & 0.106 & 0.091 & 0.273 & 0.268 & 0.214 \\
\hline NLS-IV & 0.062 & 0.104 & 0.082 & 0.194 & 0.193 & 0.069 & 0.122 & 0.159 & 0.219 & 0.206 \\
\hline NLS-CRE-IV & 0.076 & 0.063 & 0.078 & 0.076 & 0.081 & 0.073 & 0.069 & 0.150 & 0.132 & 0.122 \\
\hline FD-NLS-IV & 0.740 & 0.757 & 0.743 & 0.764 & 0.762 & 0.221 & 0.239 & 0.136 & 0.137 & 0.134 \\
\hline FD-NLS-CRE-IV & 0.740 & 0.753 & 0.742 & 0.751 & 0.746 & 0.221 & 0.238 & 0.134 & 0.131 & 0.129 \\
\hline QD-LS-MD & 0.143 & 0.143 & 0.106 & 0.107 & 0.037 & 0.127 & 0.126 & 0.152 & 0.147 & 0.054 \\
\hline QD-GMM & 0.022 & 0.025 & 0.022 & 0.023 & 0.009 & 0.081 & 0.077 & 0.128 & 0.123 & 0.083 \\
\hline E-NLS-IV & 0.020 & 0.021 & 0.022 & 0.024 & 0.019 & 0.081 & 0.072 & 0.225 & 0.232 & 0.157 \\
\hline E-NLS-CRE-IV & 0.020 & 0.017 & 0.022 & 0.016 & 0.008 & 0.071 & 0.068 & 0.158 & 0.140 & 0.135 \\
\hline E-NLS-IV-L & 0.022 & 0.028 & 0.019 & 0.028 & 0.007 & 0.645 & 0.519 & 0.519 & 0.146 & 0.346 \\
\hline E-NLS-CRE-IV-L & 0.020 & 0.028 & 0.018 & 0.028 & 0.013 & 0.690 & 0.685 & 0.599 & 0.558 & 0.579 \\
\hline E-NLS-IV-A & 0.015 & 0.014 & 0.014 & 0.015 & 0.010 & 0.411 & 0.309 & 0.259 & 0.101 & 0.158 \\
\hline E-NLS-CRE-IV-A & 0.015 & 0.017 & 0.015 & 0.017 & 0.006 & 0.444 & 0.452 & 0.333 & 0.314 & 0.390 \\
\hline E-NLS-IV-C & 0.017 & 0.019 & 0.020 & 0.026 & 0.020 & 0.589 & 0.539 & 0.505 & 0.333 & 0.411 \\
\hline E-NLS-CRE-IV-C & 0.017 & 0.015 & 0.020 & 0.016 & 0.006 & 0.612 & 0.617 & 0.548 & 0.542 & 0.549 \\
\hline E-NLS-IV-AR1 & 0.020 & 0.021 & 0.017 & 0.018 & 0.006 & 0.379 & 0.740 & 0.429 & 0.780 & 0.711 \\
\hline E-NLS-CRE-IV-AR1 & 0.020 & 0.018 & 0.020 & 0.016 & 0.006 & 0.070 & 0.069 & 0.161 & 0.148 & 0.139 \\
\hline \multicolumn{11}{|c|}{ Panel II. Root Mean Squared Error } \\
\hline $\mathrm{AH}$ & 0.518 & 0.470 & 3.378 & 2.227 & 0.221 & 0.059 & 0.050 & 0.435 & 0.259 & 0.060 \\
\hline $\mathrm{AB}$ & 0.052 & 0.056 & 0.050 & 0.054 & 0.216 & 0.034 & 0.030 & 0.068 & 0.068 & 0.039 \\
\hline $\mathrm{BB}$ & 0.188 & 0.197 & 0.184 & 0.195 & 0.226 & 0.027 & 0.024 & 0.063 & 0.061 & 0.045 \\
\hline NLS-IV & 0.066 & 0.089 & 0.076 & 0.157 & 0.155 & 0.017 & 0.029 & 0.037 & 0.050 & 0.043 \\
\hline NLS-CRE-IV & 0.078 & 0.063 & 0.077 & 0.074 & 0.069 & 0.019 & 0.018 & 0.035 & 0.032 & 0.026 \\
\hline FD-NLS-IV & 0.592 & 0.606 & 0.594 & 0.611 & 0.610 & 0.048 & 0.050 & 0.033 & 0.033 & 0.029 \\
\hline FD-NLS-CRE-IV & 0.592 & 0.603 & 0.593 & 0.601 & 0.597 & 0.048 & 0.050 & 0.032 & 0.031 & 0.028 \\
\hline QD-LS-MD & 0.146 & 0.145 & 0.105 & 0.104 & 0.037 & 0.031 & 0.030 & 0.038 & 0.037 & 0.014 \\
\hline QD-GMM & 0.022 & 0.025 & 0.022 & 0.022 & 0.009 & 0.020 & 0.019 & 0.032 & 0.031 & 0.019 \\
\hline E-NLS-IV & 0.019 & 0.020 & 0.021 & 0.023 & 0.016 & 0.020 & 0.018 & 0.051 & 0.052 & 0.033 \\
\hline E-NLS-CRE-IV & 0.019 & 0.017 & 0.020 & 0.016 & 0.007 & 0.017 & 0.017 & 0.037 & 0.033 & 0.028 \\
\hline E-NLS-IV-L & 0.022 & 0.027 & 0.019 & 0.027 & 0.007 & 0.130 & 0.105 & 0.106 & 0.036 & 0.070 \\
\hline E-NLS-CRE-IV-L & 0.020 & 0.027 & 0.018 & 0.028 & 0.011 & 0.139 & 0.138 & 0.121 & 0.114 & 0.116 \\
\hline E-NLS-IV-A & 0.015 & 0.014 & 0.014 & 0.015 & 0.009 & 0.083 & 0.063 & 0.055 & 0.025 & 0.032 \\
\hline E-NLS-CRE-IV-A & 0.015 & 0.017 & 0.015 & 0.016 & 0.006 & 0.090 & 0.091 & 0.069 & 0.065 & 0.078 \\
\hline E-NLS-IV-C & 0.017 & 0.019 & 0.019 & 0.024 & 0.017 & 0.118 & 0.108 & 0.102 & 0.068 & 0.082 \\
\hline E-NLS-CRE-IV-C & 0.017 & 0.015 & 0.019 & 0.015 & 0.006 & 0.123 & 0.124 & 0.110 & 0.109 & 0.110 \\
\hline E-NLS-IV-AR1 & 0.020 & 0.020 & 0.017 & 0.018 & 0.006 & 0.096 & 0.160 & 0.090 & 0.160 & 0.142 \\
\hline E-NLS-CRE-IV-AR1 & 0.020 & 0.018 & 0.019 & 0.016 & 0.006 & 0.018 & 0.017 & 0.038 & 0.035 & 0.029 \\
\hline
\end{tabular}

Notes: Green shading denotes values within 1.5 times the lowest value. See Table 4 and text for further details. 
Table 7. Simulation Results: $\gamma=0.2, \beta=0.2$.

\begin{tabular}{|c|c|c|c|c|c|c|c|c|c|c|}
\hline \multirow[t]{2}{*}{ Estimator } & \multicolumn{5}{|c|}{$\gamma$} & \multicolumn{5}{|c|}{$\beta$} \\
\hline & DGP1 & DGP2 & DGP3 & DGP4 & DGP5 & DGP1 & DGP2 & DGP3 & DGP4 & DGP5 \\
\hline \multicolumn{11}{|c|}{ Panel I. Mean Absolute Percentage Error } \\
\hline $\mathrm{AH}$ & 0.406 & 0.401 & 0.456 & 0.455 & 0.546 & 0.022 & 0.018 & 0.065 & 0.065 & 0.047 \\
\hline $\mathrm{AB}$ & 0.358 & 0.366 & 0.381 & 0.393 & 0.505 & 0.024 & 0.018 & 0.072 & 0.071 & 0.055 \\
\hline $\mathrm{BB}$ & 0.477 & 0.484 & 0.503 & 0.514 & 0.523 & 0.019 & 0.015 & 0.074 & 0.073 & 0.064 \\
\hline NLS-IV & 0.110 & 0.314 & 0.127 & 0.229 & 0.241 & 0.013 & 0.066 & 0.034 & 0.141 & 0.139 \\
\hline NLS-CRE-IV & 0.110 & 0.144 & 0.126 & 0.115 & 0.110 & 0.011 & 0.011 & 0.033 & 0.032 & 0.034 \\
\hline FD-NLS-IV & 0.277 & 0.311 & 0.294 & 0.339 & 0.341 & 0.016 & 0.020 & 0.030 & 0.029 & 0.024 \\
\hline FD-NLS-CRE-IV & 0.285 & 0.310 & 0.295 & 0.313 & 0.304 & 0.016 & 0.020 & 0.030 & 0.030 & 0.025 \\
\hline QD-LS-MD & 0.226 & 0.228 & 0.319 & 0.349 & 0.075 & 0.017 & 0.017 & 0.034 & 0.034 & 0.030 \\
\hline QD-GMM & 0.115 & 0.114 & 0.122 & 0.117 & 0.050 & 0.013 & 0.014 & 0.034 & 0.033 & 0.032 \\
\hline E-NLS-IV & 0.419 & 0.364 & 0.803 & 0.824 & 0.077 & 0.016 & 0.012 & 0.053 & 0.053 & 0.033 \\
\hline E-NLS-CRE-IV & 0.152 & 0.157 & 0.176 & 0.222 & 0.078 & 0.012 & 0.012 & 0.043 & 0.045 & 0.036 \\
\hline E-NLS-IV-L & 0.352 & 0.244 & 0.246 & 0.072 & 0.266 & 0.015 & 0.014 & 0.067 & 0.077 & 0.039 \\
\hline E-NLS-CRE-IV-L & 0.606 & 0.687 & 0.572 & 0.682 & 0.498 & 0.012 & 0.015 & 0.051 & 0.051 & 0.043 \\
\hline E-NLS-IV-A & 0.097 & 0.207 & 0.335 & 0.705 & 0.170 & 0.029 & 0.034 & 0.013 & 0.018 & 0.035 \\
\hline E-NLS-CRE-IV-A & 0.339 & 0.473 & 0.195 & 0.357 & 0.217 & 0.032 & 0.034 & 0.013 & 0.015 & 0.009 \\
\hline E-NLS-IV-C & 0.090 & 0.102 & 0.294 & 0.709 & 0.212 & 0.085 & 0.098 & 0.096 & 0.143 & 0.112 \\
\hline E-NLS-CRE-IV-C & 0.407 & 0.530 & 0.206 & 0.373 & 0.213 & 0.068 & 0.062 & 0.057 & 0.034 & 0.056 \\
\hline E-NLS-IV-AR1 & 0.927 & 1.200 & 0.571 & 0.791 & 0.468 & 0.012 & 0.011 & 0.059 & 0.067 & 0.042 \\
\hline E-NLS-CRE-IV-AR1 & 0.194 & 0.125 & 0.215 & 0.153 & 0.036 & 0.011 & 0.012 & 0.036 & 0.040 & 0.034 \\
\hline \multicolumn{11}{|c|}{ Panel II. Root Mean Squared Error } \\
\hline $\mathrm{AH}$ & 0.085 & 0.084 & 0.095 & 0.095 & 0.110 & 0.005 & 0.005 & 0.014 & 0.014 & 0.009 \\
\hline $\mathrm{AB}$ & 0.073 & 0.075 & 0.078 & 0.081 & 0.101 & 0.006 & 0.004 & 0.015 & 0.015 & 0.011 \\
\hline $\mathrm{BB}$ & 0.097 & 0.098 & 0.102 & 0.104 & 0.105 & 0.005 & 0.004 & 0.015 & 0.015 & 0.013 \\
\hline NLS-IV & 0.028 & 0.068 & 0.032 & 0.053 & 0.050 & 0.003 & 0.014 & 0.008 & 0.028 & 0.028 \\
\hline NLS-CRE-IV & 0.027 & 0.035 & 0.032 & 0.029 & 0.024 & 0.003 & 0.003 & 0.007 & 0.007 & 0.007 \\
\hline FD-NLS-IV & 0.057 & 0.064 & 0.061 & 0.069 & 0.069 & 0.004 & 0.005 & 0.007 & 0.007 & 0.005 \\
\hline FD-NLS-CRE-IV & 0.059 & 0.064 & 0.061 & 0.064 & 0.061 & 0.004 & 0.005 & 0.007 & 0.007 & 0.005 \\
\hline QD-LS-MD & 0.056 & 0.056 & 0.078 & 0.086 & 0.018 & 0.004 & 0.004 & 0.008 & 0.008 & 0.006 \\
\hline QD-GMM & 0.029 & 0.029 & 0.030 & 0.029 & 0.013 & 0.003 & 0.003 & 0.008 & 0.008 & 0.007 \\
\hline E-NLS-IV & 0.090 & 0.080 & 0.165 & 0.170 & 0.018 & 0.004 & 0.003 & 0.011 & 0.011 & 0.007 \\
\hline E-NLS-CRE-IV & 0.037 & 0.040 & 0.042 & 0.053 & 0.018 & 0.003 & 0.003 & 0.009 & 0.009 & 0.007 \\
\hline E-NLS-IV-L & 0.072 & 0.051 & 0.052 & 0.018 & 0.053 & 0.004 & 0.004 & 0.014 & 0.016 & 0.008 \\
\hline E-NLS-CRE-IV-L & 0.122 & 0.138 & 0.116 & 0.137 & 0.100 & 0.003 & 0.004 & 0.011 & 0.011 & 0.009 \\
\hline E-NLS-IV-A & 0.024 & 0.046 & 0.071 & 0.143 & 0.035 & 0.006 & 0.007 & 0.003 & 0.004 & 0.007 \\
\hline E-NLS-CRE-IV-A & 0.070 & 0.097 & 0.044 & 0.075 & 0.044 & 0.007 & 0.007 & 0.003 & 0.004 & 0.002 \\
\hline E-NLS-IV-C & 0.023 & 0.026 & 0.063 & 0.145 & 0.044 & 0.017 & 0.020 & 0.020 & 0.029 & 0.022 \\
\hline E-NLS-CRE-IV-C & 0.083 & 0.108 & 0.046 & 0.078 & 0.043 & 0.014 & 0.013 & 0.012 & 0.008 & 0.011 \\
\hline E-NLS-IV-AR1 & 0.194 & 0.241 & 0.118 & 0.160 & 0.094 & 0.003 & 0.003 & 0.012 & 0.014 & 0.009 \\
\hline E-NLS-CRE-IV-AR1 & 0.046 & 0.032 & 0.050 & 0.039 & 0.009 & 0.003 & 0.003 & 0.008 & 0.009 & 0.007 \\
\hline
\end{tabular}

Notes: Green shading denotes values within 1.5 times the lowest value. See Table 4 and text for further details. 
Table 8. Simulation Results: $\gamma=0.8, \beta=0.8$.

\begin{tabular}{|c|c|c|c|c|c|c|c|c|c|c|}
\hline \multirow[t]{2}{*}{ Estimator } & \multicolumn{5}{|c|}{$\gamma$} & \multicolumn{5}{|c|}{$\boldsymbol{\beta}$} \\
\hline & DGP1 & DGP2 & DGP3 & DGP4 & DGP5 & DGP1 & DGP2 & DGP3 & DGP4 & DGP5 \\
\hline \multicolumn{11}{|c|}{ Panel I. Mean Absolute Percentage Error } \\
\hline $\mathrm{AH}$ & 0.484 & 0.477 & 1.408 & 2.607 & 0.219 & 0.211 & 0.195 & 0.809 & 1.170 & 0.280 \\
\hline $\mathrm{AB}$ & 0.053 & 0.072 & 0.050 & 0.078 & 0.275 & 0.140 & 0.119 & 0.304 & 0.291 & 0.184 \\
\hline $\mathrm{BB}$ & 0.230 & 0.270 & 0.225 & 0.280 & 0.285 & 0.106 & 0.088 & 0.273 & 0.257 & 0.219 \\
\hline NLS-IV & 0.062 & 0.184 & 0.082 & 0.228 & 0.228 & 0.069 & 0.128 & 0.159 & 0.226 & 0.232 \\
\hline NLS-CRE-IV & 0.076 & 0.056 & 0.078 & 0.123 & 0.045 & 0.073 & 0.094 & 0.150 & 0.132 & 0.086 \\
\hline FD-NLS-IV & 0.740 & 0.788 & 0.743 & 0.800 & 0.821 & 0.221 & 0.244 & 0.136 & 0.139 & 0.143 \\
\hline FD-NLS-CRE-IV & 0.740 & 0.754 & 0.742 & 0.729 & 0.735 & 0.221 & 0.239 & 0.134 & 0.128 & 0.127 \\
\hline QD-LS-MD & 0.143 & 0.135 & 0.106 & 0.134 & 0.037 & 0.127 & 0.122 & 0.152 & 0.188 & 0.181 \\
\hline QD-GMM & 0.022 & 0.036 & 0.022 & 0.031 & 0.013 & 0.081 & 0.080 & 0.128 & 0.102 & 0.056 \\
\hline E-NLS-IV & 0.020 & 0.025 & 0.022 & 0.028 & 0.021 & 0.081 & 0.074 & 0.225 & 0.250 & 0.161 \\
\hline E-NLS-CRE-IV & 0.020 & 0.017 & 0.022 & 0.019 & 0.005 & 0.071 & 0.093 & 0.158 & 0.119 & 0.074 \\
\hline E-NLS-IV-L & 0.022 & 0.047 & 0.019 & 0.045 & 0.019 & 0.645 & 0.111 & 0.519 & 1.381 & 0.767 \\
\hline E-NLS-CRE-IV-L & 0.020 & 0.061 & 0.018 & 0.056 & 0.018 & 0.690 & 0.626 & 0.599 & 0.487 & 0.566 \\
\hline E-NLS-IV-A & 0.015 & 0.024 & 0.014 & 0.051 & 0.038 & 0.411 & 0.190 & 0.259 & 1.292 & 0.830 \\
\hline E-NLS-CRE-IV-A & 0.015 & 0.033 & 0.015 & 0.027 & 0.009 & 0.444 & 0.431 & 0.333 & 0.289 & 0.383 \\
\hline E-NLS-IV-C & 0.017 & 0.036 & 0.020 & 0.061 & 0.044 & 0.589 & 0.271 & 0.505 & 0.410 & 0.228 \\
\hline E-NLS-CRE-IV-C & 0.017 & 0.021 & 0.020 & 0.019 & 0.005 & 0.612 & 0.608 & 0.548 & 0.533 & 0.546 \\
\hline E-NLS-IV-AR1 & 0.025 & 0.033 & 0.017 & 0.058 & 0.021 & 0.362 & 1.244 & 0.429 & 0.661 & 0.740 \\
\hline E-NLS-CRE-IV-AR1 & 0.020 & 0.018 & 0.020 & 0.024 & 0.006 & 0.070 & 0.090 & 0.161 & 0.087 & 0.044 \\
\hline \multicolumn{11}{|c|}{ Panel II. Root Mean Squared Error } \\
\hline $\mathrm{AH}$ & 0.518 & 0.532 & 3.378 & 12.682 & 0.224 & 0.235 & 0.225 & 1.738 & 4.405 & 0.244 \\
\hline $\mathrm{AB}$ & 0.052 & 0.069 & 0.050 & 0.074 & 0.220 & 0.136 & 0.117 & 0.273 & 0.264 & 0.156 \\
\hline $\mathrm{BB}$ & 0.188 & 0.220 & 0.184 & 0.228 & 0.228 & 0.108 & 0.091 & 0.250 & 0.237 & 0.183 \\
\hline NLS-IV & 0.066 & 0.148 & 0.076 & 0.182 & 0.183 & 0.070 & 0.124 & 0.148 & 0.208 & 0.192 \\
\hline NLS-CRE-IV & 0.078 & 0.059 & 0.077 & 0.155 & 0.052 & 0.076 & 0.093 & 0.142 & 0.125 & 0.078 \\
\hline FD-NLS-IV & 0.592 & 0.630 & 0.594 & 0.640 & 0.657 & 0.190 & 0.206 & 0.130 & 0.133 & 0.121 \\
\hline FD-NLS-CRE-IV & 0.592 & 0.604 & 0.593 & 0.583 & 0.588 & 0.190 & 0.202 & 0.129 & 0.124 & 0.109 \\
\hline QD-LS-MD & 0.146 & 0.136 & 0.105 & 0.124 & 0.037 & 0.124 & 0.117 & 0.152 & 0.176 & 0.151 \\
\hline QD-GMM & 0.022 & 0.035 & 0.022 & 0.030 & 0.013 & 0.081 & 0.081 & 0.129 & 0.102 & 0.055 \\
\hline E-NLS-IV & 0.019 & 0.023 & 0.021 & 0.025 & 0.017 & 0.080 & 0.073 & 0.204 & 0.222 & 0.134 \\
\hline E-NLS-CRE-IV & 0.019 & 0.017 & 0.020 & 0.020 & 0.005 & 0.070 & 0.091 & 0.149 & 0.115 & 0.067 \\
\hline E-NLS-IV-L & 0.022 & 0.041 & 0.019 & 0.038 & 0.016 & 0.521 & 0.108 & 0.425 & 1.112 & 0.617 \\
\hline E-NLS-CRE-IV-L & 0.020 & 0.056 & 0.018 & 0.052 & 0.015 & 0.555 & 0.507 & 0.486 & 0.401 & 0.453 \\
\hline E-NLS-IV-A & 0.015 & 0.022 & 0.014 & 0.042 & 0.031 & 0.334 & 0.165 & 0.219 & 1.038 & 0.666 \\
\hline E-NLS-CRE-IV-A & 0.015 & 0.031 & 0.015 & 0.026 & 0.008 & 0.359 & 0.349 & 0.275 & 0.242 & 0.307 \\
\hline E-NLS-IV-C & 0.017 & 0.031 & 0.019 & 0.050 & 0.036 & 0.473 & 0.221 & 0.407 & 0.335 & 0.187 \\
\hline E-NLS-CRE-IV-C & 0.017 & 0.021 & 0.019 & 0.019 & 0.005 & 0.491 & 0.488 & 0.441 & 0.429 & 0.437 \\
\hline E-NLS-IV-AR1 & 0.059 & 0.030 & 0.017 & 0.058 & 0.018 & 0.368 & 0.998 & 0.361 & 0.530 & 0.592 \\
\hline E-NLS-CRE-IV-AR1 & 0.020 & 0.018 & 0.019 & 0.024 & 0.006 & 0.070 & 0.089 & 0.150 & 0.089 & 0.044 \\
\hline
\end{tabular}

Notes: Green shading denotes values within 1.5 times the lowest value. See Table 4 and text for further details. 
Table 9. Simulation Results for QD-UCI.

\begin{tabular}{|c|c|c|c|c|c|c|c|c|c|c|}
\hline & \multicolumn{5}{|c|}{$\gamma$} & \multicolumn{5}{|c|}{$\boldsymbol{\beta}$} \\
\hline & DGP1 & DGP2 & DGP3 & DGP4 & DGP5 & DGP1 & DGP2 & DGP3 & DGP4 & DGP5 \\
\hline \multicolumn{11}{|c|}{ Panel I. $\gamma=0.2, \beta=0.8$} \\
\hline Coverage & 0.400 & 0.040 & 0.408 & 0.004 & 0.000 & 0.900 & 0.784 & 0.548 & 0.608 & 0.120 \\
\hline Mean Width & 0.069 & 0.062 & 0.073 & 0.065 & 0.023 & 0.048 & 0.048 & 0.052 & 0.052 & 0.020 \\
\hline \multicolumn{11}{|c|}{ Panel II. $\gamma=0.5, \beta=0.5$} \\
\hline Coverage & 0.000 & 0.000 & 0.000 & 0.000 & 0.000 & 0.664 & 0.264 & 0.524 & 0.588 & 0.084 \\
\hline Mean Width & 0.088 & 0.083 & 0.092 & 0.085 & 0.030 & 0.043 & 0.043 & 0.049 & 0.050 & 0.019 \\
\hline \multicolumn{11}{|c|}{ Panel III. $\gamma=0.8, \beta=0.2$} \\
\hline Coverage & 0.000 & 0.000 & 0.000 & 0.000 & 0.000 & 0.580 & 0.504 & 0.864 & 0.888 & 0.584 \\
\hline Mean Width & 0.161 & 0.168 & 0.163 & 0.171 & 0.065 & 0.070 & 0.068 & 0.089 & 0.092 & 0.035 \\
\hline \multicolumn{11}{|c|}{ Panel IV. $\gamma=0.2, \beta=0.2$} \\
\hline Coverage & 0.400 & 0.224 & 0.408 & 0.188 & 0.000 & 0.900 & 0.820 & 0.548 & 0.568 & 0.064 \\
\hline Mean Width & 0.069 & 0.067 & 0.073 & 0.070 & 0.026 & 0.012 & 0.012 & 0.013 & 0.013 & 0.005 \\
\hline \multicolumn{11}{|c|}{ Panel V. $\gamma=0.8, \beta=0.8$} \\
\hline Coverage & 0.000 & 0.000 & 0.000 & 0.000 & 0.000 & 0.580 & 0.488 & 0.864 & 0.892 & 0.340 \\
\hline Mean Width & 0.161 & 0.163 & 0.163 & 0.168 & 0.062 & 0.278 & 0.283 & 0.356 & 0.377 & 0.143 \\
\hline
\end{tabular}

Table 4 and text for further details. 
Table 10. Simulation Results: Long-run Coefficient.

\begin{tabular}{|c|c|c|c|c|c|c|c|c|c|c|}
\hline \multirow[t]{3}{*}{ Estimator } & \multicolumn{10}{|c|}{$\beta /(1-\gamma)$} \\
\hline & \multicolumn{2}{|c|}{$\gamma=0.2, \beta=0.8$} & \multicolumn{2}{|c|}{$\gamma=0.5, \beta=0.5$} & \multicolumn{2}{|c|}{$\gamma=0.8, \beta=0.2$} & \multicolumn{2}{|c|}{$\gamma=0.2, \beta=0.2$} & \multicolumn{2}{|c|}{$\gamma=0.8, \beta=0.8$} \\
\hline & DGP2 & DGP4 & DGP2 & DGP4 & DGP2 & DGP4 & DGP2 & DGP4 & DGP2 & DGP4 \\
\hline \multicolumn{11}{|c|}{ Panel I. Mean Absolute Percentage Error } \\
\hline $\mathrm{AH}$ & 0.079 & 0.048 & 0.237 & 0.131 & 2.158 & 4.129 & 0.079 & 0.048 & 2.565 & 2.529 \\
\hline $\mathrm{AB}$ & 0.080 & 0.040 & 0.224 & 0.109 & 0.171 & 0.232 & 0.071 & 0.031 & 0.197 & 0.220 \\
\hline $\mathrm{BB}$ & 0.108 & 0.057 & 0.319 & 0.203 & 0.467 & 0.349 & 0.103 & 0.049 & 0.501 & 0.404 \\
\hline NLS-IV & 0.527 & 0.459 & 0.532 & 1.057 & 1.058 & 8.163 & 0.159 & 0.211 & 3.457 & 19.798 \\
\hline NLS-CRE-IV & 0.035 & 0.028 & 0.064 & 0.050 & 0.316 & 0.730 & 0.040 & 0.036 & 0.230 & 0.341 \\
\hline FD-NLS-IV & 0.105 & 0.074 & 0.389 & 0.330 & 0.811 & 0.781 & 0.089 & 0.053 & 0.818 & 0.789 \\
\hline FD-NLS-CRE-IV & 0.088 & 0.037 & 0.385 & 0.304 & 0.810 & 0.775 & 0.088 & 0.046 & 0.811 & 0.769 \\
\hline QD-LS-MD & 0.111 & 0.565 & 0.118 & 0.341 & 0.890 & 1.016 & 0.069 & 0.127 & 1.144 & 1.277 \\
\hline QD-GMM & 0.037 & 0.031 & 0.066 & 0.068 & 0.126 & 0.160 & 0.035 & 0.045 & 0.158 & 0.134 \\
\hline E-NLS-IV & 0.117 & 0.338 & 0.273 & 0.570 & 0.139 & 0.361 & 0.111 & 0.332 & 0.161 & 0.406 \\
\hline E-NLS-CRE-IV & 0.116 & 0.100 & 0.091 & 0.136 & 0.100 & 0.193 & 0.043 & 0.033 & 0.119 & 0.152 \\
\hline E-NLS-IV-L & 0.136 & 0.438 & 0.287 & 0.054 & 0.564 & 0.209 & 0.048 & 0.068 & 0.098 & 1.018 \\
\hline E-NLS-CRE-IV-L & 0.177 & 0.120 & 0.426 & 0.318 & 0.713 & 0.599 & 0.157 & 0.102 & 0.701 & 0.582 \\
\hline E-NLS-IV-A & 0.329 & 0.799 & 0.173 & 0.163 & 0.308 & 0.145 & 0.028 & 0.197 & 0.320 & 1.883 \\
\hline E-NLS-CRE-IV-A & & & & 0.259 & 0.468 & & & .072 & & 0.347 \\
\hline E-NLS-IV-C & 0.085 & 0.514 & 0.330 & 0.043 & 0.506 & 0.253 & 0.082 & 0.043 & 0.147 & 0.878 \\
\hline E-NLS-CRE-IV-C & 0.183 & 0.127 & 0.457 & 0.361 & 0.608 & 0.530 & 0.172 & 0.116 & 0.627 & 0.548 \\
\hline E-NLS-IV-AR1 & 0.303 & 0.086 & 0.453 & 0.336 & 0.734 & 0.787 & 0.229 & 0.109 & 1.285 & 0.722 \\
\hline E-NLS-CRE-IV-AR1 & 0.101 & 0.076 & 0.069 & 0.079 & 0.099 & 0.184 & 0.036 & 0.036 & 0.115 & 0.119 \\
\hline \multicolumn{11}{|c|}{ Panel II. Root Mean Squared Error } \\
\hline $\mathrm{AH}$ & 0.087 & 0.058 & 0.248 & 0.149 & 6.394 & 23.439 & 0.022 & 0.014 & 31.474 & 42.436 \\
\hline $\mathrm{AB}$ & 0.084 & 0.048 & 0.228 & 0.118 & 0.225 & 0.324 & 0.019 & 0.009 & 0.995 & 1.265 \\
\hline $\mathrm{BB}$ & 111 & & 0.320 & 0.206 & 0.473 & 0.365 & 0.026 & 0.014 & 2.025 & 1.665 \\
\hline NLS-IV & 0.530 & 0.460 & 0.543 & 1.071 & 1.228 & 21.512 & 0.041 & 0.054 & 14.363 & 287.068 \\
\hline NLS-CRE-IV & 0.042 & 0.035 & 0.081 & 0.063 & 0.450 & 1.486 & 0.012 & 0.011 & 1.178 & 1.851 \\
\hline FD-NLS-IV & 0.108 & 0.078 & 0.389 & 0.331 & 0.811 & 0.781 & 0.023 & 0.014 & 3.272 & 3.158 \\
\hline FD-NLS-CRE-IV & 0.092 & 0.043 & 0.385 & 0.305 & 0.810 & 0.776 & 0.023 & 0.013 & 3.243 & 3.078 \\
\hline QD-LS-MD & 0.148 & 0.617 & 0.152 & 0.388 & 1.332 & 1.560 & 0.022 & 0.040 & 6.511 & 6.564 \\
\hline QD-GMM & & 0.038 & 0.080 & 0.082 & 0.154 & 0.201 & 0.011 & 0.014 & 0.753 & 0.655 \\
\hline E-NLS-IV & 0.134 & 0.357 & 0.285 & 0.577 & 0.168 & 0.399 & 0.031 & 0.086 & 0.772 & 1.773 \\
\hline E-NLS-CRE-IV & 0.120 & 0.103 & 0.110 & 0.150 & 0.124 & 0.229 & 0.013 & 0.010 & 0.579 & 0.720 \\
\hline E-NLS-IV-L & 0.141 & 0.440 & 0.288 & 0.061 & 0.568 & 0.228 & 0.013 & 0.018 & 0.474 & 4.107 \\
\hline E-NLS-CRE-IV-L & 0.178 & 0.122 & 0.426 & 0.319 & 0.716 & 0.605 & 0.040 & 0.026 & 2.813 & 2.348 \\
\hline E-NLS-IV-A & 0.333 & 0.802 & 0.176 & 0.169 & 0.317 & 0.174 & 0.009 & 0.050 & 1.367 & 7.587 \\
\hline E-NLS-CRE-IV-A & 0.160 & 0.097 & 0.386 & 0.260 & 0.473 & 0.341 & 0.034 & 0.019 & 1.977 & 1.427 \\
\hline E-NLS-IV-C & 0.092 & 0.518 & 0.331 & 0.052 & 0.509 & 0.267 & 0.021 & 0.012 & 0.663 & 3.579 \\
\hline E-NLS-CRE-IV-C & 0.184 & 0.128 & 0.457 & 0.361 & 0.610 & 0.534 & 0.043 & 0.029 & 2.514 & 2.204 \\
\hline E-NLS-IV-AR1 & 0.305 & 0.088 & 0.463 & 0.337 & 0.802 & 0.807 & 0.057 & 0.028 & 5.157 & 2.892 \\
\hline E-NLS-CRE-IV-AR1 & 0.107 & 0.082 & 0.084 & 0.093 & 0.123 & 0.219 & 0.011 & 0.011 & 0.567 & 0.599 \\
\hline
\end{tabular}

Notes: Green shading denotes values within 1.5 times the lowest value. See Table 4 and text for further details. 
Table 11. Simulation Results: Pitman's Nearness Measure.

\begin{tabular}{|c|c|c|c|c|c|c|c|c|c|}
\hline & \multicolumn{3}{|c|}{ E-NLS-CRE-IV vs. E-NLS-CRE-IV-AR1 } & \multicolumn{3}{|c|}{ QD-GMM vs. E-NLS-CRE-IV } & \multicolumn{3}{|c|}{ QD-GMM vs. E-NLS-CRE-IV-AR1 } \\
\hline & $\gamma$ & $\boldsymbol{\beta}$ & $\beta /(1-\gamma)$ & $\gamma$ & $\boldsymbol{\beta}$ & $\beta /(1-\gamma)$ & $\gamma$ & $\boldsymbol{\beta}$ & $\beta /(1-\gamma)$ \\
\hline \multicolumn{10}{|c|}{ I. $\gamma=0.2, \beta=0.8$} \\
\hline DGP1 & 0.784 & 0.416 & 0.728 & 0.624 & 0.436 & 0.612 & 0.732 & 0.420 & 0.708 \\
\hline DGP2 & 0.040 & 0.552 & 0.080 & 0.996 & 0.536 & 0.980 & 0.972 & 0.536 & 0.960 \\
\hline DGP3 & 0.784 & 0.036 & 0.768 & 0.652 & 0.828 & 0.764 & 0.724 & 0.596 & 0.868 \\
\hline DGP4 & 0.016 & 0.492 & 0.024 & 1.000 & 0.896 & 0.952 & 1.000 & 0.880 & 0.844 \\
\hline DGP5 & 0.000 & 0.020 & 0.060 & 1.000 & 0.844 & 0.368 & 0.980 & 0.788 & 0.176 \\
\hline \multicolumn{10}{|c|}{ II. $\gamma=0.5, \beta=0.5$} \\
\hline DGP1 & 0.908 & 0.288 & 0.860 & 0.900 & 0.572 & 0.920 & 0.948 & 0.428 & 0.944 \\
\hline DGP2 & 0.240 & 0.700 & 0.204 & 0.712 & 0.392 & 0.632 & 0.568 & 0.444 & 0.540 \\
\hline DGP3 & 0.324 & 0.036 & 0.200 & 0.972 & 0.948 & 0.992 & 0.956 & 0.756 & 0.980 \\
\hline DGP4 & 0.004 & 0.520 & 0.060 & 0.992 & 0.976 & 0.772 & 0.960 & 0.976 & 0.568 \\
\hline DGP5 & 0.136 & 0.980 & 0.948 & 0.824 & 0.908 & 0.000 & 0.792 & 0.932 & 0.008 \\
\hline \multicolumn{10}{|c|}{ III. $\gamma=0.8, \beta=0.2$} \\
\hline DGP1 & 0.560 & 0.464 & 0.444 & 0.472 & 0.484 & 0.504 & 0.488 & 0.472 & 0.492 \\
\hline DGP2 & 0.596 & 0.520 & 0.500 & 0.372 & 0.468 & 0.416 & 0.376 & 0.496 & 0.396 \\
\hline DGP3 & 0.276 & 0.528 & 0.384 & 0.528 & 0.660 & 0.668 & 0.492 & 0.640 & 0.640 \\
\hline DGP4 & 0.404 & 0.604 & 0.400 & 0.388 & 0.604 & 0.580 & 0.368 & 0.628 & 0.544 \\
\hline DGP5 & 0.152 & 0.952 & 0.016 & 0.476 & 0.912 & 0.860 & 0.368 & 0.920 & 0.832 \\
\hline \multicolumn{10}{|c|}{ IV. $\gamma=0.2, \beta=0.2$} \\
\hline DGP1 & 0.784 & 0.416 & 0.728 & 0.624 & 0.436 & 0.612 & 0.732 & 0.420 & 0.708 \\
\hline DGP2 & 0.344 & 0.608 & 0.340 & 0.608 & 0.404 & 0.588 & 0.532 & 0.436 & 0.504 \\
\hline DGP3 & 0.784 & 0.036 & 0.768 & 0.652 & 0.828 & 0.764 & 0.724 & 0.596 & 0.868 \\
\hline DGP4 & 0.168 & 0.084 & 0.552 & 0.740 & 0.888 & 0.380 & 0.604 & 0.732 & 0.388 \\
\hline DGP5 & 0.172 & 0.000 & 0.988 & 0.708 & 0.772 & 0.080 & 0.372 & 0.680 & 0.424 \\
\hline \multicolumn{10}{|c|}{ V. $\gamma=0.8, \beta=0.8$} \\
\hline DGP1 & 0.560 & 0.464 & 0.444 & 0.472 & 0.484 & 0.504 & 0.488 & 0.472 & 0.492 \\
\hline DGP2 & 0.500 & 0.440 & 0.400 & 0.252 & 0.620 & 0.360 & 0.264 & 0.584 & 0.316 \\
\hline DGP3 & 0.276 & 0.528 & 0.384 & 0.528 & 0.660 & 0.668 & 0.492 & 0.640 & 0.640 \\
\hline DGP4 & 0.732 & 0.232 & 0.156 & 0.336 & 0.608 & 0.568 & 0.396 & 0.448 & 0.424 \\
\hline DGP5 & 0.596 & 0.088 & 0.076 & 0.208 & 0.636 & 0.640 & 0.216 & 0.444 & 0.500 \\
\hline
\end{tabular}


Table 12. Determinants of Math Achievement.

\begin{tabular}{|c|c|c|c|c|c|c|}
\hline & \multicolumn{6}{|c|}{ Math z-Score } \\
\hline & AH & $\mathbf{A B}$ & BB & QD-GMM & $\begin{array}{l}\text { E-NLS-CRE- } \\
\text { IV }\end{array}$ & $\begin{array}{l}\text { E-NLS-CRE- } \\
\text { IV-AR1 }\end{array}$ \\
\hline$\gamma$ & $\begin{array}{r}0.224 \\
(0.213)\end{array}$ & $\begin{array}{l}0.326 * \\
(0.019)\end{array}$ & $\begin{array}{l}0.314 \text { * } \\
(0.014)\end{array}$ & $\begin{array}{l}0.497 * \\
(0.021)\end{array}$ & $\begin{array}{l}0.802 * \\
(0.008)\end{array}$ & $\begin{array}{l}0.798 * \\
(0.008)\end{array}$ \\
\hline $\begin{array}{l}\text { Teacher Experience } \\
(1=1 \text { years or less })\end{array}$ & $\begin{array}{r}0.142 \\
(0.107)\end{array}$ & $\begin{array}{r}0.130 \\
(0.130)\end{array}$ & $\begin{array}{r}0.102 \\
(0.129)\end{array}$ & $\begin{array}{r}0.105 \\
(0.100)\end{array}$ & $\begin{array}{r}-0.044 \\
(0.169)\end{array}$ & $\begin{array}{r}0.050 \\
(0.136)\end{array}$ \\
\hline $\begin{array}{l}\text { Teacher Experience } \\
(1=1.5-10 \text { years })\end{array}$ & $\begin{array}{c}0.110 * \\
(0.052)\end{array}$ & $\begin{array}{l}0.114 \ddagger \\
(0.061)\end{array}$ & $\begin{array}{l}0.102 \ddagger \\
(0.060)\end{array}$ & $\begin{array}{l}0.124 * \\
(0.046)\end{array}$ & $\begin{array}{l}0.032 \dagger \\
(0.072)\end{array}$ & $\begin{array}{r}0.136 \\
(0.067)\end{array}$ \\
\hline $\begin{array}{l}\text { Teacher Education } \\
\text { (1 = MA or higher) }\end{array}$ & $\begin{array}{r}0.008 \\
(0.009)\end{array}$ & $\begin{array}{r}0.000 \\
(0.010)\end{array}$ & $\begin{array}{r}0.001 \\
(0.010)\end{array}$ & $\begin{array}{r}0.008 \\
(0.009)\end{array}$ & $\begin{array}{r}0.013 \\
(0.014)\end{array}$ & $\begin{array}{r}0.012 \\
(0.014)\end{array}$ \\
\hline $\begin{array}{l}\text { Teacher Elementary } \\
\text { Certification (1 = Yes) }\end{array}$ & $\begin{array}{l}0.042 \ddagger \\
(0.022)\end{array}$ & $\begin{array}{r}0.036 \\
(0.026)\end{array}$ & $\begin{array}{r}0.037 \\
(0.026)\end{array}$ & $\begin{array}{l}0.046 \dagger \\
(0.020)\end{array}$ & $\begin{array}{r}0.014 \\
(0.030)\end{array}$ & $\begin{array}{r}0.042 \\
(0.030)\end{array}$ \\
\hline $\begin{array}{l}\text { Certification x Teacher } \\
\text { Experience ( } 1 \text { years or less) }\end{array}$ & $\begin{array}{r}-0.025 \\
(0.050)\end{array}$ & $\begin{array}{l}-0.021 \\
(0.061)\end{array}$ & $\begin{array}{r}-0.015 \\
(0.061)\end{array}$ & $\begin{array}{r}-0.002 \\
(0.046)\end{array}$ & $\begin{array}{r}0.024 \\
(0.074)\end{array}$ & $\begin{array}{r}0.016 \\
(0.068)\end{array}$ \\
\hline $\begin{array}{l}\text { Certification x Teacher } \\
\text { Experience (1.5-10 years) }\end{array}$ & $\begin{array}{l}-0.091 * \\
(0.033)\end{array}$ & $\begin{array}{l}-0.097 * \\
(0.034)\end{array}$ & $\begin{array}{l}-0.090 * \\
(0.034)\end{array}$ & $\begin{array}{l}-0.079 * \\
(0.027)\end{array}$ & $\begin{array}{r}-0.033 \\
(0.041)\end{array}$ & $\begin{array}{l}-0.074 \ddagger \\
(0.041)\end{array}$ \\
\hline Class Size & $\begin{array}{r}0.001 \\
(0.002)\end{array}$ & $\begin{array}{r}0.000 \\
(0.002)\end{array}$ & $\begin{array}{r}0.001 \\
(0.002)\end{array}$ & $\begin{array}{r}0.001 \\
(0.001)\end{array}$ & $\begin{array}{r}-0.001 \\
(0.002)\end{array}$ & $\begin{array}{r}0.000 \\
(0.002)\end{array}$ \\
\hline $\begin{array}{l}\text { Class Size x Teacher } \\
\text { Experience (1 year or less) }\end{array}$ & $\begin{array}{r}-0.007 \\
(0.005)\end{array}$ & $\begin{array}{r}-0.007 \\
(0.006)\end{array}$ & $\begin{array}{r}-0.006 \\
(0.006)\end{array}$ & $\begin{array}{r}-0.006 \\
(0.004)\end{array}$ & $\begin{array}{r}-0.001 \\
(0.007)\end{array}$ & $\begin{array}{r}-0.004 \\
(0.005)\end{array}$ \\
\hline $\begin{array}{l}\text { Class Size x Teacher } \\
\text { Experience (1.5-10 years) }\end{array}$ & $\begin{array}{r}0.000 \\
(0.002)\end{array}$ & $\begin{array}{r}0.000 \\
(0.002)\end{array}$ & $\begin{array}{r}0.000 \\
(0.002)\end{array}$ & $\begin{array}{r}-0.002 \\
(0.002)\end{array}$ & $\begin{array}{r}0.000 \\
(0.003)\end{array}$ & $\begin{array}{r}-0.002 \\
(0.003)\end{array}$ \\
\hline $\begin{array}{l}\text { Class Behavior } \\
\text { (1 = Well or Exceptional) }\end{array}$ & $\begin{array}{l}0.095 \dagger \\
(0.048)\end{array}$ & $\begin{array}{l}0.114 \dagger \\
(0.051)\end{array}$ & $\begin{array}{l}0.119 \dagger \\
(0.051)\end{array}$ & $\begin{array}{l}0.079 \dagger \\
(0.038)\end{array}$ & $\begin{array}{r}0.079 \\
(0.062)\end{array}$ & $\begin{array}{r}0.043 \\
(0.055)\end{array}$ \\
\hline $\begin{array}{l}\text { Class Size x Class Behavior } \\
\text { (Well or Exceptional) }\end{array}$ & $\begin{array}{r}-0.003 \\
(0.002)\end{array}$ & $\begin{array}{r}-0.003 \\
(0.002)\end{array}$ & $\begin{array}{r}-0.004 \\
(0.002)\end{array}$ & $\begin{array}{r}-0.003 \\
(0.002)\end{array}$ & $\begin{array}{r}-0.003 \\
(0.003)\end{array}$ & $\begin{array}{r}-0.001 \\
(0.003)\end{array}$ \\
\hline $\begin{array}{l}\text { Class Size x Class Behavior } \\
\text { (Well or Exceptional) x } \\
\text { Teacher Experience } \\
\text { (1 years of Less) }\end{array}$ & $\begin{array}{c}0.006 * \\
(0.002)\end{array}$ & $\begin{array}{c}0.006 * \\
(0.002)\end{array}$ & $\begin{array}{c}0.006 * \\
(0.002)\end{array}$ & $\begin{array}{c}0.006 * \\
(0.002)\end{array}$ & $\begin{array}{c}0.005 \\
(0.003)\end{array}$ & $\begin{array}{l}0.005 \\
(0.003)\end{array}$ \\
\hline $\begin{array}{l}\text { Class Size x Class Behavior } \\
\text { (Well or Exceptional) x }\end{array}$ & $\begin{array}{r}-0.001 \\
(0.001)\end{array}$ & $\begin{array}{r}-0.001 \\
(0.001)\end{array}$ & $\begin{array}{r}-0.001 \\
(0.001)\end{array}$ & $\begin{array}{r}0.000 \\
(0.001)\end{array}$ & $\begin{array}{r}0.000 \\
(0.001)\end{array}$ & $\begin{array}{r}0.000 \\
(0.001)\end{array}$ \\
\hline
\end{tabular}

Teacher Experience (1.5-10 years)

\footnotetext{
Notes: $\ddagger \mathrm{p}<0.10, \dagger \mathrm{p}<0.05$, and $* \mathrm{p}<0.01$. Data from the ECLS-K. Heteroskedasticity-robust standard errors in parentheses. Number of observations $=29,855$ (5,977 students over five time periods). $\gamma$ is the coefficient on the lagged dependent variable. Abbreviation: GT $=$ Gifted and Talented. Other covariates included: number of children's books in the home, household size, dummy variables indicating 2-parent or 1-parent households, socioeconomic status, dummy vairable indicating if teacher is white, dummy variable indicating computer in the home, and dummy variables if socioeconomic status, children's books, household size, teacher experience, teacher experience in grade, teacher certification status, class size, class behavior, and number of GT or boys in class are missing. Excluded instruments used by AH and QD-GMM: number of children's books in the home, socioeconomic status, class behavior, and dummy variables if these are missing. See text for further details.
} 
Table 13. Determinants of Reading Achievement.

\begin{tabular}{|c|c|c|c|c|c|c|}
\hline & \multicolumn{6}{|c|}{ Reading z-Score } \\
\hline & AH & AB & BB & QD-GMM & $\begin{array}{l}\text { E-NLS-CRE- } \\
\text { IV }\end{array}$ & $\begin{array}{l}\text { E-NLS-CRE- } \\
\text { IV-AR1 }\end{array}$ \\
\hline$\gamma$ & $\begin{array}{r}0.775 \\
(0.564)\end{array}$ & $\begin{array}{l}0.571 * \\
(0.017)\end{array}$ & $\begin{array}{c}0.520 * \\
(0.014)\end{array}$ & $\begin{array}{c}0.709 * \\
(0.017)\end{array}$ & $\begin{array}{l}0.834 * \\
(0.008)\end{array}$ & $\begin{array}{c}0.829 * \\
(0.008)\end{array}$ \\
\hline $\begin{array}{l}\text { Teacher Experience } \\
\text { (1=1 years or less) }\end{array}$ & $\begin{array}{r}-0.149 \\
(0.152)\end{array}$ & $\begin{array}{r}-0.135 \\
(0.161)\end{array}$ & $\begin{array}{r}-0.138 \\
(0.156)\end{array}$ & $\begin{array}{r}-0.152 \\
(0.117)\end{array}$ & $\begin{array}{r}-0.162 \\
(0.174)\end{array}$ & $\begin{array}{r}-0.151 \\
(0.146)\end{array}$ \\
\hline $\begin{array}{l}\text { Teacher Experience } \\
(1=1.5-10 \text { years })\end{array}$ & $\begin{array}{r}-0.035 \\
(0.072)\end{array}$ & $\begin{array}{r}-0.048 \\
(0.072)\end{array}$ & $\begin{array}{r}-0.048 \\
(0.070)\end{array}$ & $\begin{array}{r}-0.004 \\
(0.056)\end{array}$ & $\begin{array}{r}0.000 \\
(0.074)\end{array}$ & $\begin{array}{r}0.103 \\
(0.070)\end{array}$ \\
\hline $\begin{array}{l}\text { Teacher Education } \\
\text { (1 = MA or higher) }\end{array}$ & $\begin{array}{r}-0.006 \\
(0.014)\end{array}$ & $\begin{array}{l}-0.007 \\
(0.013)\end{array}$ & $\begin{array}{r}-0.008 \\
(0.013)\end{array}$ & $\begin{array}{r}-0.005 \\
(0.011)\end{array}$ & $\begin{array}{r}-0.006 \\
(0.014)\end{array}$ & $\begin{array}{r}-0.004 \\
(0.016)\end{array}$ \\
\hline $\begin{array}{l}\text { Teacher Elementary } \\
\text { Certification ( } 1 \text { = Yes) }\end{array}$ & $\begin{array}{c}0.084 \ddagger \\
(0.050)\end{array}$ & $\begin{array}{c}0.066 \dagger \\
(0.031)\end{array}$ & $\begin{array}{l}0.063 \dagger \\
(0.030)\end{array}$ & $\begin{array}{r}0.059 * \\
(0.023)\end{array}$ & $\begin{array}{r}0.019 \\
(0.031)\end{array}$ & $\begin{array}{l}0.044 \ddagger \\
(0.026)\end{array}$ \\
\hline $\begin{array}{l}\text { Certification x Teacher } \\
\text { Experience ( } 1 \text { years or less) }\end{array}$ & $\begin{array}{r}0.000 \\
(0.084)\end{array}$ & $\begin{array}{r}0.027 \\
(0.078)\end{array}$ & $\begin{array}{r}0.030 \\
(0.076)\end{array}$ & $\begin{array}{r}0.035 \\
(0.056)\end{array}$ & $\begin{array}{r}0.053 \\
(0.081)\end{array}$ & $\begin{array}{r}0.034 \\
(0.084)\end{array}$ \\
\hline $\begin{array}{l}\text { Certification x Teacher } \\
\text { Experience (1.5-10 years) }\end{array}$ & $\begin{array}{r}-0.042 \\
(0.051)\end{array}$ & $\begin{array}{r}-0.032 \\
(0.041)\end{array}$ & $\begin{array}{r}-0.030 \\
(0.040)\end{array}$ & $\begin{array}{r}-0.011 \\
(0.031)\end{array}$ & $\begin{array}{r}0.010 \\
(0.043)\end{array}$ & $\begin{array}{r}-0.026 \\
(0.044)\end{array}$ \\
\hline Class Size & $\begin{array}{r}-0.003 \\
(0.003)\end{array}$ & $\begin{array}{r}-0.004 \\
(0.003)\end{array}$ & $\begin{array}{r}-0.004 \\
(0.003)\end{array}$ & $\begin{array}{r}-0.002 \\
(0.002)\end{array}$ & $\begin{array}{r}-0.001 \\
(0.002)\end{array}$ & $\begin{array}{r}0.003 \\
(0.002)\end{array}$ \\
\hline $\begin{array}{l}\text { Class Size x Teacher } \\
\text { Experience ( } 1 \text { year or less) }\end{array}$ & $\begin{array}{r}0.003 \\
(0.007)\end{array}$ & $\begin{array}{r}0.001 \\
(0.007)\end{array}$ & $\begin{array}{r}0.001 \\
(0.006)\end{array}$ & $\begin{array}{r}0.002 \\
(0.005)\end{array}$ & $\begin{array}{r}0.001 \\
(0.007)\end{array}$ & $\begin{array}{r}0.003 \\
(0.006)\end{array}$ \\
\hline $\begin{array}{l}\text { Class Size x Teacher } \\
\text { Experience (1.5-10 years) }\end{array}$ & $\begin{array}{r}0.004 \\
(0.003)\end{array}$ & $\begin{array}{r}0.004 \\
(0.003)\end{array}$ & $\begin{array}{r}0.004 \\
(0.003)\end{array}$ & $\begin{array}{r}0.002 \\
(0.002)\end{array}$ & $\begin{array}{r}-0.001 \\
(0.003)\end{array}$ & $\begin{array}{r}-0.003 \\
(0.003)\end{array}$ \\
\hline $\begin{array}{l}\text { Class Behavior } \\
\text { (1 = Well or Exceptional) }\end{array}$ & $\begin{array}{r}0.050 \\
(0.068)\end{array}$ & $\begin{array}{r}0.039 \\
(0.061)\end{array}$ & $\begin{array}{r}0.037 \\
(0.059)\end{array}$ & $\begin{array}{r}0.016 \\
(0.044)\end{array}$ & $\begin{array}{r}0.040 \\
(0.061)\end{array}$ & $\begin{array}{l}0.123 \ddagger \\
(0.066)\end{array}$ \\
\hline $\begin{array}{l}\text { Class Size x Class Behavior } \\
\text { (Well or Exceptional) }\end{array}$ & $\begin{array}{r}-0.001 \\
(0.003)\end{array}$ & $\begin{array}{r}0.000 \\
(0.003)\end{array}$ & $\begin{array}{r}0.000 \\
(0.003)\end{array}$ & $\begin{array}{r}0.000 \\
(0.002)\end{array}$ & $\begin{array}{r}-0.002 \\
(0.003)\end{array}$ & $\begin{array}{l}-0.005 \ddagger \\
(0.003)\end{array}$ \\
\hline $\begin{array}{l}\text { Class Size x Class Behavior } \\
\text { (Well or Exceptional) x } \\
\text { Teacher Experience } \\
\text { (1 years of Less) }\end{array}$ & $\begin{array}{l}0.006 \dagger \\
(0.003)\end{array}$ & $\begin{array}{l}0.005 \ddagger \\
(0.003)\end{array}$ & $\begin{array}{l}0.005 \ddagger \\
(0.003)\end{array}$ & $\begin{array}{l}0.005 \dagger \\
(0.002)\end{array}$ & $\begin{array}{l}0.006 \neq \\
(0.003)\end{array}$ & $\begin{array}{l}0.006 \ddagger \\
(0.003)\end{array}$ \\
\hline $\begin{array}{l}\text { Class Size x Class Behavior } \\
\text { (Well or Exceptional) x }\end{array}$ & $\begin{array}{r}0.000 \\
(0.001)\end{array}$ & $\begin{array}{r}0.000 \\
(0.001)\end{array}$ & $\begin{array}{r}0.000 \\
(0.001)\end{array}$ & $\begin{array}{r}0.000 \\
(0.001)\end{array}$ & $\begin{array}{r}0.000 \\
(0.001)\end{array}$ & $\begin{array}{r}0.000 \\
(0.001)\end{array}$ \\
\hline
\end{tabular}

Teacher Experience (1.5-10 years)

Notes: $\ddagger \mathrm{p}<0.10, \dagger \mathrm{p}<0.05$, and $* \mathrm{p}<0.01$. Data from the ECLS-K. Heteroskedasticity-robust standard errors in parentheses. Number of observations $=27,820$ (5,564 students over five time periods). See Table 12 and text for further details. 
Table 14. Determinants of Student Achievement: Marginal Effects of Teacher Certification and Class Size.

\begin{tabular}{|c|c|c|c|c|c|c|}
\hline & AH & $\mathbf{A B}$ & BB & QD-GMM & $\begin{array}{l}\text { E-NLS-CRE-E- } \\
\text { IV }\end{array}$ & $\begin{array}{l}\text {-NLS-CRE- } \\
\text { IV-AR1 }\end{array}$ \\
\hline \multicolumn{7}{|l|}{ I. Math } \\
\hline $\begin{array}{l}\text { Certification for } \\
\text { Low Experienced Teacher }\end{array}$ & $\begin{array}{r}0.017 \\
(0.046)\end{array}$ & $\begin{array}{r}0.015 \\
(0.056)\end{array}$ & $\begin{array}{r}0.022 \\
(0.056)\end{array}$ & $\begin{array}{r}0.044 \\
(0.042)\end{array}$ & $\begin{array}{r}0.038 \\
(0.069)\end{array}$ & $\begin{array}{r}0.058 \\
(0.064)\end{array}$ \\
\hline $\begin{array}{l}\text { Certification for } \\
\text { Medium Experienced Teacher }\end{array}$ & $\begin{array}{l}-0.050 \dagger \\
(0.025)\end{array}$ & $\begin{array}{l}-0.061 \dagger \\
(0.025)\end{array}$ & $\begin{array}{l}-0.053 \dagger \\
(0.025)\end{array}$ & $\begin{array}{l}-0.033 \\
(0.020)\end{array}$ & $\begin{array}{l}-0.019 \\
(0.031)\end{array}$ & $\begin{array}{r}-0.033 \\
(0.032)\end{array}$ \\
\hline $\begin{array}{l}\text { Certification for } \\
\text { High Experienced Teacher }\end{array}$ & $\begin{array}{l}0.042 \ddagger \\
(0.022)\end{array}$ & $\begin{array}{r}0.036 \\
(0.026)\end{array}$ & $\begin{array}{r}0.037 \\
(0.026)\end{array}$ & $\begin{array}{c}0.046 \dagger \\
(0.020)\end{array}$ & $\begin{array}{r}0.014 \\
(0.030)\end{array}$ & $\begin{array}{r}0.042 \\
(0.030)\end{array}$ \\
\hline $\begin{array}{l}\text { Class Size in } \\
\text { Well-Behaved Class with } \\
\text { Low Experienced Teacher }\end{array}$ & $\begin{array}{l}-0.010 \dagger \\
(0.005)\end{array}$ & $\begin{array}{l}-0.011 \neq \\
(0.006)\end{array}$ & $\begin{array}{r}-0.009 \\
(0.006)\end{array}$ & $\begin{array}{l}-0.007 \ddagger \\
(0.004)\end{array}$ & $\begin{array}{r}-0.004 \\
(0.007)\end{array}$ & $\begin{array}{r}-0.005 \\
(0.005)\end{array}$ \\
\hline $\begin{array}{l}\text { Class Size in } \\
\text { Well-Behaved Class with } \\
\text { Medium Experienced Teacher }\end{array}$ & $\begin{array}{r}-0.003 \\
(0.002)\end{array}$ & $\begin{array}{l}-0.004 \neq \\
(0.002)\end{array}$ & $\begin{array}{r}-0.003 \\
(0.002)\end{array}$ & $\begin{array}{l}-0.003 \ddagger \\
(0.002)\end{array}$ & $\begin{array}{r}-0.003 \\
(0.003)\end{array}$ & $\begin{array}{r}-0.003 \\
(0.003)\end{array}$ \\
\hline $\begin{array}{l}\text { Class Size in } \\
\text { Well-Behaved Class with } \\
\text { High Experienced Teacher }\end{array}$ & $\begin{array}{r}-0.002 \\
(0.002)\end{array}$ & $\begin{array}{l}-0.004 \ddagger \\
(0.002)\end{array}$ & $\begin{array}{r}-0.003 \\
(0.002)\end{array}$ & $\begin{array}{r}-0.002 \\
(0.002)\end{array}$ & $\begin{array}{r}-0.003 \\
(0.002)\end{array}$ & $\begin{array}{r}-0.001 \\
(0.002)\end{array}$ \\
\hline $\begin{array}{l}\text { Class Size in } \\
\text { Poorly-Behaved Class with } \\
\text { Low Experienced Teacher }\end{array}$ & $\begin{array}{r}-0.007 \\
(0.005)\end{array}$ & $\begin{array}{l}-0.007 \\
(0.006)\end{array}$ & $\begin{array}{r}-0.005 \\
(0.006)\end{array}$ & $\begin{array}{r}-0.005 \\
(0.004)\end{array}$ & $\begin{array}{r}-0.002 \\
(0.007)\end{array}$ & $\begin{array}{r}-0.004 \\
(0.005)\end{array}$ \\
\hline $\begin{array}{l}\text { Class Size in } \\
\text { Poorly-Behaved Class with } \\
\text { Medium Experienced Teacher }\end{array}$ & $\begin{array}{r}0.000 \\
(0.002)\end{array}$ & $\begin{array}{r}0.000 \\
(0.002)\end{array}$ & $\begin{array}{r}0.001 \\
(0.002)\end{array}$ & $\begin{array}{r}0.000 \\
(0.002)\end{array}$ & $\begin{array}{r}0.000 \\
(0.003)\end{array}$ & $\begin{array}{r}-0.002 \\
(0.003)\end{array}$ \\
\hline $\begin{array}{l}\text { Class Size in } \\
\text { Poorly-Behaved Class with } \\
\text { High Experienced Teacher }\end{array}$ & $\begin{array}{r}0.001 \\
(0.002)\end{array}$ & $\begin{array}{r}0.000 \\
(0.002)\end{array}$ & $\begin{array}{r}0.001 \\
(0.002)\end{array}$ & $\begin{array}{r}0.001 \\
(0.001)\end{array}$ & $\begin{array}{l}-0.001 \\
(0.002)\end{array}$ & $\begin{array}{r}0.000 \\
(0.002)\end{array}$ \\
\hline \multicolumn{7}{|l|}{ II. Reading } \\
\hline $\begin{array}{l}\text { Certification for } \\
\text { Low Experienced Teacher }\end{array}$ & $\begin{array}{r}0.084 \\
(0.067)\end{array}$ & $\begin{array}{r}0.093 \\
(0.074)\end{array}$ & $\begin{array}{r}0.093 \\
(0.072)\end{array}$ & $\begin{array}{l}0.094 \neq \\
(0.053)\end{array}$ & $\begin{array}{r}0.072 \\
(0.077)\end{array}$ & $\begin{array}{r}0.078 \\
(0.080)\end{array}$ \\
\hline $\begin{array}{l}\text { Certification for } \\
\text { Medium Experienced Teacher }\end{array}$ & $\begin{array}{r}0.041 \\
(0.032)\end{array}$ & $\begin{array}{r}0.034 \\
(0.031)\end{array}$ & $\begin{array}{r}0.032 \\
(0.031)\end{array}$ & $\begin{array}{l}0.048 \neq \\
(0.025)\end{array}$ & $\begin{array}{r}0.029 \\
(0.033)\end{array}$ & $\begin{array}{r}0.018 \\
(0.036)\end{array}$ \\
\hline $\begin{array}{l}\text { Certification for } \\
\text { High Experienced Teacher }\end{array}$ & $\begin{array}{l}0.084 \ddagger \\
(0.050)\end{array}$ & $\begin{array}{l}0.066 \dagger \\
(0.031)\end{array}$ & $\begin{array}{l}0.063 \dagger \\
(0.030)\end{array}$ & $\begin{array}{l}0.059 * \\
(0.023)\end{array}$ & $\begin{array}{r}0.019 \\
(0.031)\end{array}$ & $\begin{array}{l}0.044 \neq \\
(0.026)\end{array}$ \\
\hline $\begin{array}{l}\text { Class Size in } \\
\text { Well-Behaved Class with } \\
\text { Low Experienced Teacher }\end{array}$ & $\begin{array}{r}-0.001 \\
(0.006)\end{array}$ & $\begin{array}{r}-0.002 \\
(0.007)\end{array}$ & $\begin{array}{r}-0.002 \\
(0.006)\end{array}$ & $\begin{array}{r}0.001 \\
(0.005)\end{array}$ & $\begin{array}{l}-0.001 \\
(0.007)\end{array}$ & $\begin{array}{r}0.001 \\
(0.006)\end{array}$ \\
\hline $\begin{array}{l}\text { Class Size in } \\
\text { Well-Behaved Class with } \\
\text { Medium Experienced Teacher }\end{array}$ & $\begin{array}{r}0.000 \\
(0.003)\end{array}$ & $\begin{array}{r}0.000 \\
(0.003)\end{array}$ & $\begin{array}{r}0.000 \\
(0.003)\end{array}$ & $\begin{array}{r}0.000 \\
(0.002)\end{array}$ & $\begin{array}{r}-0.003 \\
(0.003)\end{array}$ & $\begin{array}{l}-0.006 \ddagger \\
(0.003)\end{array}$ \\
\hline $\begin{array}{l}\text { Class Size in } \\
\text { Well-Behaved Class with } \\
\text { High Experienced Teacher }\end{array}$ & $\begin{array}{r}-0.004 \\
(0.002)\end{array}$ & $\begin{array}{l}-0.004 \ddagger \\
(0.002)\end{array}$ & $\begin{array}{l}-0.004 \ddagger \\
(0.002)\end{array}$ & $\begin{array}{r}-0.002 \\
(0.002)\end{array}$ & $\begin{array}{r}-0.002 \\
(0.002)\end{array}$ & $\begin{array}{r}-0.002 \\
(0.002)\end{array}$ \\
\hline $\begin{array}{l}\text { Class Size in } \\
\text { Poorly-Behaved Class with } \\
\text { Low Experienced Teacher }\end{array}$ & $\begin{array}{r}0.000 \\
(0.007)\end{array}$ & $\begin{array}{r}-0.002 \\
(0.006)\end{array}$ & $\begin{array}{c}-0.002 \\
(0.006)\end{array}$ & $\begin{array}{r}0.000 \\
(0.005)\end{array}$ & $\begin{array}{r}0.000 \\
(0.007)\end{array}$ & $\begin{array}{r}0.006 \\
(0.006)\end{array}$ \\
\hline $\begin{array}{l}\text { Class Size in } \\
\text { Poorly-Behaved Class with } \\
\text { Medium Experienced Teacher }\end{array}$ & $\begin{array}{r}0.001 \\
(0.003)\end{array}$ & $\begin{array}{r}0.000 \\
(0.003)\end{array}$ & $\begin{array}{r}0.000 \\
(0.003)\end{array}$ & $\begin{array}{c}-0.001 \\
(0.002)\end{array}$ & $\begin{array}{r}-0.001 \\
(0.003)\end{array}$ & $\begin{array}{c}-0.001 \\
(0.003)\end{array}$ \\
\hline $\begin{array}{l}\text { Class Size in } \\
\text { Poorly-Behaved Class with } \\
\text { High Experienced Teacher }\end{array}$ & $\begin{array}{r}-0.003 \\
(0.003)\end{array}$ & $\begin{array}{r}-0.004 \\
(0.003)\end{array}$ & $\begin{array}{r}-0.004 \\
(0.003)\end{array}$ & $\begin{array}{c}-0.002 \\
(0.002)\end{array}$ & $\begin{array}{c}-0.001 \\
(0.002)\end{array}$ & $\begin{array}{r}0.003 \\
(0.002)\end{array}$ \\
\hline
\end{tabular}

Notes: $\ddagger \mathrm{p}<0.10, \dagger \mathrm{p}<0.05$, and $* \mathrm{p}<0.01$. Data from the ECLS-K. Heteroskedasticity-robust standard errors in parentheses. See Tables 12 and 13 for further details. 
Table 15. Determinants of Child Body Mass Index.

\section{BMI z-Score}

\begin{tabular}{|c|c|c|c|c|c|c|}
\hline & AH & AB & BB & QD-GMM & $\begin{array}{l}\text { E-NLS-CRE- } \\
\text { IV }\end{array}$ & $\begin{array}{c}\text { E-NLS-CRE- } \\
\text { IV-AR1 }\end{array}$ \\
\hline$\gamma$ & $\begin{array}{c}0.361 \text { * } \\
(0.059)\end{array}$ & $\begin{array}{c}0.221 \text { * } \\
(0.014)\end{array}$ & $\begin{array}{c}0.349 \text { * } \\
(0.014)\end{array}$ & $\begin{array}{c}0.389 * \\
(0.016)\end{array}$ & $\begin{array}{c}0.890 * \\
(0.006)\end{array}$ & $\begin{array}{c}0.891 \text { * } \\
(0.006)\end{array}$ \\
\hline $\begin{array}{l}\text { Socioeconomic } \\
\text { Status }\end{array}$ & $\begin{array}{r}0.018 \\
(0.011)\end{array}$ & $\begin{array}{r}0.015 \\
(0.011)\end{array}$ & $\begin{array}{l}-0.025 \dagger \\
(0.013)\end{array}$ & $\begin{array}{c}0.033 * \\
(0.010)\end{array}$ & $\begin{array}{l}0.027 \dagger \\
(0.013)\end{array}$ & $\begin{array}{r}0.007 \\
(0.012)\end{array}$ \\
\hline TANF ( $1=$ Yes $)$ & $\begin{array}{r}0.010 \\
(0.021)\end{array}$ & $\begin{array}{r}0.007 \\
(0.023)\end{array}$ & $\begin{array}{r}0.008 \\
(0.025)\end{array}$ & $\begin{array}{r}-0.004 \\
(0.018)\end{array}$ & $\begin{array}{r}0.006 \\
(0.035)\end{array}$ & $\begin{array}{r}0.000 \\
(0.035)\end{array}$ \\
\hline SNAP $(1=$ Yes $)$ & $\begin{array}{r}-0.005 \\
(0.015)\end{array}$ & $\begin{array}{r}-0.006 \\
(0.015)\end{array}$ & $\begin{array}{r}-0.006 \\
(0.016)\end{array}$ & $\begin{array}{r}-0.006 \\
(0.013)\end{array}$ & $\begin{array}{r}-0.005 \\
(0.026)\end{array}$ & $\begin{array}{r}-0.021 \\
(0.026)\end{array}$ \\
\hline $\begin{array}{l}\text { Health Insurance } \\
\text { (1 = Yes) }\end{array}$ & $\begin{array}{l}0.025 \dagger \\
(0.010)\end{array}$ & $\begin{array}{l}0.021 \mp \\
(0.011)\end{array}$ & $\begin{array}{r}0.042 * \\
(0.012)\end{array}$ & $\begin{array}{c}0.046 * \\
(0.009)\end{array}$ & $\begin{array}{r}-0.012 \\
(0.019)\end{array}$ & $\begin{array}{r}-0.010 \\
(0.013)\end{array}$ \\
\hline NSLP (1 = Yes) & $\begin{array}{l}0.022 * \\
(0.008)\end{array}$ & $\begin{array}{l}0.027 * \\
(0.008)\end{array}$ & $\begin{array}{l}0.041 * \\
(0.009)\end{array}$ & $\begin{array}{r}0.001 \\
(0.007)\end{array}$ & $\begin{array}{r}0.005 \\
(0.014)\end{array}$ & $\begin{array}{r}-0.007 \\
(0.014)\end{array}$ \\
\hline $\begin{array}{l}\text { TV - School } \\
\text { Week (hrs/day) }\end{array}$ & $\begin{array}{l}-0.007 * \\
(0.002)\end{array}$ & $\begin{array}{l}-0.007 * \\
(0.003)\end{array}$ & $\begin{array}{r}-0.005 \\
(0.003)\end{array}$ & $\begin{array}{l}-0.004 \ddagger \\
(0.002)\end{array}$ & $\begin{array}{l}-0.011 \dagger \\
(0.005)\end{array}$ & $\begin{array}{r}-0.004 \\
(0.005)\end{array}$ \\
\hline $\begin{array}{l}\text { TV - } \\
\text { Weekend (hrs/day) }\end{array}$ & $\begin{array}{c}0.007 * \\
(0.002)\end{array}$ & $\begin{array}{r}0.008 * \\
(0.002)\end{array}$ & $\begin{array}{l}0.009 * \\
(0.003)\end{array}$ & $\begin{array}{r}0.006 * \\
(0.002)\end{array}$ & $\begin{array}{l}0.008 \ddagger \\
(0.004)\end{array}$ & $\begin{array}{r}0.005 \\
(0.005)\end{array}$ \\
\hline TV Rules (1 = Yes) & $\begin{array}{r}-0.011 \\
(0.011)\end{array}$ & $\begin{array}{r}-0.008 \\
(0.012)\end{array}$ & $\begin{array}{r}-0.013 \\
(0.013)\end{array}$ & $\begin{array}{l}-0.023 \dagger \\
(0.010)\end{array}$ & $\begin{array}{r}-0.017 \\
(0.019)\end{array}$ & $\begin{array}{r}-0.026 \\
(0.020)\end{array}$ \\
\hline $\begin{array}{l}\text { HH Eats Breakfast } \\
\text { Together (days/wk) }\end{array}$ & $\begin{array}{r}0.000 \\
(0.002)\end{array}$ & $\begin{array}{r}-0.001 \\
(0.002)\end{array}$ & $\begin{array}{l}-0.004 * \\
(0.002)\end{array}$ & $\begin{array}{l}-0.003 * \\
(0.001)\end{array}$ & $\begin{array}{r}0.003 \\
(0.003)\end{array}$ & $\begin{array}{r}0.000 \\
(0.003)\end{array}$ \\
\hline $\begin{array}{l}\text { HH Eats Dinner } \\
\text { Together (days/wk) }\end{array}$ & $\begin{array}{r}-0.001 \\
(0.002)\end{array}$ & $\begin{array}{r}-0.001 \\
(0.002)\end{array}$ & $\begin{array}{r}-0.002 \\
(0.002)\end{array}$ & $\begin{array}{r}-0.003 \\
(0.002)\end{array}$ & $\begin{array}{r}0.000 \\
(0.003)\end{array}$ & $\begin{array}{r}-0.003 \\
(0.004)\end{array}$ \\
\hline
\end{tabular}

Notes: $\ddagger \mathrm{p}<0.10, \dagger \mathrm{p}<0.05$, and $* \mathrm{p}<0.01$. Data from the ECLS-K. Heteroskedasticity-robust standard errors in parentheses. Number of observations $=54,930$ (9,155 students over six time periods). $\gamma$ is the coefficient on the lagged dependent variable. Abbreviations: TANF $=$ Temporary Aid for Needy Families; SNAP = Supplemental Nutrition Assistance Program; NSLP = National School Lunch Program; HH = household. Other covariates included: number of children's books in the home, household size, dummy variables indicating 2-parent or 1-parent households, and dummy variables if socioeconomic status, children's books, household size, TANF, SNAP, health insurance, NSLP, TV variables, and how often the household eats breakfast or dinner together are missing. Excluded instruments used by AH and QD-GMM: number of children's books in the home, socioeconomic status, TV hours per day during the school week, and dummy variables if these are missing. See text for further details. 